\title{
Lancet Commission
}

\section{Global Kidney Health 2017 and beyond: A roadmap for closing gaps in care, research, and policy}

Adeera Levin MD, ${ }^{*}$ Marcello Tonelli MD, ${ }^{*}$ (co first authorship shared)

University of British Columbia, University of Calgary

*co-chairs of the ISN Global Kidney Health Summit on behalf of the International Society of Nephrology

Joseph Bonventre MD, Brigham and Women's Hospital, Harvard Medical School, Massachusetts Institute of Technology Josef Coresh MD, George W. Comstock Center for Public Health Research and

Prevention, Welch Center for Prevention, Epidemiology and Clinical Research Jo-Ann Donner, International Society of Nephrology

Agnes B. Fogo MD, Vanderbilt University Medical Center

Caroline Fox MD, Merck Research Labs, Brigham and Women's Hospital

Ron Gansevoort MD, University Medical Center Groningen

Meg Jardine MD, The George Institute for Global Health, The University of Sydney

Bert Kasiske MD, Hennepin County Medical Center, University of Minnesota

Anna Köttgen MD, Medical Center - University of Freiburg, Johns Hopkins Bloomberg

School of Public Health

Matthias Kretzler MD, University of Michigan

Hiddo JL Heerspink PhD, University Medical Center Groningen

Andrew S. Levey MD, Tufts Medical Center, Tufts University School of Medicine

Valerie Luyckx MD, University of Zurich, Brigham and Women's Hospital

Ravindra Mehta MD, University of California San Diego

Orson Moe MD, University of Texas Southwestern Medical Center

Gregorio Obrador MD, Universidad Panamericana School of Medicine

Neesh Pannu MD, University of Alberta

Chirag Parikh MD, Yale University, Veteran's Administration Connecticut Healthcare System

Vlado Perkovic MD, George Institute for Global Health, University of Sydney, Royal North Shore Hospital

Carol Pollock MD, University of Sydney, Royal North Shore Hospital

Peter Stenvinkel MD, Karolinska Institutet

Katherine Tuttle MD, Providence Health Care, University of Washington

David C. Wheeler MD, University College London

Kai-Uwe Eckardt MD* (co first authorship shared), University of Erlangen-Nürnberg

Working Group Members:

Dwomoa Adu MD, School of Medicine and Dentistry, University of Ghana

Sanjay Kumar Agarwal MD, All India Institute of Medical Sciences

Mona Alrukhaimi MD, Dubai Medical College

Hans-Joachim Anders MD, Klinikum der Universität München (LMU) 
Gloria Ashuntantang MD, Yaounde General Hospital, University of Yaounde I Shakti Basnet MD, Gautam Buddha Community Kidney Center

Aminu Bello MD, University of Alberta

Mohammed Benghanem Gharbi MD, Faculty of Medicine and Pharmacy of Casablanca, University Hassan II, University Hospital Ibn Rochd

Worawon Chailimpamontree MD, Bhumibol Adulyadej Hospital affiliated with Chulalonkorn University

Ricardo Correa-Rotter MD, National Institute of Medical Sciences and Nutrition Salvador Zubirán, National Autonomous University of Mexico, Panamerican University

Jonathan Craig MD, University of Sydney, Children's Hospital at Westmead

Walter G. Douthat MD, Hospital Privado-Universitario de Cordoba

Harold I. Feldman MD, Perelman School of Medicine, University of Pennsylvania

Mohammadreza Ganji MD, Tehran University of Medical Sciences, Shariati Hospital and Private Kasra Hospital

Guillermo Garcia-Garcia MD, Hospital Civil de Guadalajara, University of Guadalajara Health Sciences Center

David C.H. Harris MD, University of Sydney, Westmead Hospital

Vivek Jha MD, George Institute for Global Health

David W. Johnson MD, Princess Alexandra Hospital, University of Queensland and Translational Research Institute

Rumeyza Kazancioglu MD, Bezmialem Vakif University

Robyn Langham MD, Monash University

Zhihong Liu MD, National Clinical Research Center of Kidney Diseases, Jinling Hospital, Nanjing University School of Medicine

Ziad A. Massy MD, Ambroise Paré University Hospital, Paris-Ile-de-France-West University, Inserm

Masaomi Nangaku MD, The University of Tokyo Graduate School of Medicine

Robert G. Nelson MD, National Institute of Diabetes and Digestive and Kidney Diseases (NIDDK)

Donal O'Donoghue MD, Salford Royal NHS Foundation Trust and University of Manchester

Ikechi Okpechi MD, University of Cape Town

Roberto Pecoits-Filho MD, Pontifical Catholic University of Parana

Neil R. Powe MD, University of California San Francisco, Priscilla Chan and Mark

Zuckerberg San Francisco General Hospital

Giuseppe Remuzzi MD, IRCCS - Mario Negri Institute for Pharmacological Research, Azienda Socio-Sanitaria Territoriale Giovanni XXIII, University of Milan

Charlotte Roberts MD, International Consortium for Health Outcomes Measurement Jerome Rossert MD, Thrasos Therapuetics

Laura Sola MD, CASMU-IAMPP, University of the Republic, Ministry of Health

Benedicte Stengel MD, Inserm, French National Institute of Health and Medical

Research, University Paris Sud, University Paris Saclay

Ernest K. Sumaili MD, University of Kinshasa Hospital

Yusuke Suzuki MD, Juntendo University

Tetsuhiro Tanaka MD, The University of Tokyo 
Sajja Tatiyanupanwong MD, Faculty of Medicine, Faculty of Public Health Khon Kaen University

Bernadette Thomas MD, The University of Washington

Katrin Uhlig MD, Keryx Bioharmaceuticals, Tufts University School of Medicine

Robert Walker MD, University of Otago, Southern District Health Board

Sarah White PhD, The University of Sydney

Andrzej Wiecek MD, Medical University of Silesia

Chih-Wei Yang MD, Chang Gung Memorial Hospital, Chang Gung University College of Medicine

Correspondence to:

A Levin

St. Paul's Hospital

1081 Burrard Street Room 6010A

Vancouver, BC

V6Z1Y8

alevin@providencehealth.bc.ca

16048068120

Support of the Summit was made possible through unrestricted grants from various organisations in addition to the International Society of Nephrology. These include (in alphabetical order): AbbVie Inc, Akebia Therapeutics LLC, Amgen, AstraZeneca LP, Boehringer Ingelheim-Lilly, Danone Nutricia Research, Janssen Canada, Merck Global, and Regulus Therapeutics Inc. 


\begin{abstract}
The global nephrology community recognizes the need for a cohesive plan to address the problem of chronic kidney disease (CKD). To address this, a meeting was held in Vancouver, Canada (July 2016) by the International Society of Nephrology. Participants included over 85 individuals with diverse expertise and professional backgrounds from around the globe. The purpose of the meeting was to identify and prioritize key activities for the next five to ten years in the domains of clinical care, research, and advocacy; to identify potential partners within and outside the nephrology community; and to create an action plan and performance framework. Intended users of the action plan include clinicians, patients, scientists, industry partners, governments, and advocacy organizations.
\end{abstract}

Clinicians, basic scientists, clinical researchers, epidemiologists, methodologists, and industry scientists met for 2.5 days to develop the plan, based on 10 themes: 1 . Determine and monitor prevalence of CKD in different regions/countries; 2 . Identify and reduce major risk factors for CKD; 3 . Reduce progression of CKD by targeting AKI episodes; 4 . Improve understanding of the genetic causes of CKD; 5 . Improve diagnostic methods to assess alterations in kidney structure and function; 6 . Improve understanding of the natural course of CKD and define prognostic biomarkers for renal progression, CVD complications, and other adverse events; 7. Evaluate and implement established treatment options in patients with CKD; 8. Improve understanding and management of the complications of CKD; 9. Validate and establish novel therapeutic interventions to slow CKD progression and reduce CKD complications; 10. Optimize the design of clinical trials in CKD. Using an iterative process, each group produced a prioritized list of key issues, goals, activities, and a set of key deliverables. Proposed activities include clinical care, research, and advocacy.

We articulate, for the first time, a cohesive set of activities to improve the global outcomes of people affected by CKD. 


\section{Background Statements}

CKD affects as much as $10-15 \%$ of the population worldwide, and is due to multiple causes. CKD is associated with impaired quality of life and strongly reduced life expectancy. CKD is associated with enhanced rates, altered manifestations, and adverse outcomes of all types of cardiovascular disease.

CKD reflects the most serious complication of many different diseases, including diabetes, hypertension, and systemic immune disorders.

The aetiology of CKD remains uncertain in a large proportion of affected individuals; knowledge of the aetiology of CKD is important for targeting of specific therapies.

The mechanisms causing progressive kidney failure and associated systemic complications, including cardiovascular disease, remain incompletely understood, resulting in a lack of targeted therapies.

Nephrology lags behind other medical disciplines with respect to the conduct of clinical trials. CKD and AKI should be considered as related manifestations of renal impairment with mutual predisposition, functional and structural overlap, and potentiating adverse consequences.

The costs of treating CKD-associated complications (including kidney failure) provide a strong challenge for health care budgets that cannot be met in many parts of the world.

Successful prevention and treatment of CKD is strongly linked to progress on the Sustainable Development Goals.

\section{Key Messages}

A global collaborative effort of all stakeholders is required to execute a multifaceted action plan to combat the growing burden of CKD and its complications.

More work is needed to define the aetiology and pathophysiology of CKD at the individual patient level, and at the population level in regions where CKD is endemic.

A concerted effort is required to increase the number, size, and quality of clinical trials investigating how to reduce the burden of CKD and its complications.

Existing data and biomaterial sources need to be better utilized by promoting collaborative efforts and reducing administrative hurdles.

The existing clinical and research workforce is inadequate to address the global burden of CKD, especially in low and middle income countries (LMIC) 


\section{Overview}

\section{Defining the Problem}

Increasingly common. Chronic kidney disease (CKD) is increasingly recognized as a global public health problem. ${ }^{1}$ Kidney failure is the most severe form of CKD, and is fatal without treatment by renal replacement therapy (RRT; dialysis or kidney transplantation). The prevalence and associated burden of CKD and kidney failure is rising worldwide; ;-4 the fastest growth occurring in low- and low-middle-income countries (LMIC). The incidence of acute kidney injury (AKI) has also substantially increased over the last two decades, and AKI is now recognized as an important driver of CKD and kidney failure.

Exerting a major impact on individuals and society. CKD is associated with impaired quality of life and substantially reduced life expectancy at all ages, and is associated with excess risk for all types of cardiovascular disease (CVD), as well as with other conditions such as diabetes, infections, and cancer. ${ }^{5}$ Even patients in wealthy countries lack optimal access to prevention and early detection of progressive CKD. Although RRT has been available for decades in high income countries (HIC), relatively little is known about the benefits of RRT compared to conservative care in certain important patient groups, such as those with multi-morbidity, or older individuals. In LMIC, people with kidney failure routinely die of uraemia due to lack of access to life-saving dialysis and kidney transplantation. ${ }^{6,7}$ Worldwide, only half of those requiring RRT can be treated and estimates of those untreated range from 2.5 million to 5 million, based on epidemiological data. ${ }^{6}$ The costs of treating CKD and its complications, including kidney failure, are unaffordable for governments and individuals in many parts of the world. Annual costs of dialysis and kidney transplantation alone range between $\$ 35 \mathrm{~K}$ and $\$ 100 \mathrm{~K}$ per patient year. Although better access to dialysis and transplantation in LMIC reflects progress on development goals, the costs have profound consequences for families and health care systems. Apart from costs, the provision of RRT depends on sustainable health care infrastructure, personnel, and supplies. ${ }^{8}$ The costs of medications that attenuate the course of CKD and its consequences are substantially less, but also out of reach of many. ${ }^{9}$

Under-recognized by the public and policy-makers. Despite affecting as much as 10$15 \%$ of the population worldwide, CKD is not included in most priority lists of noncommunicable diseases (NCDs), and few countries have explicit policies or public programs aimed at CKD prevention and control. While there remain issues related to the ascertainment of these percentages, there is surprising concordance amongst many international estimates, irrespective of the methodology used to gain those estimates. CKD is defined as abnormalities of structure or function of the kidney, present for greater than three months, with implications for health. ${ }^{4,10}$ Despite the many recognized causes such as diabetes, hypertension, vascular disease, or glomerulonephritis (GN), the aetiology of CKD remains uncertain in a large proportion of affected individuals, hindering prevention, cause-specific treatment, and cure. In addition, acute events, such as infection, dehydration, and exposures to toxins and contrast media for imaging can 
all impact kidney function and are especially common in those with underlying CKD. Global advocacy initiatives such as World Kidney Day, 0by25, and the Lancet Kidney Campaign have all aimed to raise public awareness of the consequences, costs, and importance of CKD. World Kidney Day (www.worldkidneyday.org) showcases public awareness of CKD in over 120 countries around the world; 0by25 (www.0by25.org/) promotes awareness of AKI while devising and testing strategies to prevent AKI-related deaths; and the Lancet Kidney Campaign (www.thelancet.com/campaigns/kidney) aims to improve public and professional knowledge about kidney diseases, scientific breakthroughs, and clinical and ethical issues related to kidney care delivery.

Hampered by major knowledge gaps. Despite substantial efforts from basic, translational, and clinical scientists, optimal care of kidney patients is hampered by insufficient knowledge about mechanisms causing progressive loss of kidney function and its complications. Inconsistency and variability of clinical information and limited samples collected from individuals hinder pooling of data across studies to enable analyses with sufficient statistical power and adequate representation of less common diseases. Several high profile trials failed to show a significant benefit of promising therapies, which creates barriers to innovative treatment approaches. Overall nephrology lags behind other medical disciplines in terms of the number, size, and quality of completed clinical trials. There are multiple reasons for this, including a lack of attractive molecular targets, the relatively slow rates of progression seen in many forms of CKD, uncertainty about the value of surrogate markers, a lack of culture that fosters the robust testing of focussed hypothesis, and a failure to recognize clinical equipoise that would justify such trials. In the last three years, a number of international initiatives have emerged to address these issues, e.g., Kidney Disease: Improving Global Outcomes (KDIGO; www.kdigo.org), International Society of Nephrology Advancing Clinical Trials (ISN-ACT), International Network of CKD cohort studies (ISN-iNET CKD), CKD Prognosis Consortium (CKD-PC; http://www.jhsph.edu/research/centers-andinstitutes/chronic-kidney-disease-prognosis-consortium/), and the Kidney Health Initiative (KHI; https://www.asn-online.org/khi/mission.aspx).

\section{The need for a plan}

The global nephrology community recognizes the need for a cohesive plan to address the problem of CKD. The International Society of Nephrology (ISN) therefore organized a summit that was held in Vancouver, Canada in July 2016 which was co-chaired by the two first and the senior author of this paper, Levin, Tonelli, and Eckardt. Participants included more than 85 individuals with diverse expertise and professional background from around the globe. The purpose of the meeting was to identify and prioritize key activities for the next five to ten years in the domains of clinical care, research, and advocacy; to identify potential partners within and outside the nephrology community; and to create an action plan and performance framework. Intended users of the action plan include clinicians, patients, scientists, industry partners, governments, and advocacy organisations.

\section{Brief Methods}


Clinicians, basic scientists, clinical researchers, epidemiologists, methodologists, and industry scientists from different regions of the world met for 2.5 days to develop the plan, which was based on the following 10 themes pre-defined by the 3 co-chairs with input from the ISN Executive Committee: 1. Determine and monitor prevalence of CKD in different regions/countries; 2 . Identify and reduce major risk factors for CKD; 3.Reduce progression of CKD by targeting AKI episodes; 4. Improve understanding of the genetic causes of CKD; 5 . Improve diagnostic methods to assess alterations in kidney structure and function; 6 . Improve understanding of the natural course of CKD and define prognostic biomarkers for renal progression, CVD complications, and other adverse events; 7 . Evaluate and implement established treatment options in patients with CKD; 8. Improve understanding and management of the complications of CKD; 9. Validate and establish novel therapeutic interventions to slow CKD progression and reduce CKD complications; 10. Optimize the design of clinical trials in CKD.

Delegates participated in two out of ten working groups, each of which addressed a single theme. Pre-work for the meeting consisted of identification of key issues, supporting literature searches, and facilitated discussion. Using an iterative process, each group produced a prioritized list of key issues, goals, and activities. All groups were asked to develop a set of deliverables to inform the performance framework (Table 5), demonstrate progress, and hold stakeholders to account. Progress will be reported regularly according to the framework, and leveraging the parameters identified in the Global Kidney Health Atlas ${ }^{11}$ (GKHA; which describes CKD-relevant access to care, health infrastructure, national and regional policies, and research capacity).

\section{Developing the plan}

The plan for each theme includes a set of high-level goals and specific activities aiming at achieving the goals. The details of these activities vary by theme, but there are some common characteristics for activities in all themes. Special emphasis was placed on aligning with Sustainable Development Goals (SDGs) relevant to improving child and maternal health, ensuring access to education, clean water, essential medications and vaccines, focusing on prevention and reduction of infections, and improving access to care and health infrastructure, especially in the context of risk factors for CKD ${ }^{12}$ (Theme 2).

A performance framework, based on the overarching goals and specific working group action plans, is presented at the end of this document (Table 5).

\section{Chapter 1. Where Are We Now?}

The number, geographic distribution, size, and quality of the studies examining CKD prevalence and incidence has increased over the past decade, but global capacity for CKD surveillance remains far less developed than that for hypertension, diabetes, and CVD. General population prevalence studies of CKD have been done in multiple settings and have provided important baseline information. Some of the earliest, largest, and most rigorous studies were conducted in Australia, Europe, Japan, and the United States of America (USA). Fewer data on prevalence are available in LMIC. 


\section{Prevalence of Dialysis and Transplantation}

Liyanage et al. estimated that in 2010, globally 2.6 million people received renal replacement therapy ( 2 million on dialysis and 0.6 million living with a kidney transplant). ${ }^{6}$ They further estimated that this only represents approximately $50 \%$ of people who need RRT. These estimates are likely to be conservative. The availability of RRT is quite variable worldwide. Availability is high in the Americas, Europe, and other HIC. In contrast, Asia has nearly one million people on dialysis or with a kidney transplant, but the actual need may be three times higher. The situation is worse in Africa and low-income countries (LIC), where the impact of dialysis on personal finances can be devastating. As per capita incomes increase in LMIC, the prevalence of renal replacement is expected to rise, posing substantial challenges to health systems.

\section{Total CKD Prevalence}

A 2010 systematic review identified 33 studies that reported age and sex-specific prevalence of CKD in representative populations worldwide..$^{13}$ The global prevalence of CKD was estimated as approximately $10 \%$, corresponding to almost 500 million people; the estimates in men, women, and HIC vs LIC were relatively similar. Hill et al. metaanalysed 100 studies of CKD prevalence. ${ }^{14}$ After accepting the limitations of variable quality and pointing out the marked heterogeneity across studies, they estimated global CKD prevalence to be $13 \%$ (web appendix Figure 1), which may overestimate the true prevalence somewhat given the limitations in the source literature. Other work has documented dramatic variation in the apparent prevalence of CKD across studies done in different European populations (5-fold between Norway and Italy on the low end and Northern Germany on the high end). ${ }^{15}$ As yet, it is unclear how much of this variation is due to research methods vs. true population differences. ${ }^{16}$ Recent data from the USA suggests that initial increases in CKD prevalence ${ }^{17}$ have plateaued since the mid2000 s, ${ }^{18}$ largely due to a decrease in CKD at older age. However, CKD prevalence in high-risk groups (African Americans and diabetics) has continued to rise.

\section{Major CKD risk factors}

Prevention of CKD begins with identification of risk factors followed by mitigation strategies. CKD is caused by multiple aetiologies, both inherited and acquired. On a global scale, diabetes and hypertension are the dominant risk factors for CKD. Obesity is closely linked to diabetes and hypertension, and may also predispose to CKD. Suboptimal maternal and foetal environments and other life-time exposures such as infections, nephrotoxins (e.g., prescription drugs, ingestions, and traditional remedies), and episodes of AKI may also increase risk for CKD. ${ }^{19,20}$

Despite what is known about prevention, the prevalence of diabetes, hypertension, and obesity continue to rise worldwide. Poor diet, poverty, and unhealthy lifestyles overall increase the risk of CKD and are antecedents to traditional CKD risk factors. ${ }^{21-28} \mathrm{Good}$ management of diabetes, hypertension, and excess weight reduces the risk of CKD and improves outcomes among those with CKD. ${ }^{29-35}$ 
Nephrotoxin exposure is a common and under-recognized risk factor for AKI and CKD. ${ }^{36-42}$ Nephrotoxic agents, e.g., non-steroidal anti-inflammatory drugs (NSAIDs), iodinated contrast media, and certain alternative remedies among many others, are widely available and frequently used in patients at risk of CKD. For example, over $80 \%$ of people in LMIC use traditional remedies that are often the only affordable or accessible means of healthcare..$^{43}$ Many of these remedies are untested and unregulated, leading to high inter-product variability and risks of toxicity. ${ }^{44}$ Kidney stones are another important CKD risk factor. ${ }^{45-47}$ Modifiable contributors to stone risk include diet and environmental exposures. ${ }^{46,47}$ Individuals experiencing a stone event are at higher risk for another one, and secondary prevention is key to reduce risks of recurrent stones and CKD. 46,48

Infections are an important cause of $A K I$ and $C K D$, especially in resource-limited regions. ${ }^{37,49-51}$ Under the Millennium Development Goals (MDGs), Human Immunodeficiency Virus (HIV), malaria, and tuberculosis (TB) received particular attention. ${ }^{51-60}$ These and other infections (e.g., impetigo, hepatitis B [HBV] and hepatitis $\mathrm{C}$ [HCV], various tropical diseases) are associated with increased risk of CKD. 51,61-65

Low birth weight (LBW), prematurity, and high birth weight (HBW, e.g., infants of diabetic mothers) are associated with increased risks of hypertension, diabetes, obesity, CVD, and CKD. ${ }^{66-69}$ Childhood obesity and pre-term birth are important CKD risk amplifiers..$^{70-72}$ Mothers who experienced pre-eclampsia/eclampsia have an increased life-time risk of hypertension and CKD. ${ }^{73-75}$ Both conditions are common. ${ }^{74-76}$ Antenatal clinics and delivery sites are central locations for identification of women and children at risk of $A K I$ and $C K D$ who will require long-term follow up.

Pre-existing albuminuria and reduced eGFR are strong risk factors for AKI. ${ }^{77-81}$ Chronic renal damage, impaired renal reserve, and compromised vascular autoregulation may be contributors to AKI risk in the CKD population. However, the pathophysiology underlying this association remains incompletely understood (web appendix Figure 2). Conversely, AKI is a strong risk factor for de novo CKD, CKD progression, and endstage renal disease (ESRD) in multiple clinical settings. ${ }^{82-84}$ In a recent meta-analysis, survivors of hospital-associated AKI had an 8-fold increased risk of developing CKD. ${ }^{84}$ AKI is common in all populations irrespective of geographical location: while aetiologies may vary, the impact of episodes of AKI due to ischemia, toxins, inflammation, or some combination is profound.

Genetic causes of CKD

The past decade has witnessed several important advances in human genetics, including the sequencing of the human genome, establishment of patterns of genetic variation in worldwide human populations, the development of high-throughput genotyping and massively parallel sequencing technologies, as well as advances in statistical genetics and bioinformatics. These advances have enabled the discovery of novel risk genes and variants at unprecedented speed. ${ }^{85-88}$

Understanding the genetic component to kidney function in health and disease and the interaction between genetic susceptibility factors and the environment can provide 
important insights into renal physiology and pathophysiology, including the identification of novel therapeutic or preventive targets. Genome-wide associations studies (GWAS) as well as whole-exome and whole-genome sequencing have become standard techniques to identify genetic loci in which variation associates with complex forms of CKD as well as with kidney function and to detect mutations causing monogenic kidney diseases. ${ }^{89-91}$ Several hundred genes are currently known in which mutations can cause single-gene disorders with a kidney phenotype, as well as dozens of genetic loci in which common genetic variants are associated with kidney function and with complex diseases of the kidney ${ }^{91}$ (web appendix Figure 3).

Diagnosis, prognosis, and treatment

CKD encompasses a wide spectrum of conditions, of various aetiologies, that result in glomerular filtration barrier failure and/or loss of renal filtration capacity and tubular functions. Although estimates of glomerular filtration rate (eGFR) and albuminuria are clinically useful for identifying and staging CKD, they are insensitive and non-specific. Kidney biopsies can be used to stratify CKD into distinct subgroups of diseases based on structural evaluation of specific histological patterns in combination with the clinical presentation. In addition, kidney biopsies can provide information on disease activity, molecular mechanisms and prognosis.

However, even in HIC, renal biopsy is only performed in a small fraction of CKD patients - usually in patients with suspected glomerular disease in whom knowledge of biopsy findings may trigger a change in management. For the more common causes of CKD such as diabetes and hypertension, renal biopsies are only performed in instances where the presentation or clinical course is atypical. Increasing the use of kidney biopsy materials to gain better diagnostic and prognostic insights is important in all regions of the world.

Given the variability in kidney and CVD outcomes of CKD patients, there is a need to identify and thoroughly validate novel prognostic biomarkers that help to predict future risk and understand the underlying molecular mechanisms. Current CV risk algorithms are based on traditional CV risk factors and do not include albuminuria or eGFR, which provide additional prognostic information. Although novel biomarkers have been identified within the CKD and CVD populations, most studies to date have focused on assessing the predictive value of single biomarkers at a single time point, e.g., CRIC, ${ }^{92}$ CanPREDDICT, ${ }^{93}$ PREVEND, ${ }^{94}$ REGARDS,${ }^{95}$ and TREAT ${ }^{96}$

The utility of biomarkers in clinical care, for resource planning, for targeting of novel pathways, or for enriching clinical trials and the utility of biomarker panels and dynamics has not been well examined in nephrology: much work needs to be done, specifically in the research arena.

While there are many unanswered questions in CKD care, there are nevertheless strategies and treatment options that have been shown to be effective in improving outcomes. A fast and efficient way to improve outcomes of CKD patients would be to fully implement those therapies. Specific strategies which have been shown to improve 
outcomes of patients with CKD include: blood pressure (BP) lowering; 97,98 reduction of proteinuria; $;^{97,99}$ use of ACEi or ARB; ${ }^{100}$ and the use of statins to reduce atherosclerotic events. ${ }^{101,102}$ Glycaemic control in both type 1 and type 2 diabetics also improves outcomes ${ }^{103.104}$ and newer agents such as SGLT2 inhibitors have the additional benefit of reducing albuminuria, CV outcomes, and progression of CKD in diabetics. ${ }^{105-107}$

Recent studies suggest that specific therapies targeted at specific kidney diseases may be of long-term benefit. ${ }^{108}$ However, the implementation of established therapies is variable within and between regions. Physician, patient, and health care system factors may all play a role. Access to care or therapies is often restricted by poor availability, expense, or limited access to expert advice. Physicians may fail to adopt best practices, or lack the tools to ensure standardization of care. For example, the uptake of wellestablished therapies such as renin-angiotensin blockade in CKD patients followed by nephrologists is less than $70 \% .{ }^{109}$ In some cases, there are problems with tolerance of specific medications or adherence. ${ }^{110}$

In addition to progressive kidney function loss, CKD is associated with multiple complications that cause morbidity, mortality, and reduce quality of life. Some of these complications (e.g., CVD, hypertension, anaemia, and metabolic bone disease [hyperphosphatemia, hyperparathyroidism]) are important in day-to-day clinical practice and have been extensively studied. Others (e.g., sodium/fluid retention, metabolic acidosis) are clear clinical priorities but have been less well studied, and a third group (e.g., symptoms such as pruritus and nausea) are neither clinical nor research priorities. ${ }^{111}$ Although more research is needed for all three of these groups, increasing attention appears warranted for the causes and optimal treatment of CKD-associated symptoms. ${ }^{112}$

\section{Clinical trials}

High quality clinical trials are the cornerstone of evidence-based prevention and treatment of disease, but nephrology has a strikingly weak base of such trials. The number of trials conducted in nephrology is less than any other specialty, and shows little evidence of improvement. ${ }^{113}$ Available trials in kidney disease populations tend to be smaller than those in other specialties, and are less likely to be randomized or blinded. ${ }^{114}$ Building the evidence base to improve outcomes for people with kidney disease therefore requires both greater quantity and quality of trials.

Most Phase 2-4 trials in CKD populations have not shown benefit for their primary endpoint and several have been stopped due to safety concerns (web appendix Table 1). Different specific causes of CKD probably require targeted therapies to alter initiation of injury. On the other hand, once CKD is established, some mechanisms for progression may be similar (regardless of cause) and an inclusive approach by clinical trialists and regulatory authorities is required. Clearly the appetite for investment in new therapies for CKD by the private sector is driven by large clinical need, but hampered by the high risk of failure reinforced by the history of disappointing large studies and the lack of intermediate endpoints/biomarkers that the regulatory agencies will accept for approval. Although not exhaustive, web appendix Table 1 Recent Clinical Trials in CKD, 
details important recent and ongoing Phase 2-4 clinical trials in CKD, excluding trials in the transplant population.

A number of factors have contributed to this situation. The science of designing clinical trials needs innovation, but has received limited attention to date in nephrology, with no dedicated discussion forum and a relatively low profile at existing major kidney meetings. As a result, designs have been relatively static. Trials have mostly focused on the needs of HIC, with little input from (and limited relevance to) LMIC.

The selection of valid and appropriate endpoints in kidney disease trials has proved especially problematic. The most clinically important outcome in CKD patients is kidney failure requiring dialysis or transplantation, or leading to death. However, this endpoint typically develops over many years (or decades) so defining the effects of interventions on this endpoint is often difficult if not impossible. To make trials feasible, many enrol large numbers of people with advanced stages of CKD, where progression is considered to be more predictable than in earlier stages. However, interventions that slow progression during earlier stages of kidney disease may not be effective in later stages. A doubling of serum creatinine (equivalent to a $57 \%$ decline in eGFR) has been accepted as a surrogate for the development of kidney failure for many years. A workshop convened by the US National Kidney Foundation (NKF) and Food and Drug Administration (FDA) recommended the threshold may be reduced to $40 \%$ or even $30 \%$ GFR decline under specific circumstances, improving trial feasibility. ${ }^{115}$

\section{Chapter 2. What We Don't Know - Knowledge Gaps}

Dialysis and kidney transplantation registries are non-existent or incomplete for most of the world's population. Furthermore, RRT is only one measure of the burden of kidney failure given that many patients either choose not to receive or are unable to receive RRT. Population-based registries of less severe forms of CKD are infrequent even in wealthy countries. Estimates of the total burden of CKD suffer from methodological limitations, with sampling often relying on convenience rather than random approaches, and regional rather than national coverage. Creatinine standardization is much improved, but prevalence estimates remain very sensitive to calibration errors. The CKD-EPI equation for estimating GFR is becoming the global standard, but much of the older literature used the MDRD study equation, which results in somewhat higher prevalence estimates. ${ }^{116,117}$ Urine measures for CKD are more difficult to standardize and suffer from high physiologic variation (morning levels of albumin to creatinine ratio being lower than during daytime, and substantial day-to-day variation), ${ }^{118}$ with dipsticks providing even lower accuracy. Few studies fully staged CKD by cross-classifying GFR and ACR categories, as recommended by the most recent guidelines. ${ }^{10}$ That estimates of reduced GFR or increased albuminuria have not been confirmed in most studies may have led to some overestimation in prevalence figures. ${ }^{119,120}$ Finally, knowledge is lacking on how the burden of CKD may vary in different settings (e.g., excess risk of ESRD, CVD, and infections). This limited knowledge contributes to a poor appreciation of the disease burden among patients, clinicians, and policy makers. 
Within specific regions, CKD of undetermined origin (CKDu) is an important and growing problem. It may be the leading cause of death affecting young field workers in parts of Sri Lanka, Central America, and South India. ${ }^{121}$ Despite the increasing recognition of the CKDu hotspots, there has been limited success in determining the root cause: candidates include recurrent $\mathrm{AKI}$, heat stress, dehydration, infections, exposure to agrochemicals, over the counter medication, heavy metal contamination, and poor quality drinking water. ${ }^{122-131}$ Due to limited resources and infrastructure, diagnosing and characterising CKDu, determining its incidence/prevalence, and assessing exposures is a challenge.

Despite the recognized importance of hypertension and diabetes as CKD risk factors, several important questions remain. For example, only about a third of patients with diabetes develop CKD. Barriers to population-based strategies to reduce dietary sodium, fat, and calories, and to increase physical activity must be identified in local contexts. Studies are required to identify risk factor targets (e.g., HbA1c, BP, weight) for CKD prevention and variance of targets, e.g., by age, gender, race/ethnicity. Greater understanding of regional risks for kidney stones is important for prioritization of CKD risk-reduction strategies. The impact of medication and alternative/traditional remedy use requires surveillance and further study.

The regional CKD burden related to infections is also not well documented, and thus the impact of prophylaxis (vaccines), clean water, or treatment of these infections remains unknown. Bacterial, mycobacterial, fungal, and viral infections have all been shown to impact the incidence and prevalence of AKI and CKD. How much of this burden could be avoided by increasing effectiveness and reach of public health interventions requires coordination and collaboration within and across communicable disease programmes.

The true burden of CKD associated with maternal or foetal risk factors is poorly defined in all regions of the world. Pregnancy surveillance and delivery health care reduced risks for AKI, but whether interventions during pregnancy or soon after birth may reduce subsequent CKD risk in mother and/ or foetus remains unknown. Despite the epidemiological association of $A K I$ and $C K D$, the impact of preventing $A K I$ on long-term CKD remains to be demonstrated. Patients who develop AKI often have a higher prevalence of risk factors for CKD and CKD progression, and therefore it is possible that the observed association between AKI and rapid kidney function loss is confounded by illness severity. Moreover, it remains difficult to distinguish AKI from progressive CKD and it is possible that the observed associations are due to misclassification - especially in LMIC, where lab testing is infrequent or unavailable and baseline kidney function is often unknown. ${ }^{132}$

There are four main limitations in understanding the genetic causes of CKD. First, education and awareness of the value and importance of genetic research is limited. This is true not only for the lay public, but also for patients, researchers, and clinicians. Lack of education can pose a particular challenge in clinical genetics, especially with respect to the initiation and type of genetic testing, the assessment of the pathogenicity of detected genetic variants, and the counselling of patients. In addition, realistic 
expectations and timelines for the translation of genetic findings into the clinics (web appendix Figure 4) are not well communicated.

Second, most existing genetic research has been carried out for individuals of European ancestry, although indigenous populations of non-European ancestry often show high rates of kidney disease and evidence for region-specific genetic risk factors for CKD exists. ${ }^{133}$ Current knowledge may therefore not be representative globally, which can have significant implications. ${ }^{134}$

Third, genetic research can reach its full potential only through wide-spread data sharing, which currently is limited and often occurs in unstandardized formats. Thus, comprehensive and current inventories of existing genetic datasets as well as their findability and accessibility are prerequisites to maximize the use of existing data.

Fourth, the limited existence of tools for functional genomics research, particularly in kidney cell types, are a major roadblock for the identification of causal genes and variants, improved mechanistic insights, and translation to the clinics. ${ }^{135}$ Finally, our current understanding of gene environment interactions and their relevance for CKD are incomplete. A better understanding of these interactions will provide insights into important patient subgroups and is necessary for targeted therapy and prevention.

Diagnosis, prognosis, and treatment

Even after biopsy-driven disease categorizations, there is substantial heterogeneity in pathophysiology and prognosis among diseases within a category. Most current histologic diagnoses lump diseases with multiple underlying mechanisms together into syndromic categories. Different, specific pathogenetic events (i.e., mutations in different genes causing familial nephrotic syndrome) exhibit indistinguishable structural alterations (i.e., diagnosis of Focal segmental glomerulosclerosis [FSGS]). Conversely, the same single mechanism (i.e., mutations in podocin causing nephrotic syndrome, type 2 [NPHS II]) can give rise to different histological diagnoses in different patients (minimal change disease to FSGS).

These challenges concerning diagnoses are particularly prominent in LMIC, where access to sequential laboratory evaluations of eGFR, albuminuria, and kidney biopsies are all limited or non-existent. Consequently, the spectrum of diseases responsible for CKD in the population is often unknown, severely hampering efforts at prevention and control. How best to increase the utilization of albuminuria and eGFR in clinical practice (both HIC and LMIC) is unknown but critically important given their diagnostic and incremental prognostic value. Although the appeal of novel biomarkers is obvious, few (if any) have been shown to modify predictably with disease progression or successful treatment. In addition, most new biomarkers do not undergo thorough external validation and are not rigorously assessed for incremental clinical utility. Finally, studies examining biomarker profiles often fail to include populations from LMIC and people of non-European origin. 
"Treatment gaps," defined as the difference between the number of people who have an indication for a therapy and who actually receive the therapy, represent opportunities to improve outcomes in the short-term and are common even in HIC. ${ }^{136}$ Ongoing, systematic surveillance of treatment gaps is rare at present, although the advent of electronic medical records (EMRs) and other internet based tools offers a potential mechanism. Little is known about the magnitude and determinants of treatment gaps in LMIC; most focus has appropriately been on which treatments are available or affordable. As access to care improves in LMIC, focus should shift to identifying and closing other potential causes of treatment gaps in these settings.

There are a variety of approaches to close treatment gaps. Studies have suggested that reminders, checklists, and pre-printed orders may be of value in HIC, and universal health coverage $(\mathrm{UHC})$ or income supplementation are logical in situations where economic barriers are important. Where possible, strategies to close treatment gaps should be accompanied by studies of process-based outcomes (e.g., uptake of the treatment) and patient-important outcomes. Pragmatic trial designs such as steppedwedge trials, cluster-randomised trials, and/or registry-based trials lend themselves to implementation science evaluations and represent valuable opportunities to rigorously evaluate implementation methods and the comparative effectiveness questions. In LMIC, implementation science will maximise the efficiency of the health service investment as well as outcomes for patients.

Pruritus, restless legs, nausea, poor appetite, and sexual dysfunction are all common in CKD patients, especially those with kidney failure. These symptoms are likely multifactorial, their pathophysiology is incompletely understood, and little is known about their treatment. Similar but less pronounced knowledge gaps exist for CVDs (especially atypical coronary disease, uremic cardiomyopathy, and peripheral vascular disease) which are major causes of mortality in CKD patients. While the risk of conventional atherosclerotic CV events does increase at lower levels of kidney function, the majority of the excess risk associated with CKD are "non-Framingham/non-atherosclerotic" pathologies including LV hypertrophy with diastolic and systolic dysfunction, dysrhythmia, sudden death, valvular calcification, arterial calcification, and haemorrhagic stroke. The pathophysiology of these conditions appears to be partially due to a high burden of traditional CV risk factors as well as uraemia-specific factors. ${ }^{137}$ Although there is some evidence that management of traditional CV risks improves outcomes in earlier forms of CKD, it is unknown how best to reduce CV risk in advanced CKD or kidney failure. ${ }^{138}$

Much research has focused on the management of hypertension, anaemia, and metabolic bone disease in CKD populations, but data demonstrating that these treatments improve outcomes has been sparse, and the results of randomized trials have typically been disappointing. ${ }^{139-141}$ In addition, these haematological, hormonal, and metabolic abnormalities per se are not patient-important outcomes - and monitoring and treating these abnormalities accounts for a substantial proportion of the costs of CKD care, especially for patients with kidney failure. On the other hand, it seems clear that these abnormalities contribute to symptom burden and possibly 
outcomes in CKD populations. ${ }^{142}$ More research is needed to assess the mechanisms by which these abnormalities impact on outcomes, and determine how they can best be treated. In addition, a key priority worldwide is determining how to reduce the clinical and economic burden of appropriately monitoring them, especially in LMIC.

Better treatments to reduce the risk of progression from CKD to kidney failure are needed, and there is a limited evidence base for therapies to reduce CV mortality in CKD. Although controlling traditional risk factors has arguably not been as successful in reducing mortality in patients with kidney disease compared to the general population, BP control, ${ }^{143}$ statin use, ${ }^{144}$ and blockade of the renin angiotensin aldosterone axis ${ }^{145,146}$ have reduced $\mathrm{CV}$ events. However, excess CV mortality remains a major clinical problem in patients with CKD. ${ }^{97,147}$

Progress will require that research consortia are developed among academia, industry partners and biotechnology companies, philanthropy and funding bodies, policy makers, and government. Scientists from varied domains will need to be engaged and clinicians across the world will require education regarding novel therapeutics to involve themselves and patients in the necessary clinical trials to develop the evidence base required for the introduction of new therapies into clinical practice. Consortia members will inevitably be required to 'do things differently,' as continuing with current strategies to develop new therapeutics in CKD has not been as successful as patients, clinicians, and indeed all stakeholders, would expect. Hence, a focused strategy is required that is coupled with regional adaptation by HIC and LMIC. The hurdles - breaking down structural impediments, and scientific, regulatory, legal (including protection of intellectual property), financial, risk allocation, and management silos represent a formidable but not insurmountable challenge.

\section{Clinical trials}

There continues to be debate as to the appropriate endpoints for clinical trials. The role of change in albuminuria as an endpoint in kidney trials continues to be debated, with no clear consensus. ${ }^{148,149}$ In general, using changes in markers of kidney damage as endpoints for specific kidney diseases may also be appropriate, e.g., total kidney volume in polycystic kidney disease (PKD), but requires definition, validation, and consensus. Safety endpoints have received insufficient attention. Both efficacy and safety endpoints have generally been developed by researchers with little or no input from patients, who may have very different priorities, which is being addressed by the Standardised Outcomes in Nephrology (SONG) initiative. ${ }^{150,151}$ Much work is still required to define appropriate trial endpoints, particularly those important to patients and payers, and that are applicable in early stages of CKD.

Compared to other specialties, the nephrology community has a relative lack of experience, infrastructure, and capacity in conducting trials. Much of the existing trials infrastructure in nephrology has been funded from industry partner-run trials, without a clear overarching framework for engagement of participating centres. Similarly, there is little support for multicentre clinical trial groups from the National Institutes of Health $(\mathrm{NIH})$ or other government sponsors. Collaboration between national, regional, and 
global trial networks has been limited and ad-hoc, leading to under-utilisation of existing resources. Interaction with other health care providers (nurses, allied health, primary care, other specialties) has also been under-developed. Finally, limited training and capacity development opportunities have also meant that little infrastructure exists in many parts of the world. This leads to limitations in recruitment capacity and challenges for trial conduct in kidney disease in countries with large affected populations. The sum effect of these factors is that trials in CKD are not prioritized, and are seen as a relatively high-risk endeavour compared to other therapeutic areas.

A broad, strategic, sustained, collaborative approach is required to address these major challenges; it requires prioritization of CKD trials, better trial design, and increased capacity to deliver these trials. As a stretch goal for the community, we propose that $30 \%$ of patients with CKD should be involved in relevant clinical trials by 2030 . This will require transformative change and big ideas, but will dramatically improve methods for preventing and treating CKD.

\section{Chapter 3. What Do We Do About It?}

\section{Strengthen CKD surveillance}

The first step to making progress in improving CKD monitoring activities (see Table 1) is to fully engage stakeholders by making sure the rationale for monitoring programs is clear and tailored appropriately for different settings.

Measurement of creatinine and albuminuria are central to the diagnosis and staging of CKD. Much progress has been made over the past decade from an era when creatinine was one of the most poorly standardized measurements in clinical chemistry. However, even relatively small errors in creatinine measurement can have a substantial impact on inferences about CKD prevalence. ${ }^{152}$ Therefore, to achieve valid comparisons over time (where meaningful trends are often a small relative change of 2-10\%/year) and across regions, standardization and methods must be of high quality. For similar cost compared with local assays (given economies of scale), large studies could ship samples to a known reference laboratory. Conversely, reference materials could be prepared with known values for use in multiple studies worldwide. Where appropriate, point-of-care testing with reliable accuracy could be implemented which would increase the accessibility of diagnostic testing around the world.

Efforts should be made to add CKD to large ongoing surveys and cohorts that do not already include eGFR and albuminuria The cost of drawing a valid random sample, recruiting participants, and measuring covariates could be shared by all the diseases studied: the incremental cost of including and standardizing measurements of serum creatinine and albuminuria should be modest compared to the total cost of the survey and the importance of CKD (high prevalence, high risk, and often growing burden). A systematic effort to assure the inclusion of CKD measures in large ongoing or planned chronic disease studies could markedly enhance global efforts for CKD surveillance. 
A systematic effort to harness medical claims data for CKD surveillance would be complementary and should also be seriously considered. As EMRs are becoming standard worldwide, the potential for aggregating information is large. The validity of claims or International Classification of Diseases (ICD) code for various medical conditions is limited. CKD codes are often very insensitive, missing the majority of disease, but are quite specific. ${ }^{153,154}$ Thus, health services data need to be scrutinized carefully with ongoing efforts for quality improvement. However, even unvalidated codes can give important clues to the evolving CKD epidemic. For example, a recent publication from China showed that among 19 million tertiary hospital discharges, the prevalence of CKD due to diabetes is now higher than the prevalence of GN (substantially different than the situation a decade ago). ${ }^{155}$ When EMRs include laboratory data, researchers can apply standardized definitions and staging of CKD to large populations. For example, the SCREAM investigators tracked the prevalence of CKD in over 1 million people in the Stockholm region, ${ }^{156}$ and showed that even in a HIC with UHC not all patients with advanced CKD ultimately consult a nephrologist. Given the high cost of dedicated research studies and the increasing computerization of health care, developing methods to increase the validity of imperfect health care utilization data appears to be a promising option for improving global CKD surveillance. Using large but unvalidated databases in conjunction with focused validation studies could help with this. ${ }^{157}$

Incorporating the new CKD classification system in the World Health Organization (WHO) ICD coding ${ }^{158}$ is an important potential enabler for future CKD surveillance activities. ICD coding forms the foundation for the systematic classification and enumeration of disease globally. Therefore, it is vital that ICD codes identifying CKD follow the most recent guidelines, which reflect staging with respect to cause and consider both eGFR and albuminuria to assess risk. ${ }^{10}$ The prevailing ICD-10 coding system includes staging for eGFR (codes N18.1/5), but not for albuminuria. Efforts should be taken to integrate the globally accepted KDIGO CKD classification scheme that is based on eGFR and albuminuria in the upcoming ICD-11 coding system. In addition, a uniform system for specific coding of aetiologies should be adopted worldwide; a potential candidate is the scheme by the European Renal AssociationEuropean Dialysis and Transplant Association (ERA-EDTA), which was developed in collaboration with the International Health Terminology Standards Development Organisation (IHTSDO). ${ }^{159}$

One key special population of interest is people with kidney failure treated by dialysis or transplantation; since all have CKD by definition, the goal of surveillance is to monitor the total number of treated patients, representing access to care as well as disease burden. Therefore, emphasis should be placed on establishing registries of chronic dialysis and transplantation in all countries - especially LMIC, where registries are rare. Capturing those patients in LMIC who 'warrant' RRT, but do not receive it for whatever reason is an important task for these registries, and will be important in long term monitoring in different health care environments. Given the specialized and expensive nature of this treatment and the rapid computerization of medical care, there is an excellent opportunity to improve the quality and coverage of dialysis and transplantation 
registries. Shared minimal data standards and architecture could greatly facilitate this work.

A second important group of special populations includes children, rare diseases, and residents of regions where CKD appears to be endemic (i.e., hotspots). These populations should be targeted by simple registries, aiming to collect data that would support targeted efforts for improved care and prevention as well as vital clinical trials. Establishing and promoting a minimum dataset for registries (regardless of population or location) would enhance comparability across countries and facilitate global estimates of CKD prevalence.

A third population of interest is high-risk groups (e.g., subjects with known hypertension, diabetes, or CVD) in which testing for CKD is already recommended by an international guideline. Supporting efforts to improve implementation of this guideline worldwide by testing with both albuminuria and eGFR will help to understand and compare patientlevel risk across countries while enabling delivery of targeting therapies at the individual level. Increasing efforts to use albuminuria and eGFR in combination should be coupled with attempts to report eGFR wherever serum creatinine is measured. This is already the standard in much of the world and can be implemented at minimal cost in labs elsewhere if computerized data on age and sex are available ${ }^{160}$-- saving health care professionals the time and potential errors associated with doing the calculations. Pointof-care testing is now available for use in rural and remote areas, which improves ability to determine eGFR in LMIC, although the practicality and sustainability of long-term use in these settings has not been evaluated.

Once CKD is identified, community workers, primary care and other non-specialist practitioners will need support with management. One option could be to develop and share computer-assisted tools such as protocols and electronic decision support for identification and follow-up of CKD cases. Such tools are being used in multiple settings to identify, follow, and care for CKD patients. ${ }^{161,1623}$ Sharing these tools can be an enormously efficient way to advance CKD monitoring and care; combining implementation efforts with cluster randomized designs to demonstrate efficacy should lead to continued improvement and further investment by payers. Symptom burden for functional status assessment should also be considered as part of standardized collection in studies.

Although there is much enthusiasm for population-based CKD screening, the evidence base supporting this approach is lacking. Since expectations for potential benefits of screening are often substantially different than true benefits, screening strategies should be developed and tested in a randomized setting so that efficacy can be appropriately measured. This has never been done for CKD, probably due to limited resources. However, there are opportunities to at least evaluate new strategies with control groups, possibly using a stepped wedge design with cluster randomization. 


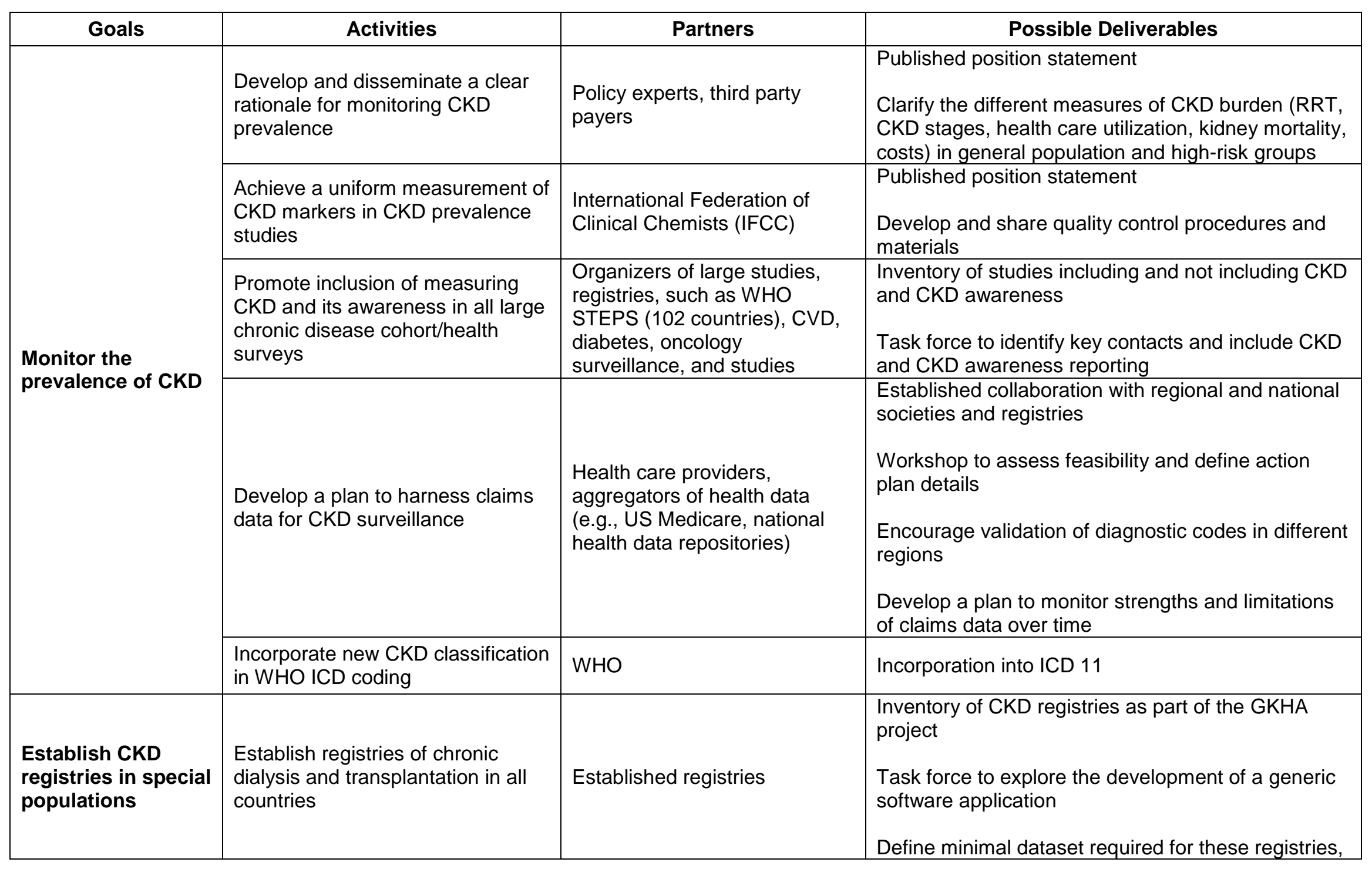




\begin{tabular}{|c|c|c|c|}
\hline Goals & Activities & Partners & Possible Deliverables \\
\hline & & & $\begin{array}{l}\text { facilitate implementation, suggest methods to } \\
\text { assess comprehensiveness } \\
\text { Encourage the use and usefulness of the registries } \\
\text { to enhance policy, observational research, and } \\
\text { clinical trials }\end{array}$ \\
\hline & $\begin{array}{l}\text { Establish registries for special } \\
\text { CKD groups, e.g., children, rare } \\
\text { diseases, special aetiologies, and } \\
\text { regions where CKD appears to be } \\
\text { endemic (i.e., hotspots) }\end{array}$ & $\begin{array}{l}\text { Established registries, special } \\
\text { interest groups }\end{array}$ & $\begin{array}{l}\text { Inventory of CKD registries as part of the GKHA } \\
\text { project } \\
\text { Task force to explore the development of a generic } \\
\text { software application to facilitate the establishment of } \\
\text { CKD registries } \\
\text { Define criteria for when a registry is high-priority C } \\
\text { Encourage impactful use of the registries to } \\
\text { enhance policy, observational research, and clinical } \\
\text { trials }\end{array}$ \\
\hline \multirow{3}{*}{$\begin{array}{l}\text { Identify individuals } \\
\text { with CKD in high- } \\
\text { risk groups }\end{array}$} & $\begin{array}{l}\text { Support efforts to strengthen the } \\
\text { evidence base underlying } \\
\text { additional screening strategies }\end{array}$ & & $\begin{array}{l}\text { Research reports (focus on high-risk groups by } \\
\text { condition, ethnicity, and region) }\end{array}$ \\
\hline & $\begin{array}{l}\text { Ensure that wherever serum } \\
\text { creatinine is measured, eGFR is } \\
\text { reported }\end{array}$ & Clinical chemists (IFCC) & $\begin{array}{l}\text { Focussed extension of the GKHA project } \\
\text { IFCC committees; National and international } \\
\text { laboratory professional groups and health care } \\
\text { institutions }\end{array}$ \\
\hline & $\begin{array}{l}\text { Develop and share computer- } \\
\text { assisted tools for identification and } \\
\text { follow-up of CKD cases }\end{array}$ & $\begin{array}{l}\text { EMR experts, health care } \\
\text { systems }\end{array}$ & $\begin{array}{l}\text { Workshop to assess feasibility } \\
\text { Position statement }\end{array}$ \\
\hline
\end{tabular}


Table 1Action Plan: Strengthen CKD surveillance 


\section{Tackle major risk factors}

Since measures of kidney function (serum creatinine/eGFR or albuminuria) are rarely included in population-based health surveys or assessments of NCD burden (see CKD surveillance section), there is limited capacity to evaluate the importance of risk factors, identify contributors to CKD hotspots (e.g., CKDu), and evaluate the impact of interventions on CKD burden. Therefore, work to enhance CKD surveillance systems will facilitate discovery of novel risk factors as well as assisting efforts to control known risk factors. For example, the inclusion of CKD measures in all large communicable and NCD surveys (including eGFR and albuminuria) can be used to identify regional variation in CKD prevalence, particularly CKDu. ${ }^{163,164}$ This will permit a true assessment of CKD prevalence in all regions of the world, allow tracking of secular changes in incidence and prevalence, identify hotspots, and facilitate between-country comparisons.

Once CKDu hotspots are identified, global expertise supplemented by scientists and practitioners familiar with the local settings should be convened. Activities should be strengthened to develop protocols with consistent definitions of cases and exposures which can be implemented in all regions where CKDu are suspected (see Table 2). Comparative studies of patients with CKDu from different areas are needed to identify similarities and differences that may help to determine the cause(s). Engagement with policy makers and stakeholders at multiple levels and a concerted multi-sectoral approach will be required to successfully tackle CKDu.

Better CKD surveillance systems (especially if coupled with surveys of other health information) will also identify regions where CKD due to traditional risk factors is especially common. Prevalence of CKD tracks in parallel with diabetes and hypertension. Moreover, obesity is a common antecedent of hypertension and diabetes and thus also linked to CKD. The prevention of obesity, diabetes, and hypertension, requires activities primarily outside the influence and responsibility of those caring for patients with kidney disease, and will probably have a significant impact on CKD prevalence. However, the impact of such prevention programs on CKD onset and CKD complications, including renal failure and CV complications, has not been quantified and deserves to be tested in population-based studies. In addition, barriers and facilitators for effective prevention programs for diabetes, hypertension, and obesity across populations in different parts of the world need to be identified. This could be coupled with efforts at case-finding for CKD among people with established indications for eGFR and albuminuria testing, such as those with diabetes, hypertension, or CVD (see Table 2).

Other risk factors besides diabetes and hypertension also warrant consideration (see Table 2). Since long-term medication use is a key risk factor for CKD, it seems likely that electronic prompting and prescription tracking can be used to reduce medication errors, reduce medication overuse and nephrotoxicity, in HIC 
especially. There is increasing interest in 'de-prescribing' medications, especially in the elderly due to high incidence of side effects and questionable effectiveness. ${ }^{165-168}$

Efforts to enhance this electronic infrastructure should be combined with education of the public and health practitioners about correct prescribing methods of potentially nephrotoxic medications and the need for surveillance. In addition, the examination of alternatives to known and emerging nephrotoxins (including traditional remedies), and surveillance for CKD among those exposed to such nephrotoxins should both be priorities, especially in LMIC.

Activities to reduce the risk of kidney stones (e.g., ensuring adequate intake of clean water, healthy diet, and work conditions that avoid dehydration) and appropriate follow-up of people with prior stones to evaluate for CKD should be considered, and may prevent long-term complications such as kidney failure. Similar initiatives aimed at prevention, timely identification, and appropriate management are potentially important for other conditions, such as infections which are linked to AKI or CKD or both, (e.g., rotavirus, pneumococcus, influenza, HBV, HCV, HIV, TB).

Also worthy of consideration are activities to support optimal maternal and foetal health (see Table 2). Improved understanding of the link between variations in birth weight, gestational age, exposure to gestational diabetes or pre-eclampsia, and the development of perinatal AKI and CKD during child- and adulthood will be valuable. Developmental programming of risk of CKD results from many factors which impact a woman and baby's health and nutrition throughout pregnancy, as well as early childhood growth and nutrition. Research is required to better understand the pathophysiology of renal risk related to developmental programming, how to rescue kidney development, how premature babies should be optimally treated and nourished, how to screen for, diagnose, and effectively treat pre-eclampsia, and potential modification of the long-term risk through healthy lifestyle or early interventions. Interventional studies targeted at addressing some of these variables are needed.

In the first instance, documentation of birth weight, gestation age at birth, exposure to gestational diabetes, or pre-eclampsia, and any neonatal AKI could be documented and this information maintained in health records. This information will be valuable in understanding the impact of foetal and maternal health on outcomes. While this should be manageable in HIC, LMIC will struggle with this: nonetheless, some form of tracking should be encouraged in LMIC as well. Strategies to improve maternal and foetal health through reduction of risk factors (including smoking, obesity, diabetes, alcohol, infections) and improvement of socioeconomic factors (including access to family planning, equity and education for women, reduction of poverty, and adequate nutrition) should be promoted. 


\section{Control AKI: a special risk factor for CKD}

Progress will require efforts to target patients with CKD who are at risk for AKI for preventive activities, identify such episodes when they occur; and increase the quality of follow-up care after AKI occurs (see Table 2).Regardless of whether the relationship is causal, patients with CKD are at high risk of developing AKI, which may in turn lead to a progressive decline in kidney function. In LMIC where access to nephrology care is scarce, hospitalization with an AKI episode may represent the only opportunity to detect and treat pre-existing or de novo CKD.

Greater recognition of CKD as a risk factor for $\mathrm{AKI}$ and selective assessment of kidney function prior to high-risk exposures (e.g., cardiac catheterization) is achievable through education, quality improvement processes, and leveraging existing tools such as EMRs. The ability to identify and flag such patients allows an opportunity for intervention (prophylactic hydration, reduction in contrast load, staged procedures) and also creates the opportunity for follow-up and specialist referral if required. Research collaborations using large population-based datasets (including participants from LMIC) may allow a more precise understanding of the exact contribution of CKD to global AKI risk and the attributable risk of $\mathrm{AKI}$ to $\mathrm{CKD}$ progression.

Educational tools for the public, CKD patients, and families may help to avoid high-risk exposures that can result in AKI (as proposed for the 0by25 initiative for AKI). ${ }^{169}$ The requisite tools and methods of dissemination will vary by location. Education for providers is also important. CKD patients worldwide are predominantly managed by primary care providers and only a small minority are under nephrology care, particularly in LMIC. Routine follow-up of CKD patients is often guided by the presence of comorbidities (e.g., diabetes, heart failure, hypertension), and testing for albuminuria and reduced eGFR may be infrequent. It is thus imperative that CKD patients be considered at risk for AKI and that providers be educated about the need for follow-up testing with measures of albuminuria and eGFR following potentially nephrotoxic insults (e.g., addition of ACEi/ARB, diuretics) in such patients. Urinalysis for proteinuria and urine microscopy with evaluation for eosinophils and casts are inexpensive methods for diagnosing AKI even in resource-poor settings. ${ }^{170,171}$

Patients should be guided to report symptoms (e.g., diarrhoea, vomiting) that might facilitate earlier recognition of AKI. ${ }^{37}$ Toolkits based on the 5R approach (risk, recognition, response, renal support, and rehabilitation) for AKI management can be customized for this purpose and be utilized to disseminate information, improve knowledge, and facilitate changes in health policy that may limit specific investigations. For instance, outpatient cardiac catheterizations and contrast CT scans are commonplace occurrences in HIC, and are frequently done in patients with or at risk for CKD. However, post-contrast testing for serum creatinine is rarely done as home visits for lab tests are generally not covered by payers. It is likely that AKI episodes are undetected in these settings and may result in CKD progression. In LMIC or remote areas in $\mathrm{HIC}$, telemedicine for 
guided management of AKI and CKD may be useful. In LMIC, patients, community workers, and pharmacists should be educated about CKD and its risk factors, as often medications are dispensed without adequate patient instruction and self-medicating is prevalent.

Even with optimal efforts at education and prevention, the incidence of $A K I$ is likely to further increase, and parallel efforts are needed to improve the quality of follow-up care. Evidence-based international guidelines for AKI management ${ }^{10}$ recommend longitudinal patient follow-up after hospitalization, targeted at providing appropriate care for patients with, or at high risk of, long-term sequelae of CKD. In settings where access to medical care is limited, the detection of AKI may represent the sole opportunity to identify and treat CKD. Several centres in Canada and the USA have established AKI survivor clinics. ${ }^{172}$ However, resources are required to establish and sustain these clinics, and no AKI-specific post-discharge interventions have been proven to improve outcomes. It is neither practical nor feasible for nephrologists to provide care for all patients with CKD who develop AKI and thus a targeted approach is needed. This further highlights the importance of education and capacity building for AKI care among primary care practitioners.

\section{Identify genetic causes of CKD}

Activities for reducing the burden of genetic causes of CKD should work toward five goals (see Table 2). First, to increase awareness about the value of genetics for understanding and treating CKD; second, to Increase the diversity of genotyped populations beyond those of European ancestry; third, to increase accessibility of genetic data to a broader range of scientists; fourth, to generate new tools for functional genomics; and fifth, to promote better understanding of gene by environment interactions that are relevant to causes and consequences of CKD.

To ensure that adequate resources and public support are available for these goals, efforts are needed to educate patients and families about the value of clinical genomics and genetic research. Education for clinicians and researchers should discuss challenges (e.g., ethical aspects, limitations in variant interpretation), as well as realistic timelines for mechanistic understanding and translation.

Professional organisations including the ISN, patient advocacy organisations, scientific journals, media, the pharmaceutical industry, medical schools, and teaching hospitals should develop and disseminate relevant educational materials. Topics should include the discussion of challenges of genetic research (e.g., privacy; how to report incidental findings) ${ }^{173,174}$ as well as opportunities (e.g., discovery of novel pathophysiological mechanisms; development of new therapies). Educational activities should include the communication of realistic timelines for the translation of genetic findings ${ }^{135}$ (web appendix Figure 4), and should include learners in LMIC as well as HIC. ${ }^{175}$ 
Findings from large-scale sequencing projects of CKD patients and healthy individuals can be relevant to patients and clinicians. ${ }^{176-180}$ The data provide adjusted estimates of the prevalence and penetrance of presumably pathogenic variants and give insights into the phenotypic presentation spectrum for variants in a given gene necessary for counselling and more precise risk prediction. Knowledge of current estimates of mutation prevalence and penetrance has important implications for which variants to pursue experimentally, timing and scope of genetic testing, pharmacogenomics decisions, and for patient counselling. ${ }^{134}$

The identification of $A P O L 1$ as a major kidney disease susceptibility gene in individuals of African ancestry ${ }^{133,181}$ illustrates that important ancestry-specific findings exist. Some indigenous populations, often found in LMIC, show high rates of CKD. Genetic research in these populations may therefore be particularly informative about additional susceptibility genes and/or important gene environment interactions (Goal 5), in addition to a better understanding of allelic diversity which can reduce the risk of falsely attributing pathogenicity to ancestry-specific variants. ${ }^{134}$ Genetic investigations in CKD high-risk populations can also address the question whether kidney function variants identified in the general population ${ }^{182-185}$ translate to the setting of endemic or advanced CKD.

To increase the application of clinical genomics to such higher risk populations (including indigenous populations, rare disease groups, ethnic minorities, and small communities) specific work will be needed. For example, existing study protocols and policies need to be reviewed to ensure the protection of indigenous populations, rare disease groups, ethnic minorities, small communities, as well as family/heritage beliefs, and to allow for culturally sensitive genetic research. The value of and challenges related to genotyping ethnically diverse populations should also include education of patients, populations, and other stakeholders. The development and implementation of culturally sensitive methods by which to engage communities worldwide is imperative if new knowledge is to be comprehensive.

Working with genotyping companies and computational scientists to provide affordable and comprehensive genotyping for worldwide populations as well as improved imputation reference panels for non-European ancestry populations is likely to considerably broaden the knowledge base.

As outlined in the FAIR ("findability, accessibility, interoperability, reusability") guidelines, ${ }^{186}$ individual and aggregate datasets should be available with limited access barriers in a useful, standardized format. The accessibility and utility of existing and future datasets could be increased by promoting standardized formats, common data elements/standard, and broad data sharing - especially if complemented by efforts to catalogue and aggregate existing data repositories, biospecimens, and to link biomarkers to genetic data to determine causality 
(Mendelian Randomization) using publicly available summary statistics databases.

There are tremendous potential benefits from developing common data elements relevant to kidney research. Comparable measurements and definitions maximize the potential for interoperability and full usage of existing datasets as well as for their combination. Important partners in this process are biomedical journals, international research collaborations (e.g., CKDGen Consortium, CKD$\mathrm{PC}$, ISN-iNet CKD) for the definitions of common renal phenotypes, and data scientists who develop and maintain resources for the establishment of data sharing formats (e.g., the NHGRI GWAS Catalogue). ${ }^{187}$ Government funders and/or the pharmaceutical industry should support data sharing infrastructure such as platforms generated as part of the BD2K Project ${ }^{188}$ or the AMP Project for type 2 diabetes. ${ }^{189}$ Although many of these resources already exist in HIC, making them more broadly available will also benefit scientists working in LMIC, where primary data generation can be challenging.

To capitalize on this increased quantity of genetic data and materials, new tools for functional genomics will be needed. The purpose of these tools is to enable the translation of loci uncovered through genetic screens including GWAS and sequencing studies ${ }^{135}$ (web appendix Figure 4). Functional genomics tools are used to determine causal genes and variants and to illuminate their mechanisms of action. Although challenging, this is necessary to focus on translation of the most promising findings. ${ }^{190,191}$ An example is the original discovery of the APOL1 gene region, where the signal was initially attributed to a neighbouring gene, MYH9. ${ }^{192}$

Recent technologies such as epigenetics, ${ }^{193}$ metagenomics, metabolomics, ${ }^{194,195}$ and proteomics will generate additional information to enable the interpretation of genetic data. The resource generated by the Genotype-Tissue Expression (GTEx) Project ${ }^{196}$ is presently limited by lack of kidney cell types. Development of libraries of kidney cell types with epigenetic maps as well as robust cellular assays in disease- and cell-type relevant models will both be necessary to realize the potential of the current discoveries in kidney disease genetics. While the short-term deliverables for this goal will include the tracking of published datasets and accessible tools, the ultimate goal is to gain insights into biologic pathways and novel biomarkers to enable prevention and drug development. In support, drug targets with underlying human genetic support are twice as likely to be ultimately approved compared to drug targets without underlying human support. ${ }^{197}$

Additional efforts will be needed to better understand how environmental factors interact with genetic variants to modify the risk of CKD. Examples of such interactions include IgA nephropathy risk and the intestinal immune response to helminthic infections that correspond to higher prevalence of IgA nephropathy in East Asia ${ }^{198}$ (web appendix Figure 5) and APOL 1-associated kidney disease and 
trypanosomiasis that correspond to higher rates of ESRD in individuals of African ancestry. ${ }^{133,199}$

An improved understanding of gene environment interactions is necessary for understanding how certain forms of CKD originate from a combination of genetic and environmental risk factors. Interactors of CKD risk variants could be diabetes and hypertension, ${ }^{200,201}$ the main causes of CKD in many regions of the world, or other yet unknown environmental factors reported in CKD hotspots (CKDu), mostly in LMIC. ${ }^{202,203}$ However, unravelling the effects of genes and environment can be challenging when their interaction is required to cause disease and/or the genetic effect or interaction is not large.

The existence of multiple hotspots (Mesoamerica, Sri Lanka, India, Malaysia) allows the possibility of determining if there is a genetic underpinning to CKDu in a given population. Prerequisites for success include the availability of inexpensive and ethnicity-specific high-throughput genotyping arrays (see Goal 2), the ability to identify individuals exposed to certain environmental factors (perhaps using existing data from populations surveys and/or EMRs, and ideally pre-existing standardized data collection tools (see Goal 3). ${ }^{163}$ Improved phenotyping can increase the power of detecting gene environment interactions and allows for the conduct of genetic studies in more homogeneous subgroups (i.e., those exposed to a certain environmental factor), which should enhance the ability to identify CKD risk genes. ${ }^{204}$ These activities can be tracked by monitoring the published literature and presentations at major scientific meetings. 


\begin{tabular}{|c|c|c|c|}
\hline Goals & Activities & Partners & Possible Deliverables \\
\hline \multirow[b]{2}{*}{$\begin{array}{l}\text { Identify yet } \\
\text { unknown risk } \\
\text { factors for CKD in } \\
\text { the population }\end{array}$} & $\begin{array}{l}\text { Promote inclusion of measuring } \\
\text { CKD in all large communicable } \\
\text { and non-communicable disease } \\
\text { surveys }\end{array}$ & & $\begin{array}{l}\text { Inventory of studies including and not including CKD } \\
\text { (and CKD awareness) } \\
\text { Task force to identify key contacts and include CKD } \\
\text { and CKD awareness reporting }\end{array}$ \\
\hline & $\begin{array}{l}\text { Establish and implement } \\
\text { comprehensive research } \\
\text { strategies to identify the causes of } \\
\text { endemic CKDu hotspots using a } \\
\text { life-cycle approach }\end{array}$ & ISN, WHO, governments & $\begin{array}{l}\text { Position statements and research reports including: } \\
\text { case definitions, research agendas, standardization } \\
\text { of data collection tools } \\
\text { Consistent framework for surveillance and } \\
\text { investigation for epidemics of CKD around the world } \\
\text { with reduction in time from identification to solving of } \\
\text { problem, through this consistent approach }\end{array}$ \\
\hline $\begin{array}{l}\text { Mitigate known risk } \\
\text { factors for CKD - } \\
\text { Diabetes }\end{array}$ & $\begin{array}{l}\text { Promote healthy lifestyles and } \\
\text { food composition, prevention } \\
\text { programs; implement surveillance, } \\
\text { screening and treatment according } \\
\text { to local/regional needs/guidelines }\end{array}$ & $\begin{array}{l}\text { Governments, payers, } \\
\text { regulatory authorities, health } \\
\text { care organisations, patients, } \\
\text { community, professional } \\
\text { groups, global, regional, and } \\
\text { national societies, public health } \\
\text { practitioners }\end{array}$ & $\begin{array}{l}\text { Appropriate references to the respective } \\
\text { recommendations in publications, educational, and } \\
\text { advocacy activities of Nephrology Organisations } \\
\text { Reduction in \% of patients with ESRD and diabetes }\end{array}$ \\
\hline \multirow[t]{2}{*}{$\begin{array}{l}\text { Mitigate known risk } \\
\text { factors for CKD - } \\
\text { Hypertension }\end{array}$} & $\begin{array}{l}\text { Promote healthy lifestyles and } \\
\text { prevention programs; implement } \\
\text { surveillance, screening and } \\
\text { treatment according to } \\
\text { local/regional needs/guidelines }\end{array}$ & $\begin{array}{l}\text { Governments, payers, health } \\
\text { care organisations, regulatory } \\
\text { authorities, patients, } \\
\text { community, professional } \\
\text { groups, global, regional, and } \\
\text { national societies } \\
\text { (hypertension, CV), public } \\
\text { health practitioners }\end{array}$ & $\begin{array}{l}\text { Appropriate references to the respective } \\
\text { recommendations in publications, educational, and } \\
\text { advocacy activities of Nephrology Organisations } \\
\text { Improved BP control in populations at risk }\end{array}$ \\
\hline & $\begin{array}{l}\text { Assess for the presence of CKD in } \\
\text { individuals with hypertension }\end{array}$ & $\begin{array}{l}\text { Governments, payers, } \\
\text { regulatory authorities, health } \\
\text { care organisations, patients, }\end{array}$ & Implementation survey \\
\hline
\end{tabular}




\begin{tabular}{|c|c|c|c|}
\hline Goals & Activities & Partners & Possible Deliverables \\
\hline & & $\begin{array}{l}\text { community, professional } \\
\text { groups, global, regional, and } \\
\text { national societies, public health } \\
\text { practitioners }\end{array}$ & \\
\hline \multirow[b]{2}{*}{$\begin{array}{l}\text { Mitigate known risk } \\
\text { factors for CKD - } \\
\text { Prescribed } \\
\text { medications }\end{array}$} & $\begin{array}{l}\text { Enhance the identification of long- } \\
\text { term medication use as a risk } \\
\text { factor for CKD }\end{array}$ & $\begin{array}{l}\text { Funding agencies, industry } \\
\text { partners, research networks }\end{array}$ & $\begin{array}{l}\text { Research reports } \\
\text { Reduction in \% of patients with ESRD attributable to } \\
\text { medication overuse/misuse }\end{array}$ \\
\hline & $\begin{array}{l}\text { Educate public and health } \\
\text { practitioners about correct } \\
\text { prescribing methods of potentially } \\
\text { nephrotoxic medications, and } \\
\text { need for surveillance }\end{array}$ & $\begin{array}{l}\text { Non-government organisations } \\
\text { (NGOs), governments, } \\
\text { practitioners, pharmacists, } \\
\text { continuing medical education } \\
\text { (CME) organisations, } \\
\text { communities, health insurance } \\
\text { organisations }\end{array}$ & Inclusion in CME Programs \\
\hline \multirow{4}{*}{$\begin{array}{l}\text { Mitigate known risk } \\
\text { factors for CKD - } \\
\text { Traditional and } \\
\text { alternative } \\
\text { remedies }\end{array}$} & $\begin{array}{l}\text { Determine which (if any) } \\
\text { traditional, alternative, and herbal } \\
\text { remedies are risk factors for CKD }\end{array}$ & & Research reports \\
\hline & $\begin{array}{l}\text { Establish health promotion and } \\
\text { public education program on the } \\
\text { risk of the use of traditional and } \\
\text { complementary medicine }\end{array}$ & $\begin{array}{l}\text { NGOs, governments, } \\
\text { traditional healers, alternative } \\
\text { practitioners, media, } \\
\text { communities, public health } \\
\text { practitioners }\end{array}$ & Inclusion in CME Programs \\
\hline & $\begin{array}{l}\text { Require regulation of alternative } \\
\text { medicine manufacture, labelling, } \\
\text { marketing }\end{array}$ & $\begin{array}{l}\text { Ministries of Health }(\mathrm{MOH}) \\
\text { industry partners, alternative } \\
\text { remedy manufacturers }\end{array}$ & $\begin{array}{l}\text { Task force to establish a concrete strategy with } \\
\text { tailored approaches }\end{array}$ \\
\hline & $\begin{array}{l}\text { Assess for the presence of CKD in } \\
\text { individuals with significant } \\
\text { exposure to risky remedies }\end{array}$ & $\begin{array}{l}\text { Governments, NGOs, } \\
\text { practitioners, traditional } \\
\text { healers, communities, global, } \\
\text { regional, and national } \\
\text { societies, researchers }\end{array}$ & \\
\hline $\begin{array}{l}\text { Mitigate known risk } \\
\text { factors for CKD - } \\
\text { Kidney stones }\end{array}$ & $\begin{array}{l}\text { Promote access to adequate } \\
\text { amounts of clean water, healthy } \\
\text { diet (e.g., intakes of sodium and } \\
\text { dietary protein) and work }\end{array}$ & $\begin{array}{l}\text { Communities, governments, } \\
\text { professional associations } \\
\text { (Center for Disease Control } \\
\text { [CDC], American College of }\end{array}$ & \\
\hline
\end{tabular}




\begin{tabular}{|c|c|c|c|}
\hline Goals & Activities & Partners & Possible Deliverables \\
\hline & conditions that avoid dehydration & $\begin{array}{l}\text { Physicians, [ACP], Caring for } \\
\text { Australians with Renal } \\
\text { Impairment [CARI], Urology } \\
\text { associations), health care } \\
\text { organisations, water } \\
\text { companies, public health } \\
\text { practitioners }\end{array}$ & \\
\hline & $\begin{array}{l}\text { Assess for the presence of CKD in } \\
\text { individuals with prior stones }\end{array}$ & $\begin{array}{l}\text { Urologists, primary care } \\
\text { providers, nephrologists }\end{array}$ & $\begin{array}{l}\text { Survey existing guidelines on kidney stones for the } \\
\text { inclusion of this recommendation and work towards } \\
\text { inclusion in future updates }\end{array}$ \\
\hline \multirow{3}{*}{$\begin{array}{l}\text { Mitigate known risk } \\
\text { factors for CKD - } \\
\text { Infections }\end{array}$} & $\begin{array}{l}\text { Endorse population-level infection } \\
\text { prevention and control policies and } \\
\text { participate in educational activities }\end{array}$ & $\begin{array}{l}\text { Public health, Centres for } \\
\text { Disease Control, primary care } \\
\text { providers }\end{array}$ & \\
\hline & $\begin{array}{l}\text { Increase access to vaccinations } \\
\text { against infections which are linked } \\
\text { to AKI or CKD or both }\end{array}$ & $\begin{array}{l}\text { Public health, Centres for } \\
\text { Disease Control, primary care } \\
\text { providers }\end{array}$ & \\
\hline & $\begin{array}{l}\text { Conduct studies to evaluate the } \\
\text { impact of interventions that } \\
\text { increase access to treatment for } \\
\text { infections on the incidence and } \\
\text { prevalence of infection-related AKI } \\
\text { and CKD }\end{array}$ & $\begin{array}{l}\text { Centres for Disease Control } \\
\text { (regional and national) }\end{array}$ & Epidemiological studies demonstrating impact \\
\hline \multirow{2}{*}{$\begin{array}{l}\text { Mitigate known risk } \\
\text { factors for CKD - } \\
\text { Maternal and foetal } \\
\text { health }\end{array}$} & $\begin{array}{l}\text { Enhance the understanding of the } \\
\text { link between variations in birth } \\
\text { weight, gestational age, exposure } \\
\text { to gestational diabetes or pre- } \\
\text { eclampsia and the development of } \\
\text { CKD in the foetus during child- and } \\
\text { adulthood }\end{array}$ & $\begin{array}{l}\text { Obstetricians, paediatricians, } \\
\text { epidemiologists, public health } \\
\text { practitioners, researchers }\end{array}$ & $\begin{array}{l}\text { Research reports } \\
\text { Increase surveillance practices of high-risk births } \\
\text { and mothers in specific }\end{array}$ \\
\hline & $\begin{array}{l}\text { Document each child's birth } \\
\text { weight, gestation age at birth, } \\
\text { exposure to gestational diabetes, } \\
\text { or pre-eclampsia, as well as any } \\
\text { neonatal AKI and maintain this } \\
\text { information in their health record in }\end{array}$ & $\begin{array}{l}\mathrm{MOH}, \mathrm{WHO} \text {, traditional birth } \\
\text { attendants, community health } \\
\text { workers, health information } \\
\text { systems, paediatricians, } \\
\text { neonatologists, obstetricians, } \\
\text { patients (build upon MDG }\end{array}$ & $\begin{array}{l}\text { Survey existing documentation policy as part of an } \\
\text { extension of the GKHA project }\end{array}$ \\
\hline
\end{tabular}




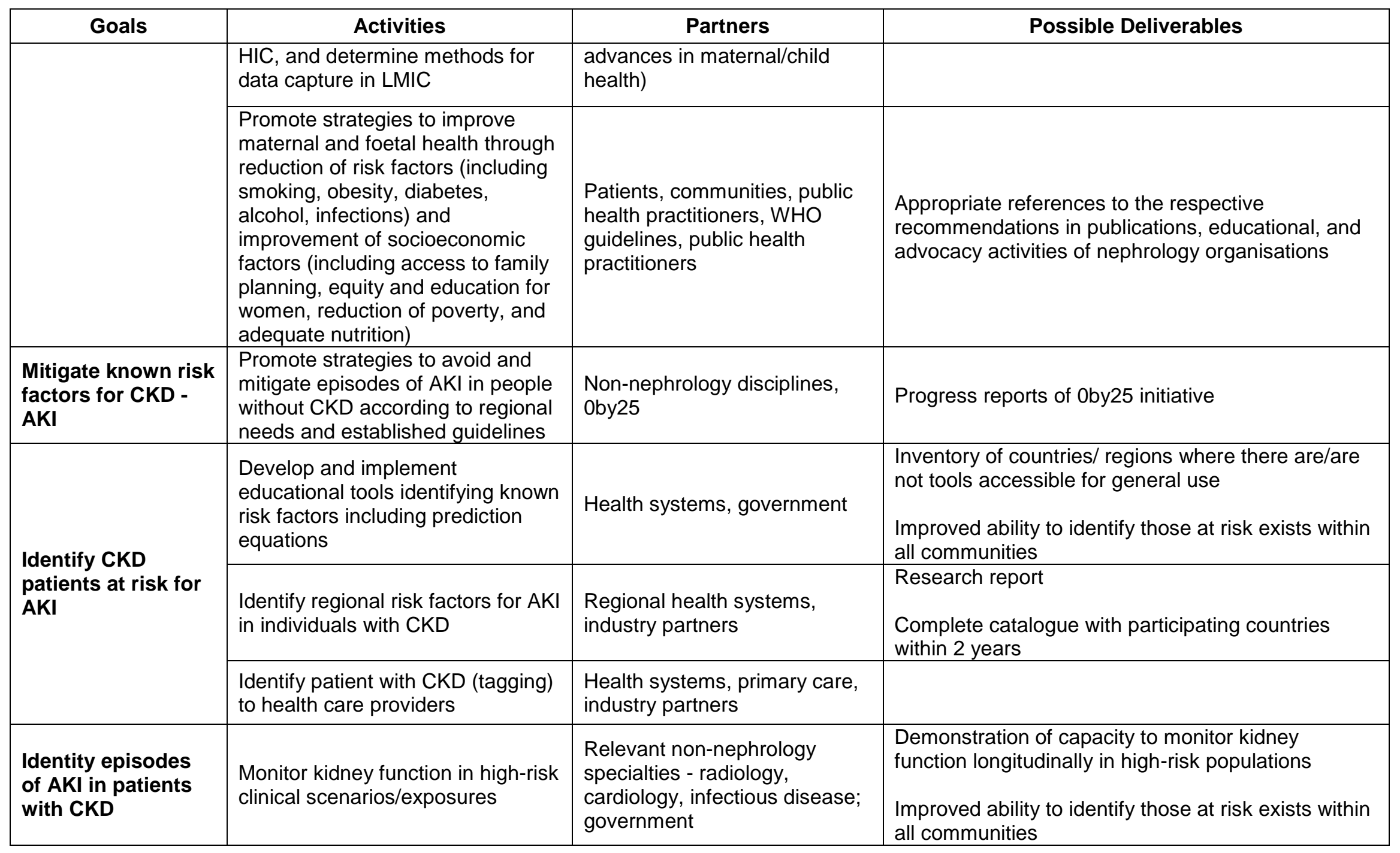




\begin{tabular}{|c|c|c|c|}
\hline Goals & Activities & Partners & Possible Deliverables \\
\hline & $\begin{array}{l}\text { Identify and assess methods to } \\
\text { better assess structural/ functional } \\
\text { aspects of the kidney in CKD and } \\
\text { post AKI }\end{array}$ & $\begin{array}{l}\text { Industry partners, research } \\
\text { funders }\end{array}$ & $\begin{array}{l}\text { Advocate to funding agencies } \\
\text { Improved access to diagnostic facilities in all regions } \\
\text { of the world }\end{array}$ \\
\hline & $\begin{array}{l}\text { Identify indications for biopsy in } \\
\text { cases where there is question } \\
\text { about AKI vs progressive CKD }\end{array}$ & Industry partners & $\begin{array}{l}\text { Consensus conference with published report } \\
\text { Increase access to diagnostic tools in all regions }\end{array}$ \\
\hline \multirow[b]{2}{*}{$\begin{array}{l}\text { Improve AKI/post } \\
\text { AKI care }\end{array}$} & $\begin{array}{l}\text { Promote and monitor kidney } \\
\text { function surveillance and CKD } \\
\text { care post AKI }\end{array}$ & $\begin{array}{l}\text { Governments, health systems, } \\
\text { primary care }\end{array}$ & $\begin{array}{l}\text { Identify capacity for AKI care as part of the GKHA } \\
\text { project }\end{array}$ \\
\hline & $\begin{array}{l}\text { Promote/ conduct trials of } \\
\text { appropriate interventions post AKI } \\
\text { to minimize risk of CKD } \\
\text { progression }\end{array}$ & & $\begin{array}{l}\text { Adding representation to trials groups } \\
\text { Improved evidence base for clinical decision } \\
\text { making; better outcomes of AKI }\end{array}$ \\
\hline $\begin{array}{l}\text { Increase } \\
\text { awareness about } \\
\text { the value and } \\
\text { importance of } \\
\text { genetics for } \\
\text { understanding and } \\
\text { treating CKD }\end{array}$ & $\begin{array}{l}\text { Educate clinicians and researchers } \\
\text { about the value and importance of } \\
\text { clinical genomics and genetic } \\
\text { research for CKD, including } \\
\text { challenges (e.g., ethical aspects, } \\
\text { limitations in variant interpretation), } \\
\text { opportunities, and realistic } \\
\text { timelines for mechanistic } \\
\text { understanding and translation }\end{array}$ & $\begin{array}{l}\text { Nephrology fellows, medical } \\
\text { schools, geneticists, } \\
\text { professional organisations, } \\
\text { patients advocacy } \\
\text { organisations groups, industry } \\
\text { partners, technology and } \\
\text { biotechnology companies, pair } \\
\text { with other organisations }\end{array}$ & $\begin{array}{l}\text { Inventory of existing training and educational } \\
\text { programs; double the number of programs in } 5 \\
\text { years } \\
\text { Offer training programs in nephrogenetics at } \\
\text { international nephrology meetings or as stand-alone } \\
\text { meetings } \\
\text { Increase in consent to participate in genetic } \\
\text { research }\end{array}$ \\
\hline
\end{tabular}




\begin{tabular}{|c|c|c|c|}
\hline Goals & Activities & Partners & Possible Deliverables \\
\hline & $\begin{array}{l}\text { Educate patients and the public } \\
\text { about the value of clinical } \\
\text { genomics and genetic research }\end{array}$ & $\begin{array}{l}\text { Geneticists, professional } \\
\text { organisations, patients } \\
\text { advocacy organisations } \\
\text { groups, journals, offprint } \\
\text { media, industry partners, pair } \\
\text { with other organisations }\end{array}$ & $\begin{array}{l}\text { Increased media coverage in the next } 2-5 \text { years } \\
\text { Increase in consent to participate in genetic } \\
\text { research }\end{array}$ \\
\hline & $\begin{array}{l}\text { Educate clinicians and researchers } \\
\text { about findings from large-scale } \\
\text { sequencing projects of nephrology } \\
\text { patients and asymptomatic } \\
\text { individuals that provide adjusted } \\
\text { estimates of prevalence and } \\
\text { penetrance of presumably } \\
\text { pathogenic variants necessary for } \\
\text { counselling and risk prediction }\end{array}$ & $\begin{array}{l}\text { Medical Schools, teaching } \\
\text { hospitals, nephrology divisions, } \\
\text { professional societies, patient } \\
\text { advocacy organisations } \\
\text { groups, industry partners, } \\
\text { nephrology journals }\end{array}$ & $\begin{array}{l}\text { Research reports and review articles in the next } 2 \\
\text { years, including discussion of potential implications } \\
\text { for counselling } \\
\text { Increase in consent to participate in genetic } \\
\text { research }\end{array}$ \\
\hline & $\begin{array}{l}\text { Educate clinicians about the } \\
\text { diverse clinical presentations of } \\
\text { genetic kidney disease and revise } \\
\text { genetic testing accordingly }\end{array}$ & $\begin{array}{l}\text { Medical Schools, teaching } \\
\text { hospitals, professional } \\
\text { societies, patient advocacy } \\
\text { organisations groups, industry } \\
\text { partners, journals, clinical } \\
\text { sequencing laboratories }\end{array}$ & $\begin{array}{l}\text { Research reports and reviews on spectrum of } \\
\text { clinical presentations for kidney disease genes } \\
\text { Published recommendations about which genes to } \\
\text { sequence for which presentation } \\
\text { Development of standard gene panels for different } \\
\text { nephrological diseases (tubular, FSGS, etc.) with } \\
\text { region-specific content }\end{array}$ \\
\hline \multirow[t]{2}{*}{$\begin{array}{l}\text { Increase diversity } \\
\text { of genotyped } \\
\text { populations } \\
\text { beyond European } \\
\text { ancestry }\end{array}$} & $\begin{array}{l}\text { Protect indigenous populations, } \\
\text { rare disease groups, ethnic } \\
\text { minorities, small communities, } \\
\text { family/heritage beliefs in order to } \\
\text { enable their inclusion in genetic } \\
\text { analysis and increase diversity of } \\
\text { genotyped populations }\end{array}$ & $\begin{array}{l}\text { Communities, governments, } \\
\text { regulatory authorities, } \\
\text { Institutional Review Boards }\end{array}$ & $\begin{array}{l}\text { Inventory of genotyped populations and their } \\
\text { diversity in CKD hotspots; review of existing } \\
\text { protocol/policy recommendations and publication of } \\
\text { recommendation where to focus genotyping efforts } \\
\text { in the next } 2 \text { years } \\
\text { Increase in consent to participate in genetic } \\
\text { research }\end{array}$ \\
\hline & $\begin{array}{l}\text { Improve SNP diversity on } \\
\text { commercially available chips; } \\
\text { improve imputation reference }\end{array}$ & $\begin{array}{l}\text { Genotyping companies } \\
\text { (Affymetrix, Illumina), } \\
\text { computational biologists (for }\end{array}$ & $\begin{array}{l}\text { Development of affordable genotyping for world- } \\
\text { wide populations; provision of improved genotype } \\
\text { imputation for non-European ancestry populations }\end{array}$ \\
\hline
\end{tabular}




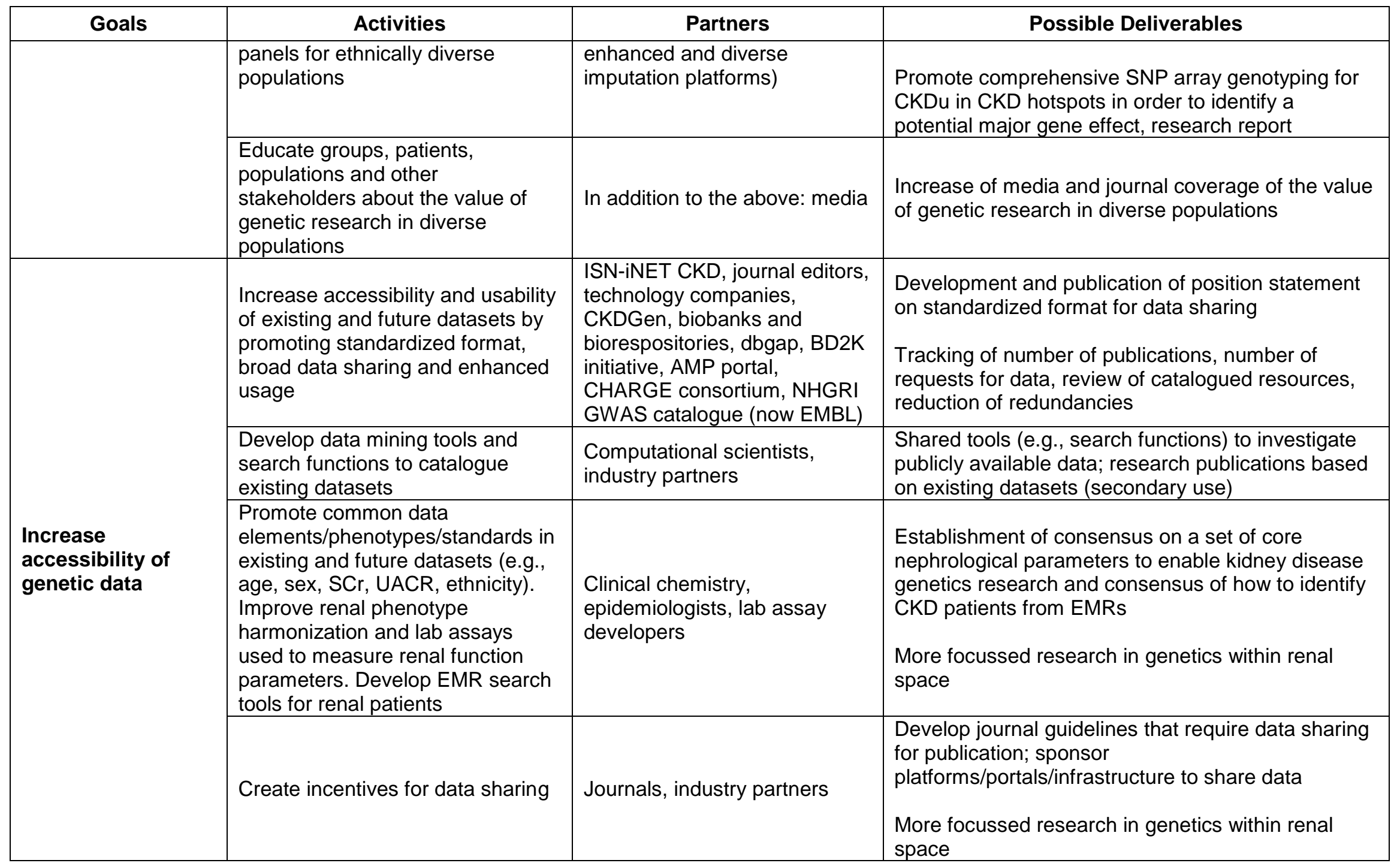




\begin{tabular}{|c|c|c|c|}
\hline Goals & Activities & Partners & Possible Deliverables \\
\hline & $\begin{array}{l}\text { Catalogue and aggregate existing } \\
\text { data repositories and biobanks / } \\
\text { biospecimens to enable more } \\
\text { rapid and accessible research }\end{array}$ & $\begin{array}{l}\text { Computational scientists, } \\
\text { industry partners }\end{array}$ & $\begin{array}{l}\text { Develop concept for centralized platforms / } \\
\text { portals/infrastructure to share data and identify } \\
\text { funding mechanisms } \\
\text { More focussed research in genetics within renal } \\
\text { space }\end{array}$ \\
\hline & $\begin{array}{l}\text { Link biomarkers to genetic data to } \\
\text { determine causality (Mendelian } \\
\text { Randomization) using publicly } \\
\text { available summary statistics } \\
\text { databases }\end{array}$ & Statisticians, industry partners & $\begin{array}{l}\text { Development of software that facilitates MR } \\
\text { analyses and make publicly available }\end{array}$ \\
\hline \multirow{2}{*}{$\begin{array}{l}\text { Generate tools for } \\
\text { functional } \\
\text { genomics }\end{array}$} & $\begin{array}{l}\text { Develop tools for functionalization } \\
\text { of genetic findings to identify the } \\
\text { causal gene/variant and genetic } \\
\text { mechanism of action to facilitate } \\
\text { translational research. Tools } \\
\text { should be shared broadly }\end{array}$ & $\begin{array}{l}\text { Geneticists, bioinformaticians } \\
\text { and computational biologists, } \\
\text { technology companies, } \\
\text { industry partners, funding } \\
\text { agencies }\end{array}$ & $\begin{array}{l}\text { Inventory of available tools, cell types, cell lines in } \\
\text { the next 2-5 years } \\
\text { Tracking of published papers with mechanism of } \\
\text { action of genetic findings and collection in a } \\
\text { centralized resource } \\
\text { Faster time from discovery to phase } 1,2 \text { trials in } \\
\text { nephrology with less failure of compounds }\end{array}$ \\
\hline & $\begin{array}{l}\text { Generate tools to study genetic } \\
\text { modifiers including epigenetic } \\
\text { effects to understand mutations in } \\
\text { their genomic context and identify } \\
\text { potential therapeutic targets }\end{array}$ & $\begin{array}{l}\text { Geneticists, bioinformaticians } \\
\text { and computational biologists, } \\
\text { technology companies, } \\
\text { industry partners, funding } \\
\text { agencies }\end{array}$ & $\begin{array}{l}\text { Creation of tools as documented in published } \\
\text { research reports of epigenetic catalogues of } \\
\text { different kidney cell types } \\
\text { Faster time from discovery to phase } 1,2 \text { trials in } \\
\text { nephrology with less failure of compounds }\end{array}$ \\
\hline
\end{tabular}




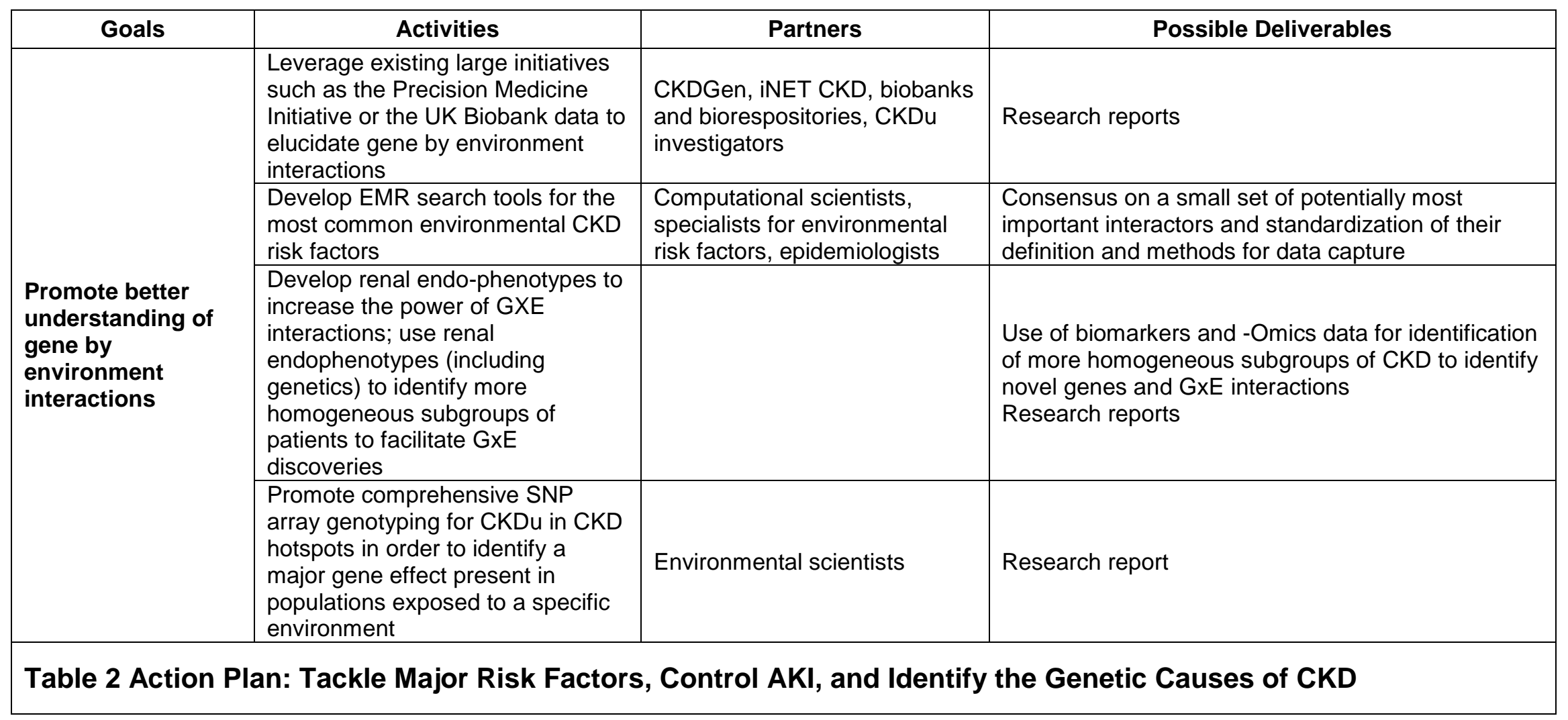




\section{Establish better diagnostic methods}

The current international guideline recommends attempts to establish a specific renal diagnosis (assess or attempt to assess aetiology) in addition to staging of CKD based on measuring or estimating GFR and measuring albuminuria. The KDIGO definition enables the diagnosis of CKD in the absence of knowledge about the aetiology in individual cases. ${ }^{10}$ While this has been an essential concept to determine the incidence and prevalence of CKD, to identify CKD cases, and to increase disease awareness, attempting to assess the aetiology is nevertheless another explicit KDIGO recommendation. Working towards global implementation of the diagnosis together with staging of CKD based on measuring or estimating GFR and measuring albuminuria is considered of high importance (see Table 3).

Even when concerted attempts are made to determine aetiology, the underlying cause of CKD is often not apparent. However, this is likely due in part to the frequent failure to obtain a kidney biopsy in patients with non-proteinuric CKD or with AKI; specific causes and potential opportunities for treatment may be uncovered by considering biopsy in a broader range of clinical presentations. Successfully increasing the use of kidney biopsy will require education (endorsing the need to obtain renal biopsy in a broader range of presentations, including CKD, AKI, and GN); capacity building (increasing capacity to perform renal biopsies; establishing regional centres of excellence for renal biopsy interpretation globally); and enhancing efforts to compare biopsy findings across centres and settings (supporting implementation of standards for renal biopsy reporting).

Regional centres to perform renal biopsies should be established and sustained worldwide, with appropriate access to technical expertise and supplies. For optimal renal biopsy analysis and interpretation, there must be a network of regional centres performing these services. Key elements will include: technical expertise with hands-on training of histology technicians and sectioning and staining technologies, including additional special stains beyond haematoxylin and eosin (e.g., periodic acid Schiff and silver stains). Such sophisticated staining technology is key because multiple steps are needed to detect focal lesions. For example, immunofluorescence or immunohistochemistry staining is essential for diagnosis of specific GN. Specifically, to distinguish between different variations of kidney disease, staining for $\lg G$, $\lg A$, IgM, C3, C1q, kappa, and lambda should be performed. Specific technical protocols for allocation, processing, and staining are detailed in the ISN Histology Manual (available online). ${ }^{205}$

Renal pathology centres should also perform electron microscopy (EM) for optimal diagnostic sensitivity. Some specific conditions, such as IgA nephropathy and membranous nephropathy, can be adequately diagnosed from light and immunofluorescence//HC alone. However, allocating tissue for and performing 
EM is ideal, as patients are misdiagnosed about $15-20 \%$ of the time when EM is not performed. ${ }^{206}$

These biopsies should be reported by expert renal pathologists using standard nomenclature and formats. A lack of well-trained renal pathologists is a major obstacle to biopsy utilization in many LMIC, and ISN is working worldwide to enhance development of local renal pathology expertise. Current standards for biopsy reporting have been published by the Renal Pathology Society (RPS) and by a joint working group of renal pathologists and nephrologists from the Mayo Clinic. 207

Although even traditional pathological evaluation of biopsy tissue would be extremely useful if more broadly available, the potential for impact would be magnified if attempts to increase use of kidney biopsies were coupled with broader availability of techniques for molecular diagnosis of renal biopsies, as well as with capacity to link existing and novel renal biopsy registries with clinical data. To ensure impact of such registries, standard values like minimum needed data and clinical follow-up variables need to be defined, as well as additional parameters for specific subcategories of diseases. After diagnosis, remaining tissue should be stored for potential future studies to explore aetiology and pathogenesis of disease. Unfortunately, lack of funding is a major obstacle to the establishment of such central registries.

Although enhanced use of kidney biopsies will be extremely important, it will not be sufficient on its own. Accurately defining potential treatment options for a given CKD patient relies on blood and urine-based laboratory assays and ready access to renal imaging. Identification, validation, and implementation of diagnostic biomarkers for CKD is discussed in the next section. Ultrasoundguided visualization of the kidney and the lower urinary tract is safe, requires minimal training, and can be performed with low-cost equipment -- but is rarely available in LMIC. Therefore, working towards global availability of diagnostic ultrasound imaging should be a priority, as well as developing better non-invasive imaging tools of renal structure and function.

Imaging and tissue diagnosis are the mainstays of current clinical diagnosis for CKD patients; based on developments in other fields, it appears likely that bloodand urine-based biomarkers will play an increasingly important role in future. This will require sustained and enhanced efforts to identify and validate biomarkers that indicate aetiology, dominant pathophysiological mechanisms, and/or therapeutic responsiveness. To avoid knowledge silos and maximize statistical power, it appears worthwhile to facilitate translational research networks that support sustainable and integrated biobanking and biomarker research including the use of common protocols and practices. A key early activity would be to develop best practice rules for research network governance including internal network policies, biosample usage policies, and policies on sample sharing within and between networks. 
As the field moves toward more complete assessment of CKD based on imaging, tissue and fluid-based biomarkers, it will be important to incorporate assessments of functional status into diagnostic processes. Tools for evaluating renal functional domains and pathological mechanisms are already available, and could be refined to target more specific parameters (function of different tubular segments, presence of inflammation or fibrosis, renal endothelial function). Assessment of renal function reserve could be considered as an adjunct, but would require a careful assessment of its diagnostic and prognostic utility.

Work in this area should aim to improve capacity for prognostication in people with CKD, including progressive loss of kidney function over time and CV events (see Table 3). The initial focus should be on optimally using existing tools: guidelines already recommend to measure albuminuria periodically over time in people with CKD. ${ }^{208}$ This recommendation is inconsistently followed even in HIC, which compromises our understanding of CKD progression for individuals and populations.

Although much is already known about how to use temporal trends in albuminuria and eGFR for prognostication, more needs to be learned about how such changes should influence clinical action. Key research questions include: 1) What changes in albuminuria and eGFR over time are clinically meaningful, and how should they affect clinical management? 2) Should higher levels of GFR (i.e., GFR $>60 \mathrm{~mL} / \mathrm{min} / 1.73 \mathrm{~m}^{2}$ ) without albuminuria be included in the CKD definition, given that CKD prevalence, sex ratios, and KDIGO composite risk groupings varied widely depending on the eGFR equation used? ${ }^{209}$ Once these studies are complete, they should be rapidly incorporated into international practice guidelines and their results disseminated to end-users.

The ability to better predict CVD in CKD patients would permit evaluation of targeted therapies in clinical trials and risk stratification in clinical practice. Given the different CVD phenotypes observed with increasing severity of CKD, risk prediction instruments should be evaluated for their ability to discriminate between events mediated by traditional atherosclerotic processes vs. those mediated by CKD-specific processes. Therefore, there is obvious potential for developing a risk prediction tool that integrates CKD markers with traditional CVD risk factors, but the benefit of this approach would need to be demonstrated. ${ }^{210}$

The renal community should take advantage of existing large observational cohort studies with stored biomarkers and long-term follow-up to study and validate established and novel biomarkers. Testing of novel web-based CV risk scores involving the renal risk markers albuminuria and eGFR can be accomplished with existing databases and collaborations (e.g., EUTox), ${ }^{211}$ industry partners, and various CKD biomarkers consortia. It will be important to achieve agreement on strategy by which to investigate and validate the potential 
complex and diverse expression of CVD in CKD. Given that CV risk profiles, CKD populations, and health systems vary worldwide, special consideration should be given to whether recommendations should differ by setting (e.g., LMIC vs $\mathrm{HIC}$ ). ${ }^{212}$ After validation/calibration, and once incremental clinical utility has been shown, it will also be important to promote the implementation of these prognostic models in practice.

Although additional benefit can be derived from better use of existing parameters such as eGFR and albuminuria, new prognostic biomarkers in CKD are needed. Creating formal collaborations between existing research consortia will sustain efforts to identify and rigorously evaluate such biomarkers. Given the clinical heterogeneity of most unselected CKD populations, progress may be most likely in well-characterized cohorts of people with specific kidney diseases. Real-world assessments of the performance of new biomarkers should be performed to determine whether or not they improve clinical care at reasonable cost before recommending their uptake into practice. ${ }^{213} \mathrm{As}$ for genetic epidemiology cohorts, this will require specific efforts to standardize outcomes, identify sharing protocols, protect the privacy of subjects, and enhance relationships with regulatory authorities and industry partners (see genetics sections). An international meeting of key stakeholders worldwide should be arranged in 20182019 to advance the biomarker research agenda.

Important, and often forgotten, is the determination of how these novel biomarkers modify with disease progression or with therapy, and whether such changes predict clinical outcomes including CKD progression. High-throughput screening techniques (i.e., transcriptomics- proteomics- metabolomics) in conjunction with well phenotyped clinical cohorts offer an opportunity to achieve this objective ${ }^{214}$ (see genetics sections). There is an initial success story of the omic marker identification and replication in global cohorts, ${ }^{215}$ and thus we are encouraged that this technique has promise.

To increase the likelihood of success, it will be important to enhance the training of young researchers on all aspects of biomarker research, from discovery to clinical implementation.

\section{Ensure more consistent implementation of effective treatments}

Better use of available treatments will require a combination of education in parallel with improving access for underserved populations, especially in LMIC. Clinical practice guidelines and associated tools are important potential mechanism for achieving these goals (see Table 3).

Worldwide, most people with access to care for early CKD receive such care in primary and general health settings. Non-nephrologists therefore have access to the vast majority of people at risk and the greatest opportunity to intervene in the course of CKD progression. A toolkit that provides simple targeted advice regarding medications and goals of care to slow common causes of CKD 
progression targeted at non-nephrology health providers could reduce the global burden of CKD. To promote uptake and utility, the recommended approaches should be generalizable to different work forces and health settings.

Historically, much of the effort to reduce the burden of CKD has focussed on discovering new therapies and improving treatment modalities. The yield from this investment will be maximised by a similar investment in ensuring the effective dissemination of established therapies to all those who will potentially benefit.

Several treatments have been well established in large randomised trials and endorsed by guideline bodies but are underused in CKD populations in LMIC, constituting a major treatment gap. These include medications for controlling BP and blood sugar as well as interrupting the renin-angiotensin system (to slow the progression of CKD) and statins (for preventing CV events in the CKD population). Insights from prior studies should be used to inform the design of interventions to reduce the treatment gap. Affordable versions of these medications should be available in all health settings but particularly in low and middle income settings. The renal community should advocate for the widespread uptake of the WHO Model List of Essential Medications ${ }^{216}$, which will also help to achieve this objective.

Primary glomerular diseases are the third most common cause of ESRD, often affect young and working people, cause faster progression to ESRD, and may be associated with other systemic complications. Unlike most other causes of CKD, some primary glomerular diseases are potentially curable with relatively short periods of treatment, so identifying patients who may benefit from specific therapy is key. Therefore, like proven medications such as antihypertensives and statins, access to appropriate renal biopsy services is an essential tool for improving the management of people with glomerulonephritis and other common forms of CKD. Work is needed to establish best practices and indications for biopsy procedures and sample handling; enhance capacity for trained pathologists to interpret specimens; establish key accessible medications for treatment of common GN.

Centres of expertise could potentially service a relatively wide area and better access to kidney biopsy (see section on diagnostic methods) is critical. However, identification and characterization of disease is only valuable if treatments are accessible, so making low-cost immunosuppressive medications more widely available is also paramount. An inventory of current and potential capacity for diagnosis and treatment is an important short-term goal to define unmet need and inform health services planning.

In parallel with efforts to make these treatments and infrastructure available, work is needed to help practitioners optimally use them in practice. One option could be the expanded use of decision support tools where guideline-based advice is 
automatically generated from the entry of routine clinical data, for example in laboratory systems or EMRs. These tools are particularly useful in assisting the delivery of CKD care by non-specialists, and coupled with the toolkit would facilitate the identification of patients at risk, timing of interventions, and changes in medications. Decision support tools are often developed for multiple jurisdictions in parallel, reflecting possible duplication of effort. Although some adaptation for local settings may be appropriate, an inventory of available decision support tools is an achievable short-term goal that should increase efficiency and reduce costs. A longer-term goal is the development of tools to meet identified gaps, particularly for tools that are readily accessible in resourceconstrained settings.

The adoption of best practices will promote the delivery of high quality care and efficient resource use. Clinical practice guidelines are an important tool for achieving such practice, and guideline development should continue, aiming to cover the major CKD management issues. Guideline impact will be enhanced if guidelines are routinely adapted for different settings, especially LMIC. There is an increasing need to ensure that guidelines and treatment strategies are also tailored to LMIC, and that decision-makers understand the clinical and socioeconomic benefits of improving access to care.

Guideline development must be complemented by effective knowledge translation efforts aimed at end-users, including care providers, patients, and families. A better understanding of the factors driving effective implementation will lead to more effective dissemination of established therapies. Benefits will include an expansion of the number of people receiving current established therapies, reduction in the time to uptake of beneficial new therapies, and potentially increased efficiencies for health service providers. Implementation science capacity should be actively developed that is nephrology-specific. Achievable short-term targets for building nephrology-specific capacity in implementation science include formal curricula and the creation of training positions, perhaps within nephrology residency programs.

The introduction or dissemination of any therapy represents a potential opportunity to evaluate implementation methods and conduct comparative effectiveness studies. Such evaluations should preferably contain a randomised aspect.

\section{Better treatment of symptoms and other complications of CKD}

Key complications that should be targeted include CKD-related symptoms, certain haematological, hormonal, and metabolic abnormalities associated with CKD, and CV events (see Table 3). The clinical and epidemiologic characteristics associated with the presence, severity, onset, and remission of CKD-related symptoms are poorly described. How symptoms (individually and collectively) influence HRQOL and other patient-important outcomes such as employability and functional status has not been completely studied. In addition, the relative 
importance of each symptom to the total symptom burden is not well understood. This information is required to characterize the impact of symptoms on patient well-being (thus building the case for action), and to identify the symptoms and patient populations that should be the highest priority for immediate study.

Little is known about how to manage symptoms that are associated with CKD, and since their pathophysiology is poorly characterized, there is little prospect of identifying effective treatments. ${ }^{112}$ Management of these symptoms is a high priority for patients and therefore research that comprehensively addresses the existing knowledge gaps is needed.

Multidisciplinary research efforts should capitalize on new technologies such as metabolomics and proteomics to link uremic toxins with symptoms and to identify the pathophysiology that causes or exacerbates symptom burden. Consideration should be given to creating research teams that study potentially related symptoms together (e.g., pain and pruritus, which have similar neurobiology). Besides scientists from multiple appropriate disciplines, research teams should also include patients and representatives from industry partners to ensure maximum potential for clinical impact and facilitate commercialization.

Few if any drugs to treat uremic symptoms have been approved by regulatory authorities and there often is very little evidence to support the off-label treatments that are recommended. Summarizing what is known about available treatments and evaluating the best candidates in well-designed clinical trials should be a high priority: this could include treatments for similar symptoms associated with other conditions (e.g., chemotherapy-associated nausea) as well as treatments targeted at uremic-specific conditions (e.g., phototherapy for pruritus). As the work and activities needed to move the field forward are realized, these newer candidate treatments should be moved from phase 1 into later phase clinical trials.

Global practice guidelines advise on how the haematological, hormonal, and metabolic abnormalities associated with CKD may be monitored and managed. ${ }^{139,141,217}$ Although based on the best available evidence, many knowledge gaps remain. In addition, this guidance does not account for the practice conditions in $\mathrm{LMIC}$ - where the capacity for affordable monitoring and management of these abnormalities may not exist.

Most literature on the management of laboratory abnormalities in CKD population are based on studies done in HIC. However, it is likely that the underlying causes of these abnormalities vary by country, especially in LMIC. For example, parasitic infection or nutritional deficiency likely cause or exacerbate anaemia in certain settings (e.g., nematode infection causing anaemia), whereas country-specific dietary practices may influence the likelihood of hyperphosphatemia. Further research is needed to document how the causes and consequences of laboratory abnormalities may vary by setting, focusing on factors that may 
influence monitoring or treatment practices in LMIC. Global practice guidelines for monitoring and management of these abnormalities should be adapted for LMIC. Available global guidelines assume the availability of sophisticated laboratory assays and treatments, but these are often not available or affordable in LMIC. Even if available, they may not always represent good value for money in settings with scarce health resources. Work is needed to adapt existing guidelines for LMIC, incorporating information that is gained from activities in this arena and explicitly acknowledging opportunity cost.

A critical barrier to monitoring haematological, hormonal, and metabolic abnormalities in CKD populations is increasing proportion of such patients who live in LMIC, where the requisite laboratory testing is not available, is very expensive, or is located only in referral centres. Developing new point-of-care devices with acceptable performance at affordable prices should be a high priority for future research and perhaps public - private partnerships. Data from a variety of settings that document the current availability of affordable assays (and lack thereof) would help to make the case that these innovations are worthwhile, and should be included in future global CKD surveys.

Most CV research in CKD has focused on atherosclerotic (or arteriosclerotic) heart and vascular disease. However, it is clear that other forms of CVD also have a major impact on morbidity and mortality in this population (see above). ${ }^{137,138}$ The well-documented but poorly understood regional variations in CVD phenotype among CKD populations may offer new insights into how outcomes can be improved. In addition, much remains to be learned about fundamental aspects of vascular risk reduction in CKD populations (e.g., optimal target BP or benefits of aspirin in dialysis patients). ${ }^{218}$ Finally, continued work is needed to develop novel therapies for CKD-related CVD.

The risks of arrhythmia (including sudden cardiac death), stroke, and heart failure are all substantially increased in people with CKD (especially in those with kidney failure), and the basic epidemiology of these conditions is well-described. However, major gaps remain in understanding the pathophysiology of vascular and cardiac diseases in CKD populations, and especially in how they should be treated. Current approaches emphasize the application of treatments developed for the general population to people with kidney disease, although the efficacy-toharm ratio of these therapies is unclear. There is an urgent need for focused research programs that rigorously evaluate the benefits of standard treatment approaches (e.g., ARB for heart failure; implantable defibrillators to prevent sudden cardiac death) in kidney populations - as well as novel interventions that might reduce the risk of CV events in people with kidney disease (e.g., intradialytic potassium profiling).

The phenotype of CVD in people with CKD exhibits potentially important regional variation. For example, Japanese haemodialysis patients appear to have a markedly lower risk of sudden death than those in other countries. Whether this 
is due to patient characteristics, environmental factors, or treatment practices is unknown. If confirmed, between-country variations in risk and outcomes might lead to new insights about pathophysiology or optimal management, or both. Careful observational studies that use common definitions to compare the epidemiology of these conditions across countries are a high priority.

Although new research is certainly needed, there are other areas in which knowledge translation (rather than knowledge generation) should be the key priority. For example, although the target for BP control in dialysis patients is unknown, severe hypertension is clearly harmful -- and organized programs should emphasize the prevention of very poor blood pressure control without causing side effects. Similarly, there is little controversy about the merits of controlling blood pressure, blood sugar, and dyslipidaemia in people with less advanced CKD -- yet many people worldwide do not have access to these treatments. Knowledge translation and advocacy efforts should focus on the implementation of global guidelines in renal populations, especially in LMIC.

In addition to a high burden of traditional risk factors, CVD in CKD appears to also be driven by novel (CKD-specific) risk factors. For example, abnormalities in phosphate, fibroblast growth factor 23, and Klotho all appear to contribute to CVDs in renal populations. Continued work is needed to translate discoveries from biomedical science into novel therapies that address these risk factors and mitigate the burden of CVD.

Key knowledge gaps exist about fundamental aspects of CVD management and prevention in CKD populations, especially in dialysis patients. Clinical trials are needed to examine the risks and benefits of treatments like aspirin, renin/angiotensin system interruption, and spironolactone in patients with advanced kidney disease and kidney failure. Since these trials are unlikely to be funded by industry partners, their success likely depends on cooperation between public research funders from different countries. 


\begin{tabular}{|c|c|c|c|}
\hline Goals & Activities & Partners & Possible Deliverables \\
\hline $\begin{array}{l}\text { Promote diagnosis } \\
\text { and staging of CKD } \\
\text { as proposed by } \\
\text { KDIGO }\end{array}$ & $\begin{array}{l}\text { Work towards global } \\
\text { implementation of the diagnosis } \\
\text { (assess or attempt to assess } \\
\text { aetiology) and staging of CKD } \\
\text { based on measuring or estimating } \\
\text { GFR and measuring albuminuria }\end{array}$ & $\begin{array}{l}\text { Health care providers, clinical } \\
\text { chemists }\end{array}$ & $\begin{array}{l}\text { Increased ability to accurately diagnose CKD in } \\
\text { different regions }\end{array}$ \\
\hline \multirow{6}{*}{$\begin{array}{l}\text { Enhance renal } \\
\text { biopsy based CKD } \\
\text { diagnosis }\end{array}$} & $\begin{array}{l}\text { Endorse need to obtain renal } \\
\text { biopsy in a broader range of } \\
\text { presentations, including CKD, AKI, } \\
\text { and GN }\end{array}$ & $\begin{array}{l}\text { KDIGO; Health care system, } \\
\text { pathology departments }\end{array}$ & $\begin{array}{l}\text { Consensus conference with published report } \\
\text { Increased ability to accurately diagnose CKD in } \\
\text { different regions }\end{array}$ \\
\hline & $\begin{array}{l}\text { Sustain or establish regional } \\
\text { centres of excellence for renal } \\
\text { biopsy analyses and interpretation } \\
\text { globally }\end{array}$ & $\begin{array}{l}\text { Ongoing efforts of the ISN } \\
\text { Renal Pathology Committee }\end{array}$ & $\begin{array}{l}\text { Consensus report with definition of standards for } \\
\text { tissue processing and histological analyses } \\
\text { Increase biopsy capacity in all countries }\end{array}$ \\
\hline & $\begin{array}{l}\text { Support implementation of } \\
\text { standards in renal biopsy reporting }\end{array}$ & RPS & $\begin{array}{l}\text { Consensus report, e.g., RPS, Mayo Clinic } \\
\text { standardized reporting of GN }\end{array}$ \\
\hline & $\begin{array}{l}\text { Sustain and expand efforts to } \\
\text { increase capacity for performing } \\
\text { renal biopsies globally }\end{array}$ & ISN interventional Nephrology & $\begin{array}{l}\text { Offering of renal biopsy training courses, covering } \\
\text { indication, risk, performance and monitoring } \\
\text { Increase biopsy capacity in all countries }\end{array}$ \\
\hline & $\begin{array}{l}\text { Evaluate and implement } \\
\text { opportunities for molecular } \\
\text { diagnosis of renal biopsies }\end{array}$ & $\begin{array}{l}\text { Funding agencies, research } \\
\text { networks }\end{array}$ & $\begin{array}{l}\text { Research reports } \\
\text { Increase biopsy capacity in all countries }\end{array}$ \\
\hline & $\begin{array}{l}\text { Link existing and novel renal } \\
\text { biopsy registries with clinical data }\end{array}$ & & $\begin{array}{l}\text { Establishment of a global network and exploration of } \\
\text { opportunities for data sharing and joint analyses }\end{array}$ \\
\hline \multirow{2}{*}{$\begin{array}{l}\text { Enhance non- } \\
\text { invasive imaging } \\
\text { analyses of the } \\
\text { kidney in CKD }\end{array}$} & $\begin{array}{l}\text { Work towards global availability of } \\
\text { diagnostic ultrasound imaging }\end{array}$ & Public policy & $\begin{array}{l}\text { Monitoring of access to ultrasound diagnosis as part } \\
\text { of the GKHA project }\end{array}$ \\
\hline & $\begin{array}{l}\text { Develop better non-invasive } \\
\text { imaging tools of renal structure } \\
\text { and function }\end{array}$ & $\begin{array}{l}\text { Funding agencies, Radiology } \\
\text { Society }\end{array}$ & $\begin{array}{l}\text { Research conference devoted to this topic } \\
\text { Increase number and types of tools available for } \\
\text { assessment of CKD }\end{array}$ \\
\hline $\begin{array}{l}\text { Facilitate } \\
\text { identification, }\end{array}$ & $\begin{array}{l}\text { Sustain and enhance efforts to } \\
\text { identify and validate biomarkers }\end{array}$ & $\begin{array}{l}\text { Research networks, industry } \\
\text { partners }\end{array}$ & Research reports \\
\hline
\end{tabular}




\begin{tabular}{|c|c|c|c|}
\hline Goals & Activities & Partners & Possible Deliverables \\
\hline \multirow{4}{*}{$\begin{array}{l}\text { validation and } \\
\text { implementation of } \\
\text { diagnostic } \\
\text { biomarkers in CKD }\end{array}$} & $\begin{array}{l}\text { that indicate aetiology, dominant } \\
\text { pathophysiological mechanisms } \\
\text { and/or therapeutic responsiveness }\end{array}$ & & $\begin{array}{l}\text { Increase number and types of tools available for } \\
\text { assessment of CKD }\end{array}$ \\
\hline & $\begin{array}{l}\text { Advocate for local / (inter) national } \\
\text { biobanking efforts to include } \\
\text { "renal" samples }\end{array}$ & & $\begin{array}{l}\text { Task force to explore opportunities and develop a } \\
\text { concrete strategy }\end{array}$ \\
\hline & $\begin{array}{l}\text { Provide guidance on biosampling } \\
\text { for markers of renal structure and } \\
\text { function }\end{array}$ & CKD research networks & $\begin{array}{l}\text { Development of a consensus statement with } \\
\text { minimum standards and outline of how sample } \\
\text { collection and storage procedures impact sample } \\
\text { utility } \\
\text { Increase engagement of CKD networks in } \\
\text { collaborative research }\end{array}$ \\
\hline & $\begin{array}{l}\text { Promote sharing of biobanking } \\
\text { inventories, protocols and } \\
\text { biosamples }\end{array}$ & $\begin{array}{l}\text { Funding agencies, CKD } \\
\text { research networks }\end{array}$ & $\begin{array}{l}\text { Development of a guidance document for } \\
\text { governance of research network: network internal } \\
\text { policy developments / biosamples usage / sample } \\
\text { sharing / challenges of international collaboration }\end{array}$ \\
\hline \multirow{2}{*}{$\begin{array}{l}\text { Enhance the } \\
\text { clinical } \\
\text { assessment of } \\
\text { renal (dys) function } \\
\text { and underlying } \\
\text { pathomechanisms } \\
\text { in CKD }\end{array}$} & $\begin{array}{l}\text { Endorse research efforts to assess } \\
\text { renal functional domains and } \\
\text { pathomechanisms with their } \\
\text { interaction and complexity } \\
\text { (function of different tubular } \\
\text { segments, inflammation, fibrosis, } \\
\text { renal endothelial function) }\end{array}$ & Funding agencies & \\
\hline & $\begin{array}{l}\text { Evaluate the diagnostic and } \\
\text { prognostic utility of renal functional } \\
\text { reserve assessment }\end{array}$ & Funding agencies & \\
\hline \multirow{2}{*}{$\begin{array}{l}\text { Improve } \\
\text { monitoring of } \\
\text { kidney disease } \\
\text { progression among } \\
\text { patients with CKD }\end{array}$} & $\begin{array}{l}\text { Implement regular measurements } \\
\text { of ACR and serum creatinine } \\
\text { based eGFR for monitoring CKD }\end{array}$ & $\begin{array}{l}\text { Policy makers, professional } \\
\text { societies, guideline } \\
\text { developers, WHO }\end{array}$ & $\begin{array}{l}\text { Increase in number of countries able to measure } \\
\text { ACR/eGFR relative to current state }\end{array}$ \\
\hline & $\begin{array}{l}\text { Increase awareness and empower } \\
\text { patients in self-management and } \\
\text { their understanding of their health } \\
\text { (e.g., by implementing health } \\
\text { technology applications) }\end{array}$ & $\begin{array}{l}\text { Patient organisations, print and } \\
\text { electronic media, ISN }\end{array}$ & $\begin{array}{l}\text { Formal interactions with partners to develop a } \\
\text { collaboration to accomplish the goal (e.g. } \\
\text { International Federation of Kidney Foundation) }\end{array}$ \\
\hline
\end{tabular}




\begin{tabular}{|c|c|c|c|}
\hline Goals & Activities & Partners & Possible Deliverables \\
\hline & $\begin{array}{l}\text { Define changes in albuminuria and } \\
\text { GFR that are meaningful for } \\
\text { individual patients and how they } \\
\text { should relate to clinical action }\end{array}$ & $\begin{array}{l}\text { Scientists, Food and Drug } \\
\text { Administration (FDA), } \\
\text { European Medicines Agency } \\
\text { (EMA) }\end{array}$ & $\begin{array}{l}\text { Report on optimal change in albuminuria and } \\
\text { association with outcome in } 2018 \\
\text { International collaboration with ongoing initiatives } \\
\text { (e.g. NKF/FDA/EMA workshop) }\end{array}$ \\
\hline $\begin{array}{l}\text { Improve CVD risk } \\
\text { prediction in } \\
\text { patients with CKD }\end{array}$ & $\begin{array}{l}\text { Develop a risk prediction tool, } \\
\text { integrating CKD markers in CVD } \\
\text { risk assessment among CKD } \\
\text { patients }\end{array}$ & $\begin{array}{l}\text { Endocrinologists, cardiologists, } \\
\text { general practitioners, if } \\
\text { possible renal pharmacists }\end{array}$ & $\begin{array}{l}\text { Web-based risk scores for CVD involving renal risk } \\
\text { markers (albuminuria / eGFR) } \\
\text { Evidence of use of risk scores in clinical practice }\end{array}$ \\
\hline \multirow{2}{*}{$\begin{array}{l}\text { Facilitate } \\
\text { identification, } \\
\text { validation and } \\
\text { implementation of } \\
\text { prognostic } \\
\text { biomarkers in CKD }\end{array}$} & $\begin{array}{l}\text { Sustain and enhance efforts to } \\
\text { identify and validate biomarkers } \\
\text { that indicate the progression } \\
\text { and/or therapeutic responsiveness } \\
\text { of CKD }\end{array}$ & $\begin{array}{l}\text { Regulatory authorities (e.g., } \\
\text { FDA, EMA), Industry partners, } \\
\text { payers }\end{array}$ & $\begin{array}{l}\text { Conference with the partners to develop guidance } \\
\text { and principles }\end{array}$ \\
\hline & $\begin{array}{l}\text { Sustain and enhance efforts to } \\
\text { identify and validate biomarkers } \\
\text { that indicate the development of } \\
\text { CVD events in CKD patients }\end{array}$ & $\begin{array}{l}\text { EUTox, CKD biomarkers } \\
\text { consortium, industry partners }\end{array}$ & $\begin{array}{l}\text { Conference with the partners } \\
\text { Correlation of uremic toxins to phenotype } \\
\text { Increased acceptance and uptake of diagnostic } \\
\text { tests for specific conditions in many regions }\end{array}$ \\
\hline \multirow{2}{*}{$\begin{array}{l}\text { Enhance global } \\
\text { access to } \\
\text { strategies and } \\
\text { agents that retard } \\
\text { progression of } \\
\text { CKD }\end{array}$} & $\begin{array}{l}\text { Development of early stage CKD } \\
\text { toolkit }\end{array}$ & $\begin{array}{l}\text { Non-nephrology health care } \\
\text { providers, health care } \\
\text { politicians }\end{array}$ & $\begin{array}{l}\text { CKD-toolkits for different regional settings: } \\
\text { - Distillation of generic summary } \\
\text { - Generation of toolkit - multi-interventional, } \\
\text { specific goals, simple interventions, (simple } \\
\text { measures: BP, urine dipstick); } \\
\text { - Identification of workforce with capacity to } \\
\text { deliver package; } \\
\text { - Translations into different languages }\end{array}$ \\
\hline & $\begin{array}{l}\text { Work towards global access to: } \\
\text { 1) affordable BP lowering drugs } \\
\text { 2) glucose lowering drugs } \\
\text { 3) renin-angiotensin system } \\
\text { blockade for proteinuric diabetic } \\
\text { kidney disease, } \\
\text { 4) statins for CVD prevention n }\end{array}$ & $\begin{array}{l}\text { WHO, regional health care } \\
\text { providers }\end{array}$ & $\begin{array}{l}\text { Monitor availability of the four treatments; evaluate } \\
\text { implementation delta and publicise results } \\
\text { Extend the GKHA project to include this monitoring } \\
\text { Increase availability of these agents or polypill for at } \\
\text { risk populations }\end{array}$ \\
\hline
\end{tabular}




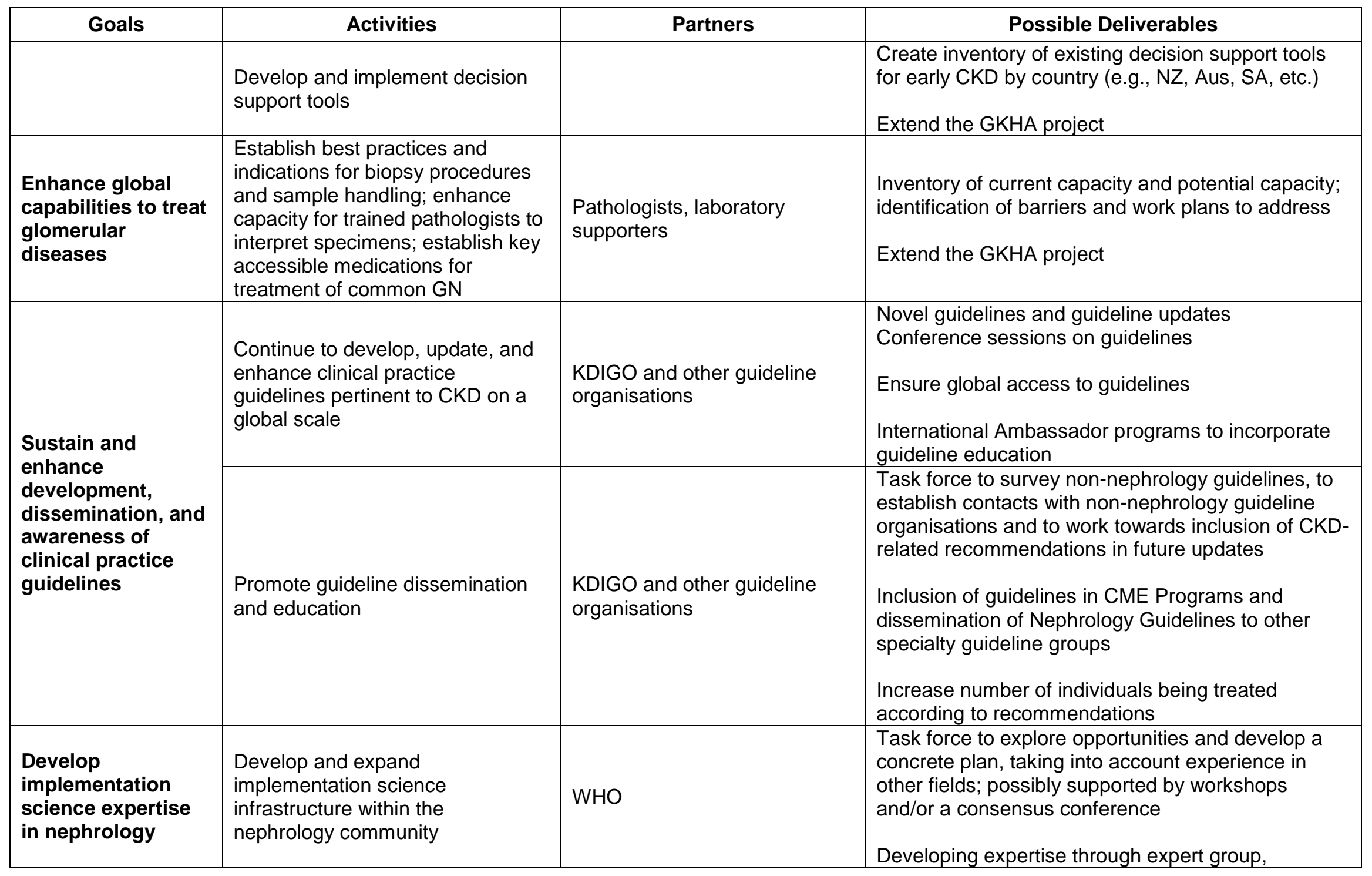




\begin{tabular}{|c|c|c|c|}
\hline Goals & Activities & Partners & Possible Deliverables \\
\hline & & & $\begin{array}{l}\text { educational meetings, and training mechanisms; } \\
\text { tool and curriculum/plan } \\
\text { Funding for international and country specific } \\
\text { Fellowships, Ambassadors } \\
\text { Regional presentations, collaboration on specific } \\
\text { projects }\end{array}$ \\
\hline & $\begin{array}{l}\text { Evaluate implementation } \\
\text { strategies pertinent to CKD in } \\
\text { clinical trials, tailor effective trial } \\
\text { design to local circumstances and } \\
\text { scale/spread successful } \\
\text { dissemination strategies for } \\
\text { maximum global impact }\end{array}$ & $\begin{array}{l}\text { Government health ministries, } \\
\text { industry partners, funding } \\
\text { agencies }\end{array}$ & $\begin{array}{l}\text { Conduct a trial to evaluate pre-intervention use } \\
\text { versus short-term and long-term effects of } \\
\text { intervention; tailor effective trial designs to the local } \\
\text { circumstances (e.g., comparative effectiveness, } \\
\text { step-wedge trials) } \\
\text { Partner with government and health services to } \\
\text { embed research in clinical care - facilitation of } \\
\text { comparative effectiveness studies when previously } \\
\text { unused therapies are introduced to ensure focus of } \\
\text { resources on high-yielding interventions }\end{array}$ \\
\hline & $\begin{array}{l}\text { Inclusion of considerations related } \\
\text { to implementation in guidelines }\end{array}$ & $\begin{array}{l}\text { KDIGO and other guideline } \\
\text { organisations }\end{array}$ & $\begin{array}{l}\text { Future guidelines consider recommending an 'ideal' } \\
\text { and an 'absolutely acceptable minimum' } \\
\text { recommendation for increase uptake in HIC and } \\
\text { LMIC alike }\end{array}$ \\
\hline \multirow[t]{2}{*}{$\begin{array}{l}\text { Improve symptoms } \\
\text { associated with } \\
\text { CKD }\end{array}$} & $\begin{array}{l}\text { Develop better understanding of } \\
\text { symptoms associated with CKD } \\
\text { and their impact on HRQOL, } \\
\text { employability, and functional status }\end{array}$ & Patients and caregivers & $\begin{array}{l}\text { Task force to establish interaction and joint plan with } \\
\text { patient groups } \\
\text { Symptom survey of patients with CKD } \\
\text { Review summarizing current evidence and gaps in } \\
\text { knowledge } \\
\text { Reduction in suffering of pts with CKD }\end{array}$ \\
\hline & $\begin{array}{l}\text { Promote basic and clinical } \\
\text { research into understanding the } \\
\text { pathophysiology of the key } \\
\text { symptoms, in order to better target }\end{array}$ & $\begin{array}{l}\text { Industrial partners, Funding } \\
\text { agencies }\end{array}$ & Research reports \\
\hline
\end{tabular}




\begin{tabular}{|c|c|c|c|}
\hline Goals & Activities & Partners & Possible Deliverables \\
\hline & therapeutic efforts & & \\
\hline & $\begin{array}{l}\text { Improve symptom management in } \\
\text { patients with CKD }\end{array}$ & & $\begin{array}{l}\text { Multidisciplinary meetings } \\
\text { Educational materials for different target groups } \\
\text { Consider educational and advocacy activities about } \\
\text { the symptom burden (e.g., World Kidney Day) } \\
\text { (patients, health care providers,...) }\end{array}$ \\
\hline \multirow{2}{*}{$\begin{array}{l}\text { Optimise the } \\
\text { management of } \\
\text { haematological, } \\
\text { hormonal, and } \\
\text { metabolic } \\
\text { abnormalities } \\
\text { associated with } \\
\text { CKD }\end{array}$} & $\begin{array}{l}\text { Promote consistent assessment } \\
\text { and documentation of laboratory } \\
\text { abnormalities in CKD populations } \\
\text { according to KDIGO guideline }\end{array}$ & Patients & Survey of guideline implementation \\
\hline & $\begin{array}{l}\text { Promote availability of affordable } \\
\text { point-of-care measurement } \\
\text { devices and treatments for } \\
\text { hormonal, haematological and } \\
\text { biochemical abnormalities }\end{array}$ & Policy Makers & $\begin{array}{l}\text { Survey availability as part of the GKHA project } \\
\text { Access to point-of-care testing in many areas where } \\
\text { it does not exist now }\end{array}$ \\
\hline $\begin{array}{l}\text { Improve prevention } \\
\text { and management } \\
\text { of CV } \\
\text { complications in } \\
\text { people with CKD }\end{array}$ & $\begin{array}{l}\text { Develop an integrated research } \\
\text { program to better understand } \\
\text { vascular and cardiac diseases } \\
\text { occurring in the context of CKD } \\
\text { populations }\end{array}$ & $\begin{array}{l}\text { Funding agencies, industry } \\
\text { partners }\end{array}$ & $\begin{array}{l}\text { Research reports } \\
\text { Research conferences }\end{array}$ \\
\hline
\end{tabular}




\begin{tabular}{|c|c|c|c|}
\hline Goals & Activities & Partners & Possible Deliverables \\
\hline & $\begin{array}{l}\text { Improve understanding of global } \\
\text { variation in CVD associated with } \\
\text { CKD }\end{array}$ & Cardiologists & $\begin{array}{l}\text { Analysis of CVD morbidity in cohort studies } \\
\text { established in different regions }\end{array}$ \\
\hline & $\begin{array}{l}\text { Determine barriers to } \\
\text { dissemination and implementation } \\
\text { of existing guidelines on } \\
\text { dyslipidaemia and hypertension } \\
\text { management to reduce CV risk in } \\
\text { CKD, and implement strategies to } \\
\text { overcome those barriers }\end{array}$ & KDIGO & $\begin{array}{l}\text { Research reports } \\
\text { More patients receive appropriate care (current } \\
\text { reports }<65 \% \text { ) }\end{array}$ \\
\hline & $\begin{array}{l}\text { Develop new therapeutic } \\
\text { approaches to reduce CVD risk in } \\
\text { CKD patients }\end{array}$ & $\begin{array}{l}\text { Funding agencies, industry } \\
\text { partners }\end{array}$ & $\begin{array}{l}\text { New therapeutic agents } \\
\text { Clinical trials focussing on CVD outcomes in CKD } \\
\text { patients }\end{array}$ \\
\hline & $\begin{array}{l}\text { Promote further research into } \\
\text { optimal therapeutic targets for } \\
\text { CVD risk factor management (e.g., } \\
\text { BP control) and how best to } \\
\text { achieve them }\end{array}$ & Policy makers & $\begin{array}{l}\text { Research reports } \\
\text { Clinical trials }\end{array}$ \\
\hline
\end{tabular}




\section{Develop novel interventions in partnership with industry}

To drive the availability of new treatments for CKD, three linked sets of activities are required: identifying "druggable" therapeutic targets; enhancing capacity for pre-clinical and early clinical development; and encouraging increased investment in the development of CKD therapies (see Table 4).

The likelihood of identifying druggable targets will be enhanced by coordinated efforts to interrogate human samples using state of the art 'omics approaches, merged with detailed patient phenotyping and existing biomarkers to identify and qualify new therapeutic targets. Such efforts should to link genetic data with existing phenotypic information and/or generate personalized human tissue models using induced pluripotent stem cells (iPS) cells and targeted mutation followed by differentiation to human kidney tissue. To support these efforts, better models of disease (animal and human) are needed to reflect the complexity of human CKD (e.g., AKI in the setting of CKD, CKD in the setting of vascular disease, diabetes, metabolic syndrome).

Building capacity for pre-clinical and early clinical development could be facilitated by better use of existing infrastructure (e.g., leveraging research networks for CKD to facilitate data acquisition and trial recruitment), as well as developing new infrastructure to collect and analyse biological materials (e.g., kidney biopsy specimens). Human capacity will also be critical: there is a need to facilitate interaction and exchange of ideas between academic researchers and drug/device/diagnostic manufacturers with the aim to promote collaborations and mutual understanding of each other's environment and objectives.

Partnerships with industry are critically important for drug discovery, but existing paradigms for academic-industry collaboration do not incent (and may even inhibit) such collaborations. Work is needed on how best to recognize and support academic nephrologists and kidney $\mathrm{PhD}$ scientists who move in and out of an industry/biotechnology research environment. An essential element will be determining how to give academic credit to researchers who participate in such interactions, which may not always yield traditional scholarly deliverables.

Other factors will require consideration in addition to the development and validation of novel targets. Given the explosion of therapeutics beyond small molecules to DNA and RNA therapeutics together with targeted bioavailablity to reduce side effects and enhance efficacy, drug delivery systems are of parallel importance to novel targets. Although the focus has been on scientific development, many of the problems in developing novel therapeutics relate to identifying project-funding sources, finding suitable contract manufacturing companies that are Good Manufacturing Practice (GMP) compliant, and protecting intellectual property generated from the scientific studies when collaboration is essential. Taxation and regulatory policies, including offering patent exclusivity and expedited review for breakthrough therapies for CKD, should provide incentives to develop innovative therapeutics in CKD. Trials with the aim of repurposing generic therapeutics should be prioritised if sufficient scientific evidence 
is available. Examples include allopurinol and metformin, both of which demonstrate potential in the attenuation of progression of CKD through mechanisms related to oxidative stress and fibrosis. ${ }^{219,220}$ Furthermore, strategies used to extend the patent life of drugs, but without investment to assess repurposing, should be discouraged. If the above goals are achieved, new therapies will certainly become available to stop, slow, or reverse CKD. Most importantly, these therapies may actually be accessible to populations around the globe.

\section{Increase the quantity and quality of clinical trials}

Given the importance of clinical trials for changing clinical practice and improving outcomes, it is critical to increase the number of trials relevant to the care of CKD patients, and (to improve the likelihood that such trials yield useful information) to optimize the design of future CKD-related trials. Both goals will be facilitated by thoughtful efforts to build capacity for conducting clinical trials in this population (see Table 4).

Greater investment in kidney disease trials is required, and will require a business case, with clear articulation of the benefits that are achievable, and the value for money gained. This will involve a multi-pronged strategy, starting with advocacy from relevant bodies, and include identification of both the health and financial benefits of trials in the area. For example, hospitalisation is a common and expensive outcome in CKD and needs to be considered and assessed.

Many individual kidney diseases are uncommon or rare, have protracted time courses, thus rendering so called "hard outcome studies" less feasible. Motivated people with kidney disease, advocacy organisations, and health care funders are important stakeholders in kidney disease trials, and have been inadequately engaged to date. They are key partners who can advocate strongly for greater investment in kidney disease trials. Advocacy efforts should aim at increasing investment in CKD research, and at aligning the efforts of researchers with the needs of patients - including the development and selection of appropriate, meaningful, and feasible outcomes for such trials. Markers of kidney damage, including biopsy findings or biomarkers of disease activity, might be suitable in some kidney diseases. For example, the FDA has approved total kidney volume as a prognostic marker for PKD trials, but required substantial scientific collaboration by members of the PKD Outcomes Consortium. ${ }^{221}$

A key barrier to greater investment in kidney disease trials generally (but especially by smaller biotechnology companies) is the long-term nature of trials required to generate regulatory approvals and allow revenue to be generated. In other areas of medicine, conditional approval is granted by regulatory agencies based on benefits on approved surrogate outcomes while requiring appropriate trials assessing effects on hard outcomes to be undertaken as post approval (e.g., glucose lowering agents approved based on glycaemic effects). A similar approach in CKD would likely increase investment in the area, so should be promoted by kidney disease organisations. 
Many trials routinely exclude participants with CKD; in some casesthis is due to concerns about the safety profile of novel agents, but limits generalizability, given the high prevalence of CKD as a comorbid condition and the likelihood of approved agents subsequently being used in CKD. More generally, the incorporation of people with CKD into trials should be encouraged to provide specific data on safety and efficacy in this population, of medications for conditions that are common and impactful in CKD populations.

Unlike other disciplines such as cardiology, CKD trialists lack a regular stand-alone meeting to review ongoing and planned clinical trials with CKD patients on a global scale. Development of such a meeting is a priority for the field. Issues that could be discussed include endpoint selection: better and more relevant endpoints are crucial to facilitate appropriate trials and several initiatives are already underway. A workshop by the US NKF, FDA, and EMA is being planned for 2018 to address changes in albuminuria and rates of GFR decline (slopes) as surrogate endpoints for earlier stages of CKD. This and other activities, such as the SONG initiative and KHI, should be aligned and endorsed to ensure a single set of appropriate endpoints is approved globally.

More broadly than endpoint selection, a dedicated CKD trials meeting would offer opportunities to learn from prior work. Many trials in kidney disease have demonstrated evidence of harm or lack of efficacy, e.g., ALTIDUDE, ${ }^{222}$ BEACON,, 223 ASCEND, ${ }^{224}$ VANEPHRON D, ${ }^{225}$ and TREAT. ${ }^{226}$ The reasons for this may relate to the endpoint chosen, or to aspects of study design or conduct. The regular stand-alone meeting proposed above offers an ideal opportunity to ensure future trials learn from these experiences.

The likelihood of successful trials, and the appropriate generalization of evidence from these trials, will be enhanced if participants can be enrolled based on likelihood of a positive response as well as risk of progression. Active 'run-in' periods are one way that this is being done, but enrichment and/or adaptive approaches are likely to add value. They will also add complexity so more work to understand the trade-offs is required.

A number of novel or alternative approaches to conducting trials are being undertaken in other areas, but may be particularly well suited to CKD. Large simple trial designs have proven useful in other diseases, but may have limitations for endpoints in earlier stages of kidney disease that require repeated laboratory measures for endpoint ascertainment. Randomised-registry trials, cluster randomised trials, adaptive trials, and other approaches should be considered as methods to dramatically increase the feasibility of trials in CKD. Simple trials with minimal data collection would increase the feasibility of including more countries (with the ethnic diversity that brings), and thus improve the generalisability of studies, once completed.

The limited capacity in conducting kidney disease trials highlights the need to study interventions that are most likely to improve outcomes for people with CKD, rather than those that will deliver commercial returns. Prioritising these interventions is a key goal, 
and should be done regionally as well as globally to account for local differences in needs. In parallel, the nephrology community should work to build additional capacity.

A repository of information that can provide information on centres, networks, and coordinating centres with interest (and where possible experience) in kidney disease trials would strongly support better collaboration and more feasible conduct of trials. Finally, training through courses, formal and informal mentorship and structured programs, and partnerships will be crucial to increasing the number and quality of CKD trials. 


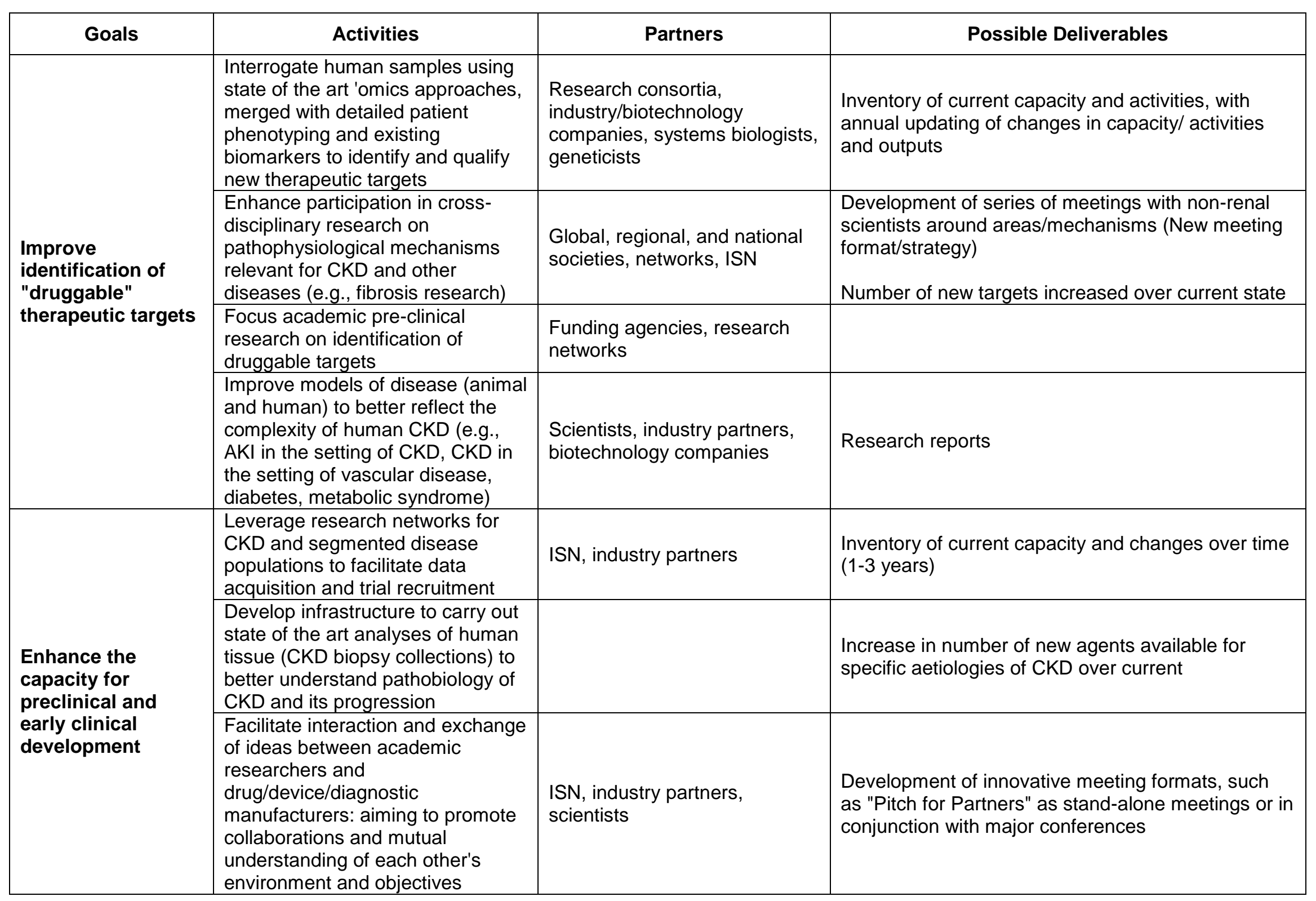




\begin{tabular}{|c|c|c|c|}
\hline Goals & Activities & Partners & Possible Deliverables \\
\hline & $\begin{array}{l}\text { Recognize and support academic } \\
\text { nephrologists and kidney PhD } \\
\text { scientists to move in and out of a } \\
\text { Industry/biotechnology research } \\
\text { environment }\end{array}$ & $\begin{array}{l}\text { Industry partners and } \\
\text { academic institutions }\end{array}$ & $\begin{array}{l}1 \text { year and ongoing: Establishment of special } \\
\text { scholarships to increase capacity; expanding if } \\
\text { successful year on year }\end{array}$ \\
\hline & $\begin{array}{l}\text { Give credit to ongoing involvement } \\
\text { academic/industry/biotechnology } \\
\text { collaborations in therapeutic } \\
\text { development in academic career } \\
\text { development }\end{array}$ & $\begin{array}{l}\text { Academic institutions and } \\
\text { health sector, biotechnology } \\
\text { companies and industry } \\
\text { partners }\end{array}$ & $\begin{array}{l}\text { Policy statement at academic institutions } \\
\text { recognizing activities and tabulating towards career } \\
\text { development }\end{array}$ \\
\hline \multirow{2}{*}{$\begin{array}{l}\text { Encourage } \\
\text { increased } \\
\text { investment in the } \\
\text { development of } \\
\text { CKD therapies }\end{array}$} & $\begin{array}{l}\text { Document differences in CKD } \\
\text { practice patterns and therapeutic } \\
\text { needs in different countries }\end{array}$ & $\begin{array}{l}\text { ISN, global, regional, and } \\
\text { national nephrology societies }\end{array}$ & Extension of the GKHA project \\
\hline & $\begin{array}{l}\text { Encourage industry / } \\
\text { biotechnology / government } \\
\text { investment in development of new } \\
\text { therapies for CKD }\end{array}$ & As per activity & $\begin{array}{l}\text { Tailored, leveraged plans for funders, governments, } \\
\text { WHO, World Bank, foundations }\end{array}$ \\
\hline \multirow{4}{*}{$\begin{array}{l}\text { Strongly } \\
\text { encourage and } \\
\text { promote the } \\
\text { conduct of clinical } \\
\text { trials in people with } \\
\text { CKD }\end{array}$} & $\begin{array}{l}\text { Develop value proposition for trials } \\
\text { in kidney disease }\end{array}$ & Health economists, payers & Published position statement \\
\hline & $\begin{array}{l}\text { Promote trials in areas of unmet } \\
\text { need and orphan diseases, } \\
\text { including outcome development } \\
\text { (e.g., biopsy, hospitalisation) }\end{array}$ & $\begin{array}{l}\text { Advocacy organisations, } \\
\text { regulatory authorities, KDIGO }\end{array}$ & Consensus conference with published report \\
\hline & $\begin{array}{l}\text { Engage activated patient groups, } \\
\text { payers and other stakeholders, } \\
\text { aiming to substantially increase } \\
\text { the number of clinical trials in CKD }\end{array}$ & $\begin{array}{l}\text { Advocacy organisations, major } \\
\text { payers, WHO }\end{array}$ & $\begin{array}{l}\text { Trial stakeholder workshop within } 2 \text { years } \\
\text { Increase in number of clinical trials in Nephrology }\end{array}$ \\
\hline & $\begin{array}{l}\text { Promote models for early } \\
\text { conditional approval of new } \\
\text { therapies to encourage investment }\end{array}$ & Regulatory authorities, $\mathrm{KHI}$ & Position statement \\
\hline
\end{tabular}




\begin{tabular}{|c|c|c|c|}
\hline Goals & Activities & Partners & Possible Deliverables \\
\hline & $\begin{array}{l}\text { Work to increase the number of } \\
\text { people with CKD who are included } \\
\text { in } C V \text {, diabetes, and oncology } \\
\text { trials, aiming to reflect the } \\
\text { prevalence of CKD in such patient } \\
\text { populations. }\end{array}$ & $\begin{array}{l}\text { Regulatory authorities, FDA, } \\
\text { EMA, non-nephrology } \\
\text { disciplines }\end{array}$ & $\begin{array}{l}\text { Position statement } \\
\text { Inventory of CKD related 'in- and exclusion criteria' } \\
\text { in major non-kidney trials to monitor implementation } \\
\text { Increase in number of clinical trials with CKD } \\
\text { included (vs. excluded) as important subgroup }\end{array}$ \\
\hline & $\begin{array}{l}\text { Develop a regular stand-alone } \\
\text { meeting to review ongoing and } \\
\text { planned clinical trials with CKD } \\
\text { patients on a global scale }\end{array}$ & $\begin{array}{l}\text { KDIGO, KHI, global, regional, } \\
\text { and national nephrology } \\
\text { societies }\end{array}$ & First stand-alone meeting within 2 years \\
\hline \multirow{6}{*}{$\begin{array}{l}\text { Optimise the } \\
\text { design of clinical } \\
\text { trials in people with } \\
\text { CKD }\end{array}$} & $\begin{array}{l}\text { Develop and refine appropriate } \\
\text { endpoints for CKD trials and } \\
\text { promote their uptake and } \\
\text { dissemination }\end{array}$ & NKF, FDA, EMA, KHI, SONG & $\begin{array}{l}\text { Conference on albuminuria / eGFR in } 2018 \text { (US } \\
\text { NKF, FDA, EMA) } \\
\text { Position statement }\end{array}$ \\
\hline & $\begin{array}{l}\text { Evaluate factors that lead to } \\
\text { "success" or "failure" of clinical } \\
\text { trials in CKD trials }\end{array}$ & Industry partners & $\begin{array}{l}\text { Conference --> report; to be continued as part of the } \\
\text { proposed annual meeting }\end{array}$ \\
\hline & $\begin{array}{l}\text { Facilitate strategies to pre-select } \\
\text { patients for clinical trials according } \\
\text { to their risk for progression or } \\
\text { likelihood to respond to an } \\
\text { intervention }\end{array}$ & $\begin{array}{l}\text { Industry partners, } \\
\text { bioinformaticians clinicians, } \\
\text { scientists }\end{array}$ & $\begin{array}{l}\text { Published reanalysis of selected trials to } \\
\text { differentiate progressors/non-progressors and } \\
\text { responders/non-responders }\end{array}$ \\
\hline & $\begin{array}{l}\text { Develop innovative trial designs to } \\
\text { enhance feasibility and success of } \\
\text { CKD trials }\end{array}$ & & Integration into clinical trial meetings \\
\hline & $\begin{array}{l}\text { Implement priority setting } \\
\text { exercises for interventions to be } \\
\text { tested in clinical trials globally and } \\
\text { by region }\end{array}$ & $\begin{array}{l}\text { ISN, KDIGO, global, regional, } \\
\text { and national nephrology } \\
\text { societies }\end{array}$ & $\begin{array}{l}\text { Global exercise completed in } 2 \text { years } \\
\text { At least } 2 \text { regional processes within } 3 \text { years }\end{array}$ \\
\hline & $\begin{array}{l}\text { Establish recommendations for } \\
\text { clinical trials in people with CKD } \\
\text { for use by ethical and regulatory } \\
\text { boards, including opportunities for } \\
\text { sample collection for future } \\
\text { analyses }\end{array}$ & $\begin{array}{l}\text { Industry partners, ISN, global, } \\
\text { regional, and national } \\
\text { nephrology societies }\end{array}$ & $\begin{array}{l}\text { Convene a panel to address this topic, including } \\
\text { stakeholders with appropriate expertise in relevant } \\
\text { disciplines }\end{array}$ \\
\hline
\end{tabular}




\begin{tabular}{|c|c|c|c|}
\hline Goals & Activities & Partners & Possible Deliverables \\
\hline \multirow{3}{*}{$\begin{array}{l}\text { Grow capacity in } \\
\text { conducting clinical } \\
\text { trials in people with } \\
\text { CKD }\end{array}$} & $\begin{array}{l}\text { Develop networks of kidney clinical } \\
\text { trialists including community } \\
\text { physicians, and other specialties, } \\
\text { etc. }\end{array}$ & Funding agencies & $\begin{array}{l}\text { Convene a meeting of established clinical trial } \\
\text { groups }\end{array}$ \\
\hline & $\begin{array}{l}\text { Catalogue sites/centres capable of } \\
\text { participating in kidney trials }\end{array}$ & $\begin{array}{l}\text { Academic Research } \\
\text { Organisations }\end{array}$ & $\begin{array}{l}\text { Catalogue and mechanism available by end } 2017 \text {, } \\
\text { with mechanism for linking trials and centres } \\
\text { Develop mechanisms for internationalisation of } \\
\text { trials, particularly including LMIC }\end{array}$ \\
\hline & $\begin{array}{l}\text { Develop and implement } \\
\text { professional training in trial design } \\
\text { and conduct, involving nephrology } \\
\text { and related specialties }\end{array}$ & $\begin{array}{l}\text { Trial training providers, global, } \\
\text { regional, and national } \\
\text { nephrology societies }\end{array}$ & $\begin{array}{l}\text { First course at WCN 2017, put online by end 2017, } \\
\text { roll out in at least } 2 \text { regions during } 2018 \\
\text { Award fellowships for the planning and conduct of } \\
\text { clinical trials } \\
\text { Increase size and quality of clinical trials in } \\
\text { nephrology }\end{array}$ \\
\hline
\end{tabular}




\section{SUMMARY and CONCLUSIONS}

There are significant gaps in research, care, and policy that have seriously compromised our ability to improve the outcomes of patients with CKD around the world. The international community has recognized these gaps, and for the first time, has developed a comprehensive plan to systematically these gaps.

We involved many stakeholders: individuals with broad and diverse expertise and different professional, scientific, and cultural backgrounds. The content of this document, including the recommendations, was developed in a step-wise process, including several rounds of internal review and plenary discussion at the summit meeting. Despite this strength, the selection of goals and activities and their priorities remains subjective, and views on several issues are likely to differ among members of the community. In the current era of patient centred care, many efforts to engage patients in these processes are ongoing. The broad scope precluded an in depthanalysis of each topic, however, including the full spectrum of themes relevant to the prevention and treatment of CKD is an important strength of this document.

Proposed activities include education, research, and policy creation and implementation. Partners in these endeavours include academic institutions, health care institutions, governmental agencies, industry partners, research funding agencies, clinicians, researchers, policy makers, and patients.

Educational activities to address public and patient awareness in all areas of the world are critical for progress. The development of targeted and culturally appropriate materials for patients, policy makers, and clinicians will improve communication and knowledge. Education about risk factors, the importance of genetics, and the need to be involved in clinical studies will enhance the community's capacity to close many of the gaps identified.

Herein, we have described a wide range of research activities which harness existing databases and biorepositories, both within and outside the nephrology community. This requires the development of standardization of definitions, methods of data collection and storage, and some minimal standard 'dataset' across countries. The development or enhancement of registries in countries around the world will be an important step forward in documenting current disease burden and changes. The existence and accessibility of national or renal registries is easily quantifiable, and thus can be measured as an indicator of progress. The ability to collaborate across borders and disciplines is predicated on a change in policies and attitude about data sharing and academic-industry collaborations: progress towards this goal should be quantifiable using bibliometric indices.

It is clear that activities should be targeted to all regions of the globe, although tools, strategies, and research methods will all need to be adapted based on geographical, socioeconomic, cultural, and political considerations. 
Given the potential granularity of each of the plans, it is possible to develop a performance measurement framework by which activities are documented, timelines and responsible parties are identified, and the impact on specific metrics anticipated.

Table 5 offers such the initial high level framework, based on the overarching goals and specific working group action plans, and will hold the nephrology community to account. We are optimistic that this tracking of events, activities, and desired outcomes will galvanize the nephrology community to close the identified gaps -- to reduce the global burden of kidney disease around the world.

None of the authors have direct conflicts of interest with this paper and material contained herein; full disclosures are listed in the individual authors' Conflict of Interest forms. 


\begin{tabular}{|c|c|c|c|}
\hline ing Goal & ctivities & uts & Data Sources \\
\hline $\begin{array}{l}\text { Improve the } \\
\text { surveillance of CKD } \\
\text { 1.Determine and monitor } \\
\text { prevalence of CKD in } \\
\text { different } \\
\text { regions/countries }\end{array}$ & $\begin{array}{l}\text { Support of novel collaborative } \\
\text { translational and clinical research } \\
\text { Position statements to aid in } \\
\text { awareness, advocacy, and collaboration } \\
\text { Workshops of multiple stakeholders in } \\
\text { order to address complex problems } \\
\text { Consensus conferences to develop } \\
\text { unified messaging } \\
\text { Specific time-limited task forces to } \\
\text { address barriers to collaboration and } \\
\text { progress across jurisdictions } \\
\text { Develop inventories by which to } \\
\text { objectively measure current state and } \\
\text { progress } \\
\text { Surveys to establish current state and } \\
\text { perspectives and to use as update tools } \\
\text { Develop, update, and implement } \\
\text { guidelines }\end{array}$ & $\begin{array}{l}\text { Increase in uptake and knowledge of position } \\
\text { statements as outputs of workshops, } \\
\text { consensus conferences, and task forces } \\
\text { Proportion of high-risk populations receiving } \\
\text { simple urine and blood tests to detect CKD } \\
\text { Increased number of countries with written } \\
\text { policies on CKD identification and care } \\
\text { Increased number of countries with capacity } \\
\text { to diagnose CKD (kidney biopsies/laboratory) } \\
\text { Number of people with access to essential } \\
\text { CKD care, basic CKD-relevant medications } \\
\text { Global Kidney Policy Forums held: number, } \\
\text { participants, and locations } \\
\text { Proportion of medical schools with AKI and } \\
\text { CKD modules within curriculum }\end{array}$ & $\begin{array}{l}\text { WHO, ISN, national } \\
\text { research groups } \\
\text { Patient organisations, } \\
\text { industry partners } \\
\text { Documents in public } \\
\text { domain } \\
\text { Global Kidney Health Atlas } \\
\text { (GKHA) } \\
\begin{array}{l}\text { National and regional } \\
\text { documents }\end{array} \\
\text { International, national, and } \\
\text { regional societies }\end{array}$ \\
\hline $\begin{array}{l}\text { Identify and reduce the } \\
\text { risk factors and } \\
\text { identify the genetic } \\
\text { causes of CKD } \\
\text { 2. Identify and reduce } \\
\text { major risk factors for } \\
\text { CKD } \\
\text { 3. Reduce progression } \\
\text { of CKD by targeting AKI } \\
\text { episodes } \\
\text { 4. Improve }\end{array}$ & $\begin{array}{l}\text { Support of novel collaborative } \\
\text { translational and clinical research } \\
\text { Position statements to aid in } \\
\text { awareness, advocacy, and collaboration } \\
\text { Workshops of multiple stakeholders in } \\
\text { order to address complex problems } \\
\text { Consensus conferences to develop } \\
\text { unified messaging } \\
\text { Specific time-limited task forces to } \\
\text { address barriers to collaboration and }\end{array}$ & $\begin{array}{l}\text { Increase in uptake and knowledge of position } \\
\text { statements as outputs of workshops, } \\
\text { consensus conferences, and task forces } \\
\text { Proportion of high-risk populations receiving } \\
\text { simple urine and blood tests to detect CKD } \\
\text { Increased number of countries with written } \\
\text { policies on CKD identification and care } \\
\text { Increased number of countries with capacity } \\
\text { to diagnose CKD (kidney biopsies/laboratory) } \\
\text { Number of people with access to essential }\end{array}$ & $\begin{array}{l}\text { WHO, ISN, national } \\
\text { research groups } \\
\text { Patient organisations, } \\
\text { industry partners } \\
\text { Documents in public } \\
\text { domain } \\
\text { Global Kidney Health Atlas } \\
\text { (GKHA) } \\
\begin{array}{l}\text { National and regional } \\
\text { documents }\end{array} \\
\end{array}$ \\
\hline
\end{tabular}




\begin{tabular}{|c|c|c|c|}
\hline $\begin{array}{l}\text { understanding of the } \\
\text { genetic causes of CKD }\end{array}$ & $\begin{array}{l}\text { progress across jurisdictions } \\
\text { Develop inventories by which to } \\
\text { objectively measure current state and } \\
\text { progress } \\
\text { Surveys to establish current state and } \\
\text { perspectives and to use as update tools } \\
\text { Develop, update, and implement } \\
\text { guidelines }\end{array}$ & $\begin{array}{l}\text { CKD care, basic CKD-relevant medications } \\
\text { Global Kidney Policy Forums held: number, } \\
\text { participants, and locations } \\
\text { Proportion of medical schools with AKI and } \\
\text { CKD modules within curriculum }\end{array}$ & $\begin{array}{l}\text { International, national, and } \\
\text { regional societies }\end{array}$ \\
\hline $\begin{array}{l}\text { Improve diagnosis, } \\
\text { prognosis, and } \\
\text { treatment } \\
\text { 5. Improve diagnostic } \\
\text { methods to assess } \\
\text { alterations in kidney } \\
\text { structure and function } \\
\text { 6. Improve } \\
\text { understanding of the } \\
\text { natural course of CKD } \\
\text { and define prognostic } \\
\text { biomarkers for renal } \\
\text { progression, CVD } \\
\text { complications, and other } \\
\text { adverse events } \\
\text { 7. Evaluate and } \\
\text { implement established } \\
\text { treatment options in } \\
\text { patients with CKD } \\
\text { 8. Improve } \\
\text { understanding and } \\
\text { management of the } \\
\text { complications of CKD }\end{array}$ & $\begin{array}{l}\text { Support of novel collaborative } \\
\text { translational and clinical research } \\
\text { Position statements to aid in } \\
\text { awareness, advocacy, and collaboration } \\
\text { Workshops of multiple stakeholders in } \\
\text { order to address complex problems } \\
\text { Consensus conferences to develop } \\
\text { unified messaging } \\
\text { Specific time-limited task forces to } \\
\text { address barriers to collaboration and } \\
\text { progress across jurisdictions } \\
\text { Develop inventories by which to } \\
\text { objectively measure current state and } \\
\text { progress } \\
\text { Surveys to establish current state and } \\
\text { perspectives and to use as update tools } \\
\text { Develop, update, and implement } \\
\text { guidelines }\end{array}$ & $\begin{array}{l}\text { Number of completed clinical trials focusing } \\
\text { on CKD or ESRD patients } \\
\text { Number of completed clinical trials including } \\
\text { patients with stage } 3 \text { or } 4 \text { CKD } \\
30 \% \text { of CKD patients worldwide involved in a } \\
\text { clinical trial by } 2030 \\
\text { Number of new agents available for CKD or } \\
\text { symptoms treatment } \\
\text { Proportion of patients with ESRD who report } \\
\text { their symptom burden as "mild" or "very mild" } \\
\text { Creation of administrative data platform for } \\
\text { kidney research developed in collaboration } \\
\text { with international groups } \\
\text { Number of international collaborative } \\
\text { consortiums conducting CKD-relevant } \\
\text { research } \\
\text { Median survival among patients with ESRD in } \\
\text { HIC and LMIC } \\
\text { Uptake of international CKD-relevant } \\
\text { guidelines in HIC and LMIC }\end{array}$ & $\begin{array}{l}\text { WHO, ISN, national } \\
\text { research groups } \\
\text { Patient organisations, } \\
\text { industry partners } \\
\text { Documents in public } \\
\text { domain } \\
\text { Global Kidney Health Atlas } \\
\text { (GKHA) } \\
\text { National and regional } \\
\text { documents } \\
\text { International, national, and } \\
\text { regional societies }\end{array}$ \\
\hline
\end{tabular}




\begin{tabular}{|c|c|c|c|}
\hline & & $\begin{array}{l}\text { Number of tools and strategies developed to } \\
\text { enhance access to ethical dialysis or living } \\
\text { donor transplantation }\end{array}$ & \\
\hline $\begin{array}{l}\text { Develop and test new } \\
\text { therapeutic strategies } \\
\text { 9. Validate and establish } \\
\text { novel therapeutic } \\
\text { interventions to slow } \\
\text { CKD progression and } \\
\text { reduce CKD } \\
\text { complications } \\
\text { 10. Optimize the design } \\
\text { of clinical trials in CKD }\end{array}$ & $\begin{array}{l}\text { Support of novel collaborative } \\
\text { translational and clinical research } \\
\text { Position statements to aid in } \\
\text { awareness, advocacy, and collaboration } \\
\text { Workshops of multiple stakeholders in } \\
\text { order to address complex problems } \\
\text { Consensus conferences to develop } \\
\text { unified messaging } \\
\text { Specific time-limited task forces to } \\
\text { address barriers to collaboration and } \\
\text { progress across jurisdictions } \\
\text { Develop inventories by which to } \\
\text { objectively measure current state and } \\
\text { progress } \\
\text { Surveys to establish current state and } \\
\text { perspectives and to use as update tools } \\
\text { Develop, update, and implement } \\
\text { guidelines }\end{array}$ & $\begin{array}{l}\text { Total funding for CKD-relevant research } \\
\text { Number of formal agreements with funding } \\
\text { partners } \\
\text { Number of clinical trials conducted in LMIC } \\
\text { Number of clinical trials conducted which } \\
\text { include CKD as important subgroup } \\
\text { Number of clinical trials which report important } \\
\text { outcomes in CKD subgroup } \\
\text { Number of knowledge translation tools } \\
\text { developed } \\
\text { Number of knowledge translation events held }\end{array}$ & $\begin{array}{l}\text { Study registries, } \\
\text { clinicaltrials.gov, other } \\
\text { publications }\end{array}$ \\
\hline
\end{tabular}




\section{References}

1. Eckardt K-U, Coresh J, Devuyst O, Johnson RJ, Köttgen A, Levey AS, et al. Evolving importance of kidney disease: from subspecialty to global health burden. Lancet. 2013 Jul 13;382(9887):158-69.

2. Global, regional, and national incidence, prevalence, and years lived with disability for 310 diseases and injuries, 1990-2015: a systematic analysis for the Global Burden of Disease Study 2015. Lancet. 2016 Oct;388(10053):1545-602.

3. Couser WG, Remuzzi G, Mendis S, Tonelli M. The contribution of chronic kidney disease to the global burden of major noncommunicable diseases. Kidney Int. 2011;80(12):1258-1270.

4. Levey AS, de Jong PE, Coresh J, El Nahas M, Astor BC, Matsushita K, et al. The definition, classification, and prognosis of chronic kidney disease: a KDIGO Controversies Conference report. Kidney Int. 2011;80(1):17-28.

5. Matsushita K, van der Velde M, Astor BC, Woodward M, Levey AS, de Jong PE, et al. Association of estimated glomerular filtration rate and albuminuria with allcause and cardiovascular mortality: a collaborative meta-analysis of general population cohorts. Lancet. 2010 Jun 12;375(9731):2073-81.

6. Liyanage T, Ninomiya T, Jha V, Neal B, Patrice HM, Okpechi I, et al. Worldwide access to treatment for end-stage kidney disease: a systematic review. Lancet. 2015 May 16;385(9981):1975-82.

7. Jha V, Garcia-Garcia G, Iseki K, Li Z, Naicker S, Plattner B, et al. Chronic kidney disease: global dimension and perspectives. Lancet. 2013 Jul;382(9888):260-72.

8. Luyckx VA, Naicker S, Mckee M. Equity and economics of kidney disease in sub-Saharan Africa. Lancet. 2013 Jul 13;382(9887):103-4.

9. Khatib R, McKee M, Shannon H, Chow C, Rangarajan S, Teo K, et al. Availability and affordability of cardiovascular disease medicines and their effect on use in high-income, middle-income, and low-income countries: an analysis of the PURE study data. Lancet. 2016 Jan;387(10013):61-9.

10. Kidney Disease: Improving Global Outcomes (KDIGO) CKD Work Group. KDIGO 2012 Clinical Practice Guideline for the Evaluation and Management of Chronic Kidney Disease. Kidney Int Suppl. 2013;3:1-150

11. The Global Kidney Health Atlas [Internet]. [cited 2016 Oct 10]. Available from: http://www.theisn.org/news/item/2623-the-global-kidney-health-atlas

12. Nino FS. Sustainable development goals - United Nations [Internet]. United Nations Sustainable Development. [cited 2016 Oct 5]. Available from: http://www.un.org/sustainabledevelopment/sustainable-development-goals/

13. Mills KT, Xu Y, Zhang W, Bundy JD, Chen C-S, Kelly TN, et al. A systematic analysis of worldwide population-based data on the global burden of chronic kidney disease in 2010. Kidney Int. 2015 Nov;88(5):950-7.

14. Hill NR, Fatoba ST, Oke JL, Hirst JA, O'Callaghan CA, Lasserson DS, et al. Global Prevalence of Chronic Kidney Disease - A Systematic Review and MetaAnalysis. PLOS ONE. 2016 Jul 6;11(7):e0158765.

15. Brück K, Stel VS, Gambaro G, Hallan S, Völzke H, Ärnlöv J, et al. CKD Prevalence Varies across the European General Population. J Am Soc Nephrol. $2016 \mathrm{Jul} ; 27(7): 2135-47$. 
16. Brück K, Jager KJ, Dounousi E, Kainz A, Nitsch D, Ärnlöv J, et al. Methodology used in studies reporting chronic kidney disease prevalence: a systematic literature review. Nephrol Dial Transplant. 2016 Apr 1;31(4):680-680.

17. Coresh J, Selvin E, Stevens LA, Manzi J, Kusek JW, Eggers P, et al. Prevalence of Chronic Kidney Disease in the United States. JAMA. 2007 Nov 7;298(17):2038.

18. Murphy D, McCulloch CE, Lin F, Banerjee T, Bragg-Gresham JL, Eberhardt MS, et al. Trends in Prevalence of Chronic Kidney Disease in the United StatesTrends in Prevalence of CKD in the United States. Ann Intern Med. 2016 Oct 4;165(7):473-81.

19. Mills KT, Bundy JD, Kelly TN, Reed JE, Kearney PM, Reynolds K, et al. Global Disparities of Hypertension Prevalence and Control: A Systematic Analysis of Population-Based Studies From 90 Countries, Circulation. 2016 Aug 9;134(6):441-50.

20. Ng M, Fleming T, Robinson M, Thomson B, Graetz N, Margono C, et al. Global, regional and national prevalence of overweight and obesity in children and adults 1980-2013: A systematic analysis. Lancet. 2014 Aug 30;384(9945):766-81.

21. Ghosh-Dastidar B, Cohen D, Hunter G, Zenk SN, Huang C, Beckman R, et al. Distance to store, food prices, and obesity in urban food deserts. Am J Prev Med. 2014 Nov;47(5):587-95.

22. Gutiérrez OM. Contextual Poverty, Nutrition and Chronic Kidney Disease. Adv Chronic Kidney Dis. 2015 Jan;22(1):31-8.

23. Rebholz CM, Anderson CAM, Grams ME, Bazzano LA, Crews DC, Chang AR, et al. Relationship of the American Heart Association's Impact Goals (Life's Simple 7) With Risk of Chronic Kidney Disease: Results From the Atherosclerosis Risk in Communities (ARIC) Cohort Study, J Am Heart Assoc. 2016 Apr 1;5(4):e003192.

24. Freudenberg N. Healthy-food procurement: using the public plate to reduce food insecurity and diet-related diseases. Lancet Diabetes \& Endocrinology. 2016 May;4(5):383-4.

25. Crews DC, Kuczmarski MF, Grubbs V, Hedgeman E, Shahinian VB, Evans MK, et al. Effect of Food Insecurity on Chronic Kidney Disease in Lower Income Americans. Am J Nephrol. 2014;39(1):27-35.

26. Crews DC, Kuczmarski MF, III ERM, Zonderman AB, Evans MK, Powe NR. Dietary Habits, Poverty, and Chronic Kidney Disease in an Urban Population. J Ren Nutr. 2015 Mar;25(2):103-10.

27. Suarez JJ, Isakova T, Anderson CAM, Boulware LE, Wolf M, Scialla JJ. Food Access, Chronic Kidney Disease, and Hypertension in the U.S. Am J Prev Med. 2015 Dec;49(6):912-20.

28. Manuel DG, Perez R, Sanmartin C, Taljaard M, Hennessy D, Wilson K, et al. Measuring Burden of Unhealthy Behaviours Using a Multivariable Predictive Approach: Life Expectancy Lost in Canada Attributable to Smoking, Alcohol, Physical Inactivity, and Diet. PLOS Med. 2016 Aug 16;13(8):e1002082.

29. Tuttle KR, Bakris GL, Bilous RW, Chiang JL, de Boer IH, Goldstein-Fuchs J, et al. Diabetic kidney disease: a report from an ADA Consensus Conference. Am J Kidney Dis. 2014 Oct;64(4):510-33. 
30. Stenvinkel P, Zoccali C, Ikizler TA. Obesity in CKD-What Should Nephrologists Know? J Am Soc Nephrol. 2013 Nov;24(11):1727-36.

31. Jun M, Hemmelgarn BR. Strategies for BP Control in Developing Countries and Effects on Kidney Function. CJASN. 2016 Jun 6;11(6):932-4.

32. Jafar TH, Allen JC, Jehan I, Hameed A, Saffari SE, Ebrahim S, et al. Health Education and General Practitioner Training in Hypertension Management: LongTerm Effects on Kidney Function. CJASN. 2016 Jun 6;11(6):1044-53.

33. James PA, Oparil S, Carter BL, Cushman WC, Dennison-Himmelfarb C, Handler $\mathrm{J}$, et al. 2014 evidence-based guideline for the management of high blood pressure in adults: report from the panel members appointed to the Eighth Joint National Committee (JNC 8). JAMA. 2014 Feb 5;311(5):507-20.

34. Group TAS. Nine-Year Effects of 3.7 Years of Intensive Glycemic Control on Cardiovascular Outcomes. Diabetes Care. 2016 May 1;39(5):701-8.

35. Zoungas S, Chalmers J, Neal B, Billot L, Li Q, Hirakawa Y, et al. Follow-up of Blood-Pressure Lowering and Glucose Control in Type 2 Diabetes. N Engl J Med. 2014 Oct 9;371(15):1392-406.

36. Pannu N, Nadim MK. An overview of drug-induced acute kidney injury. Crit Care Med. 2008 Apr;36(4 Suppl):S216-223.

37. Mehta RL, Burdmann EA, Cerdá J, Feehally J, Finkelstein F, García-García G, et al. Recognition and management of acute kidney injury in the International Society of Nephrology 0by25 Global Snapshot: a multinational cross-sectional study. Lancet. 2016 May 14;387(10032):2017-25.

38. Rhone ET, Carmody JB, Swanson JR, Charlton JR. Nephrotoxic medication exposure in very low birth weight infants. The Journal of Maternal-Fetal \& Neonatal Medicine. 2014 Sep;27(14):1485-90.

39. Menon S, Kirkendall ES, Nguyen H, Goldstein SL. Acute kidney injury associated with high nephrotoxic medication exposure leads to chronic kidney disease after 6 months. J Pediatr. 2014 Sep;165(3):522-527.e2.

40. Lazarus B, Chen Y, Wilson FP, Sang Y, Chang AR, Coresh J, et al. Proton Pump Inhibitor Use and the Risk of Chronic Kidney Disease. JAMA Intern Med. 2016 Feb;176(2):238-46.

41. Moledina DG, Perazella MA. Proton Pump Inhibitors and CKD. J Am Soc Nephrol. 2016 Apr 14;

42. Radhakrishnan J, Perazella MA. Drug-Induced Glomerular Disease: Attention Required! Clin J Am Soc Nephrol. 2015 Jul 7;10(7):1287-90.

43. Luyckx VA. Nephrotoxicity of alternative medicine practice. Adv Chronic Kidney Dis. 2012 May;19(3):129-41.

44. De Smet PAGM. Herbal medicine in Europe--relaxing regulatory standards. $\mathrm{N}$ Engl J Med. 2005 Mar 24;352(12):1176-8.

45. Keddis MT, Rule AD. Nephrolithiasis and loss of kidney function. Curr Opin Nephrol Hypertens. 2013 Jul;22(4):390-6.

46. Scales CD, Tasian GE, Schwaderer AL, Goldfarb DS, Star RA, Kirkali Z. Urinary Stone Disease: Advancing Knowledge, Patient Care, and Population Health. CJASN. 2016 Jul 7;11(7):1305-12.

47. López M, Hoppe B. History, epidemiology and regional diversities of urolithiasis. Pediatr Nephrol. 2010 Jan;25(1):49-59. 
48. Taylor EN, Stampfer MJ, Curhan GC. Dietary Factors and the Risk of Incident Kidney Stones in Men: New Insights after 14 Years of Follow-up. JASN. 2004 Dec 1;15(12):3225-32.

49. Lameire NH, Bagga A, Cruz D, De Maeseneer J, Endre Z, Kellum JA, et al. Acute kidney injury: an increasing global concern. Lancet. $2013 \mathrm{Jul}$ 13;382(9887):170-9.

50. Kayange NM, Smart LR, Tallman JE, Chu EY, Fitzgerald DW, Pain KJ, et al. Kidney disease among children in sub-Saharan Africa: a systematic review. Pediatr Res. 2015 Feb;77(2):272-81.

51. Jha V, Prasad N. CKD and Infectious Diseases in Asia Pacific: Challenges and Opportunities. Am J Kidney Dis. 2016 Jul;68(1):148-60.

52. UN AIDS. Global AIDS Update 2016 | UNAIDS [Internet]. [cited 2016 Sep 11]. Available from: http://www.unaids.org/en/resources/documents/2016/GlobalAIDS-update-2016

53. Rosenberg AZ, Naicker S, Winkler CA, Kopp JB. HIV-associated nephropathies: epidemiology, pathology, mechanisms and treatment. Nat Rev Nephrol. 2015 Mar;11(3):150-60.

54. Lucas GM, Ross MJ, Stock PG, Shlipak MG, Wyatt CM, Gupta SK, et al. Clinical Practice Guideline for the Management of Chronic Kidney Disease in Patients Infected With HIV: 2014 Update by the HIV Medicine Association of the Infectious Diseases Society of America. Clin Infect Dis. 2014 Nov 1;59(9):e96138.

55. White NJ, Pukrittayakamee S, Hien TT, Faiz MA, Mokuolu OA, Dondorp AM. Malaria. Lancet. 2014 Feb 22;383(9918):723-35.

56. Ehrich JHH, Eke FU. Malaria-induced renal damage: facts and myths. Pediatr Nephrol. 2007 May;22(5):626-37.

57. Siriwardhana EARIE, Perera PAJ, Sivakanesan R, Abeysekara T, Nugegoda DB, Jayaweera JAAS. Dehydration and malaria augment the risk of developing chronic kidney disease in Sri Lanka. Indian J Nephrol. 2015;25(3):146-51.

58. WHO. Global Tuberculosis Report 2015 [Internet]. Geneva: World Health Organization; 2015. Available from: http://apps.who.int/iris/bitstream/10665/191102/1/9789241565059_eng.pdf?ua=1

59. Daher EDF, Junior GB da S, Barros EJG. Renal Tuberculosis in the Modern Era. Am J Trop Med Hyg. 2013 Jan 9;88(1):54-64.

60. Oliveira JL de, Junior GB da S, Daher EDF. Tuberculosis-Associated Chronic Kidney Disease. Am J Trop Med Hyg. 2011 Jun 1;84(6):843-4.

61. Hoy WE, White AV, Dowling A, Sharma SK, Bloomfield H, Tipiloura BT, et al. Post-streptococcal glomerulonephritis is a strong risk factor for chronic kidney disease in later life. Kidney Int. 2012 May;81(10):1026-32.

62. Global Burden of Disease Study 2013 Collaborators. Global, regional, and national incidence, prevalence, and years lived with disability for 301 acute and chronic diseases and injuries in 188 countries, 1990-2013: a systematic analysis for the Global Burden of Disease Study 2013. Lancet. 2015 Aug 22;386(9995):743-800.

63. Gupta A, Quigg RJ. Glomerular Diseases Associated With Hepatitis B and C. Adv Chronic Kidney Dis. 2015 Sep;22(5):343-51. 
64. Azmi AN, Tan S-S, Mohamed R. Hepatitis C and kidney disease: An overview and approach to management. World J Hepatol. 2015 Jan 27;7(1):78-92.

65. Barsoum RS, Esmat G, El-Baz T. Human Schistosomiasis: Clinical Perspective: Review. Journal of Advanced Research. 2013 Sep;4(5):433-44.

66. Jong F de, Monuteaux MC, Elburg RM van, Gillman MW, Belfort MB. Systematic Review and Meta-Analysis of Preterm Birth and Later Systolic Blood Pressure. Hypertension. 2012 Feb 1;59(2):226-34.

67. Mu M, Wang S-F, Sheng J, Zhao Y, Li H-Z, Hu C-L, et al. Birth weight and subsequent blood pressure: A meta-analysis. Archives of Cardiovascular Diseases. 2012 Feb;105(2):99-113.

68. Whincup PH, Kaye SJ, Owen CG, et al. Birth weight and risk of type 2 diabetes: A systematic review. JAMA. 2008 Dec 24;300(24):2886-97.

69. Cnattingius S, Villamor E, Lagerros YT, Wikström A-K, Granath F. High birth weight and obesity - a vicious circle across generations. International Journal of Obesity. 2012 Oct;36(10):1320-4.

70. Luyckx VA, Brenner BM. Birth weight, malnutrition and kidney-associated outcomes—a global concern. Nat Rev Nephrol. 2015 Mar;11(3):135-49.

71. Selewski DT, Charlton JR, Jetton JG, Guillet R, Mhanna MJ, Askenazi DJ, et al. Neonatal Acute Kidney Injury. Pediatrics. 2015 Aug 1;136(2):e463-73.

72. Mammen C, Al Abbas A, Skippen P, Nadel H, Levine D, Collet JP, et al. Longterm risk of CKD in children surviving episodes of acute kidney injury in the intensive care unit: a prospective cohort study. Am J Kidney Dis. 2012 Apr;59(4):523-30.

73. Vikse BE. Pre-eclampsia and the risk of kidney disease. Lancet. $2013 \mathrm{Jul}$ 13;382(9887):104-6.

74. Paauw ND, Luijken K, Franx A, Verhaar MC, Lely AT. Long-term renal and cardiovascular risk after preeclampsia: towards screening and prevention. Clin Sci. 2016 Feb;130(4):239-46.

75. Damm P, Houshmand-Oeregaard A, Kelstrup L, Lauenborg J, Mathiesen ER, Clausen TD. Gestational diabetes mellitus and long-term consequences for mother and offspring: a view from Denmark. Diabetologia. 2016 Jul;59(7):13969.

76. Kanguru L, Bezawada N, Hussein J, Bell J. The burden of diabetes mellitus during pregnancy in low- and middle-income countries: a systematic review. Glob Health Action. 2014;7:23987.

77. Hsu C, Ordoñez J, Chertow G, Fan D, McCulloch C, Go A. The risk of acute renal failure in patients with chronic kidney disease. Kidney Int. 2008 Jul;74(1):101-7.

78. Huang T-M, Wu V-C, Young G-H, Lin Y-F, Shiao C-C, Wu P-C, et al. Preoperative Proteinuria Predicts Adverse Renal Outcomes after Coronary Artery Bypass Grafting. J Am Soc Nephrol. 2011 Jan;22(1):156-63.

79. Grams ME, Astor BC, Bash LD, Matsushita K, Wang Y, Coresh J. Albuminuria and Estimated Glomerular Filtration Rate Independently Associate with Acute Kidney Injury. J Am Soc Nephrol. 2010 Oct;21(10):1757-64. 
80. James MT, Hemmelgarn BR, Wiebe N, Pannu N, Manns BJ, Klarenbach SW, et al. Glomerular filtration rate, proteinuria, and the incidence and consequences of acute kidney injury: a cohort study. Lancet. 2010 Dec 18;376(9758):2096-103.

81. Pannu N, James M, Hemmelgarn BR, Dong J, Tonelli M, Klarenbach S, et al. Modification of outcomes after acute kidney injury by the presence of CKD. Am J Kidney Dis. 2011 Aug;58(2):206-13.

82. Pannu N. Bidirectional relationships between acute kidney injury and chronic kidney disease. Curr Opin Nephrol Hypertens. 2013 May;22(3):351-6.

83. Chawla LS, Eggers PW, Star RA, Kimmel PL. Acute Kidney Injury and Chronic Kidney Disease as Interconnected Syndromes. N Engl J Med. 2014 Jul 3;371(1):58-66.

84. Coca SG, Singanamala S, Parikh CR. Chronic Kidney Disease after Acute Kidney Injury: A Systematic Review and Meta-analysis. Kidney Int. 2012 Mar;81(5):442-8.

85. Manolio TA. Genomewide association studies and assessment of the risk of disease. N Engl J Med. 2010 Jul 8;363(2):166-76.

86. Bamshad MJ, Ng SB, Bigham AW, Tabor HK, Emond MJ, Nickerson DA, et al. Exome sequencing as a tool for Mendelian disease gene discovery. Nat Rev Genet. 2011 Nov;12(11):745-55.

87. Visscher PM, Brown MA, McCarthy MI, Yang J. Five Years of GWAS Discovery. Am J Hum Genet. 2012 Jan 13;90(1):7-24.

88. Chong JX, Buckingham KJ, Jhangiani SN, Boehm C, Sobreira N, Smith JD, et al. The Genetic Basis of Mendelian Phenotypes: Discoveries, Challenges, and Opportunities. Am J Hum Genet. 2015 Aug 6;97(2):199-215.

89. O'Seaghdha CM, Fox CS. Genome-wide association studies of chronic kidney disease: what have we learned? Nat Rev Nephrol. 2011 Dec 6;8(2):89-99.

90. Vivante A, Hildebrandt $F$. Exploring the genetic basis of early-onset chronic kidney disease. Nat Rev Nephrol. 2016 Mar;12(3):133-46.

91. Wuttke $M$, Köttgen $A$. Insights into kidney diseases from genome-wide association studies. Nat Rev Nephrol. 2016 Sep;12(9):549-62.

92. Denker M, Boyle S, Anderson AH, Appel LJ, Chen J, Fink JC, et al. Chronic Renal Insufficiency Cohort Study (CRIC): Overview and Summary of Selected Findings. CJASN. 2015 Nov 6;10(11):2073-83.

93. Levin A, Rigatto C, Brendan B, Madore F, Muirhead N, Holmes D, et al. Cohort profile: Canadian study of prediction of death, dialysis and interim cardiovascular events (CanPREDDICT). BMC Nephrol. 2013 Jun 11;14:121.

94. Smink PA, Heerspink HJL, Gansevoort RT, Jong PE de, Hillege HL, Bakker SJL, et al. Albuminuria, Estimated GFR, Traditional Risk Factors, and Incident Cardiovascular Disease: The PREVEND (Prevention of Renal and Vascular Endstage Disease) Study. Am J Kidney Dis. 2012 Nov 1;60(5):804-11.

95. Deo R, Khodneva YA, Shlipak MG, Soliman EZ, Judd SE, McClellan WM, et al. Albuminuria, kidney function, and sudden cardiac death: Findings from The Reasons for Geographic and Racial Differences in Stroke (REGARDS) study. Heart Rhythm. 2016 Aug 11.

96. Desai AS, Toto R, Jarolim P, Uno H, Eckardt K-U, Kewalramani R, et al. Association between cardiac biomarkers and the development of ESRD in 
patients with type 2 diabetes mellitus, anemia, and CKD. Am J Kidney Dis. 2011 Nov;58(5):717-28.

97. Lv J, Ehteshami P, Sarnak MJ, Tighiouart H, Jun M, Ninomiya T, et al. Effects of intensive blood pressure lowering on the progression of chronic kidney disease: a systematic review and meta-analysis. CMAJ. 2013 Aug 6;185(11):949-57.

98. Lv J, Neal B, Ehteshami P, Ninomiya T, Woodward M, Rodgers A, et al. Effects of Intensive Blood Pressure Lowering on Cardiovascular and Renal Outcomes: A Systematic Review and Meta-Analysis. PLOS Med. 2012 Aug 21;9(8):e1001293.

99. Perkovic V, Verdon C, Ninomiya T, Barzi F, Cass A, Patel A, et al. The Relationship between Proteinuria and Coronary Risk: A Systematic Review and Meta-Analysis. PLOS Med. 2008 Oct 21;5(10):e207.

100. Xie X, Liu Y, Perkovic V, Li X, Ninomiya T, Hou W, et al. Renin-Angiotensin System Inhibitors and Kidney and Cardiovascular Outcomes in Patients With CKD: A Bayesian Network Meta-analysis of Randomized Clinical Trials. Am J Kidney Dis. 2016 May;67(5):728-41.

101. Hou W, Lv J, Perkovic V, Yang L, Zhao N, Jardine MJ, et al. Effect of statin therapy on cardiovascular and renal outcomes in patients with chronic kidney disease: a systematic review and meta-analysis. European Heart Journal. 2013 Jun 21;34(24):1807-17.

102. Baigent C, Landray MJ, Reith C, Emberson J, Wheeler DC, Tomson C, et al. The effects of lowering LDL cholesterol with simvastatin plus ezetimibe in patients with chronic kidney disease (Study of Heart and Renal Protection): a randomised placebo-controlled trial. Lancet. 2011;377(9784):2181-2192.

103. Group TDR. Intensive Diabetes Therapy and Glomerular Filtration Rate in Type 1 Diabetes. N Engl J Med. 2011 Dec 22;365(25):2366-76.

104. Wong MG, Perkovic V, Chalmers J, Woodward M, Li Q, Cooper ME, et al. Longterm Benefits of Intensive Glucose Control for Preventing End-Stage Kidney Disease: ADVANCE-ON. Diabetes Care. 2016 May;39(5):694-700.

105. 204. Wanner C, Inzucchi SE, Lachin JM, Fitchett D, von Eynatten M, Mattheus M, et al. Empagliflozin and Progression of Kidney Disease in Type 2 Diabetes. N Engl J Med. 2016 Jul 28;375(4):323-34.

106. Heerspink HJL, Desai M, Jardine M, Balis D, Meininger G, Perkovic V. Canagliflozin Slows Progression of Renal Function Decline Independently of Glycemic Effects. J Am Soc Nephrol. 2016 Aug 18;

107. Zinman B, Wanner C, Lachin JM, Fitchett D, Bluhmki E, Hantel S, et al. Empagliflozin, Cardiovascular Outcomes, and Mortality in Type 2 Diabetes. N Engl J Med. 2015 Nov 26;373(22):2117-28.

108. Torres VE, Chapman AB, Devuyst O, Gansevoort RT, Grantham JJ, Higashihara $\mathrm{E}$, et al. Tolvaptan in Patients with Autosomal Dominant Polycystic Kidney Disease. N Engl J Med. 2012 Dec 20;367(25):2407-18.

109. Tonelli M, Gill J, Pandeya S, Bohm C, Levin A, Kiberd BA. Barriers to blood pressure control and angiotensin enzyme inhibitor use in Canadian patients with chronic renal insufficiency. Nephrol Dial Transplant. 2002 Aug 1;17(8):1426-33.

110. Benner JS, Glynn RJ, Mogun H, Neumann PJ, Weinstein MC, Avorn J. Longterm persistence in use of statin therapy in elderly patients. JAMA. 2002 Jul 24;288(4):455-61. 
111. Manns B, Hemmelgarn B, Lillie E, Dip SCPG, Cyr A, Gladish M, et al. Setting Research Priorities for Patients on or Nearing Dialysis. CJASN. 2014 Oct 7;9(10):1813-21.

112. Tonelli M. The roads less traveled? Diverging research and clinical priorities for dialysis patients and those with less severe CKD. Am J Kidney Dis. 2014 Jan;63(1):124-32.

113. Palmer SC, Sciancalepore M, Strippoli GFM. Trial quality in nephrology: how are we measuring up? Am J Kidney Dis. 2011 Sep;58(3):335-7.

114. Inrig JK, Califf RM, Tasneem A, Vegunta RK, Molina C, Stanifer JW, et al. The Landscape of Clinical Trials in Nephrology: A Systematic Review of ClinicalTrials.gov. Am J Kidney Dis. 2014 May 1;63(5):771-80.

115. Levey AS, Inker LA, Matsushita K, Greene T, Willis K, Lewis E, et al. GFR Decline as an End Point for Clinical Trials in CKD: A Scientific Workshop Sponsored by the National Kidney Foundation and the US Food and Drug Administration. Am J Kidney Dis. 2014 Dec 1;64(6):821-35.

116. Matsushita K, Selvin E, Bash LD, Astor BC, Coresh J. Risk Implications of the New CKD Epidemiology Collaboration (CKD-EPI) Equation as Compared With the MDRD Study Equation for Estimated GFR: The Atherosclerosis Risk in Communities (ARIC) Study. Am J Kidney Dis. 2010 Apr;55(4):648-59.

117. Matsushita K, Mahmoodi BK, Woodward M, et al. Comparison of risk prediction using the ckd-epi equation and the mdrd study equation for estimated glomerular filtration rate. JAMA. 2012 May 9;307(18):1941-51.

118. Witte EC, Lambers Heerspink HJ, de Zeeuw D, Bakker SJL, de Jong PE, Gansevoort R. First Morning Voids Are More Reliable Than Spot Urine Samples to Assess Microalbuminuria. J Am Soc Nephrol. 2009 Feb;20(2):436-43.

119. Benghanem Gharbi M, Elseviers M, Zamd M, Belghiti Alaoui A, Benahadi N, Trabelssi EH, et al. Chronic kidney disease, hypertension, diabetes, and obesity in the adult population of Morocco: how to avoid 'over'- and 'under'-diagnosis of CKD. Kidney Int. 2016 Jun;89(6):1363-71.

120. Selvin E, Juraschek SP, Eckfeldt J, Levey AS, Inker LA, Coresh J. Within-Person Variability in Kidney Measures. Am J Kidney Dis. 2013 May;61(5):716-22.

121. GBD 2015 Mortality and Causes of Death Collaborators. Global, regional, and national life expectancy, all-cause mortality, and cause-specific mortality for 249 causes of death, 1980-2015: a systematic analysis for the Global Burden of Disease Study 2015. Lancet. 2016 Oct;388(10053):1459-544.

122. Soderland P, Lovekar S, Weiner DE, Brooks DR, Kaufman JS. Chronic kidney disease associated with environmental toxins and exposures. Adv Chronic Kidney Dis. 2010 May;17(3):254-64.

123. Correa-Rotter R, Wesseling C, Johnson RJ. CKD of unknown origin in Central America: the case for a Mesoamerican nephropathy. Am J Kidney Dis. 2014 Mar;63(3):506-20.

124. Glaser J, Lemery J, Rajagopalan B, Diaz HF, García-Trabanino R, Taduri G, et al. Climate Change and the Emergent Epidemic of CKD from Heat Stress in Rural Communities: The Case for Heat Stress Nephropathy. CJASN. 2016 Aug 8;11(8):1472-83. 
125. Johnson RJ, Stenvinkel P, Jensen T, Lanaspa MA, Roncal C, Song Z, et al. Metabolic and Kidney Diseases in the Setting of Climate Change, Water Shortage, and Survival Factors. JASN. 2016 Aug 1;27(8):2247-56.

126. Weaver VM, Fadrowski JJ, Jaar BG. Global dimensions of chronic kidney disease of unknown etiology (CKDu): a modern era environmental and/or occupational nephropathy? BMC Nephrology. 2015;16(1):1-8

127. Debelle FD, Vanherweghem J-L, Nortier JL. Aristolochic acid nephropathy: a worldwide problem. Kidney Int. 2008 Jul;74(2):158-69.

128. Grollman AP. Aristolochic acid nephropathy: Harbinger of a global iatrogenic disease. Environ Mol Mutagen. 2013 Jan;54(1):1-7.

129. Bui-Klimke T, Wu F. Evaluating Weight of Evidence in the Mystery of Balkan Endemic Nephropathy. Risk Anal. 2014 Sep;34(9):1688-705.

130. Yang L, Su T, Li X-M, Wang X, Cai S-Q, Meng L-Q, et al. Aristolochic acid nephropathy: variation in presentation and prognosis. Nephrol Dial Transplant. 2012 Jan $1 ; 27(1): 292-8$.

131. Kataria A, Trasande $L$, Trachtman $\mathrm{H}$. The effects of environmental chemicals on renal function. Nat Rev Nephrol. 2015 Oct;11(10):610-25.

132. Silver SA, Wald R. Improving outcomes of acute kidney injury survivors. Curr Opin Crit Care. 2015 Dec;21(6):500-5.

133. Genovese G, Friedman DJ, Ross MD, Lecordier L, Uzureau P, Freedman BI, et al. Association of Trypanolytic ApoL1 Variants with Kidney Disease in AfricanAmericans. Science. 2010 Aug 13;329(5993):841-5.

134. Manrai AK, Funke BH, Rehm HL, Olesen MS, Maron BA, Szolovits P, et al. Genetic Misdiagnoses and the Potential for Health Disparities. N Engl J Med. 2016 Aug 18;375(7):655-65.

135. Fox CS, Hall JL, Arnett DK, Ashley EA, Delles C, Engler MB, et al. Future Translational Applications From the Contemporary Genomics Era. Circulation. 2015 May 12;131(19):1715-36.

136. Razavian M, Heeley EL, Perkovic V, Zoungas S, Weekes A, Patel AA, et al. Cardiovascular risk management in chronic kidney disease in general practice (the AusHEART study). Nephrol Dial Transplant. 2012 Apr 1;27(4):1396-402.

137. Tonelli M, Karumanchi SA, Thadhani R. Epidemiology and Mechanisms of Uremia-Related Cardiovascular Disease. Circulation. 2016 Feb 2;133(5):518-36.

138. Herzog CA, Asinger RW, Berger AK, Charytan DM, Díez J, Hart RG, et al. Cardiovascular disease in chronic kidney disease. A clinical update from Kidney Disease: Improving Global Outcomes (KDIGO). Kidney Int. 2011;80(6):572-586.

139. Ketteler M, Elder GJ, Evenepoel P, Ix JH, Jamal SA, Lafage-Proust M-H, et al. Revisiting KDIGO clinical practice guideline on chronic kidney disease-mineral and bone disorder: a commentary from a Kidney Disease: Improving Global Outcomes controversies conference. Kidney Int. 2015 Mar;87(3):502-28.

140. Levin NW, Kotanko P, Eckardt K-U, Kasiske BL, Chazot C, Cheung AK, et al. Blood pressure in chronic kidney disease stage 5D—report from a Kidney Disease: Improving Global Outcomes controversies conference. Kidney Int. 2010;77(4):273-284.

141. Locatelli F, Nissenson AR, Barrett BJ, Walker RG, Wheeler DC, Eckardt KU, et al. Clinical practice guidelines for anemia in chronic kidney disease: problems 
and solutions. A position statement from Kidney Disease: Improving Global Outcomes (KDIGO). Kidney Int. 2008;74(10):1237-1240.

142. Davison SN, Jassal SV. Supportive Care: Integration of Patient-Centered Kidney Care to Manage Symptoms and Geriatric Syndromes. Clin J Am Soc Nephrol. 2016 Aug 10;

143. Heerspink HJL, Ninomiya T, Zoungas S, de Zeeuw D, Grobbee DE, Jardine MJ, et al. Effect of lowering blood pressure on cardiovascular events and mortality in patients on dialysis: a systematic review and meta-analysis of randomised controlled trials. Lancet. 2009 Mar;373(9668):1009-15.

144. Palmer SC, Navaneethan SD, Craig JC, Johnson DW, Perkovic V, Hegbrant J, et al. HMG CoA reductase inhibitors (statins) for people with chronic kidney disease not requiring dialysis. Cochrane Database Syst Rev. 2014;(5):CD007784.

145. Ruggenenti P, Porrini E, Motterlini N, Perna A, llieva AP, lliev IP, et al. Measurable Urinary Albumin Predicts Cardiovascular Risk among Normoalbuminuric Patients with Type 2 Diabetes. JASN. 2012 Oct 1;23(10):1717-24.

146. Cice G, Di Benedetto A, D'Isa S, D'Andrea A, Marcelli D, Gatti E, et al. Effects of Telmisartan Added to Angiotensin-Converting Enzyme Inhibitors on Mortality and Morbidity in Hemodialysis Patients With Chronic Heart Failure: A Double-Blind, Placebo-Controlled Trial. JACC. 2010 Nov 16;56(21):1701-8.

147. Cardiovascular disease, diabetes and chronic kidney disease: Australian facts mortality (AIHW) [Internet]. [cited 2016 Sep 25]. Available from: http://www.aihw.gov.au/publication-detail/?id=60129549287

148. Inker LA, Levey AS, Pandya K, Stoycheff N, Okparavero A, Greene T. Early Change in Proteinuria as a Surrogate Endpoint for Kidney Disease Progression: An Individual Patient Meta-analysis. Am J Kidney Dis. 2014 Jul;64(1):74-85.

149. Heerspink HJL, Kröpelin TF, Hoekman J, Zeeuw D de. Drug-Induced Reduction in Albuminuria Is Associated with Subsequent Renoprotection: A Meta-Analysis. JASN. 2015 Aug 1;26(8):2055-64.

150. Tong A, Manns B, Hemmelgarn B, Wheeler DC, Evangelidis N, Tugwell P, et al. on behalf of the SONG-HD Investigators. Establishing core outcome domains in hemodialysis: report of the Standardised Outcomes in Nephrology Hemodialysis (SONG-HD) consensus workshops. Am J Kidney Dis. 2016 (Article in Press).

151. Tong A, Crowe S, Chando S, Cass A, Chadban SJ, Chapman JR, et al. Research Priorities in CKD: Report of a National Workshop Conducted in Australia. Am J Kidney Dis. 2015 Aug;66(2):212-22.

152. Parrinello CM, Grams ME, Couper D, Ballantyne CM, Hoogeveen RC, Eckfeldt $\mathrm{JH}$, et al. Recalibration of blood analytes over 25 years in the Atherosclerosis Risk in Communities Study: The impact of recalibration on chronic kidney disease prevalence and incidence. Clin Chem. 2015 Jul;61(7):938-47.

153. Grams ME, Rebholz C, MacMahon B, Whelton S, Ballew SH, Selvin E, et al. Identification of Incident CKD Stage 3 in Research Studies. Am J Kidney Dis. 2014 Aug;64(2):214-21.

154. Rebholz CM, Coresh J, Ballew SH, McMahon B, Whelton SP, Selvin E, et al. Kidney Failure and ESRD in the Atherosclerosis Risk in Communities (ARIC) 
Study: Comparing Ascertainment of Treated and Untreated Kidney Failure in a Cohort Study. Am J Kidney Dis. 2015 Aug;66(2):231-9.

155. Zhang L, Long J, Jiang W, Shi Y, He X, Zhou Z, et al. Trends in Chronic Kidney Disease in China. N Engl J Med. 2016 Sep 1;375(9):905-6.

156. Carrero JJ, Grams ME, Sang Y, Ärnlöv J, Gasparini A, Matsushita K, et al. Albuminuria changes and subsequent risk of end-stage renal disease and mortality. Kidney Int. 2016 (In press)

157. Agarwal SK, Wruck L, Quibrera M, Matsushita K, Loehr LR, Chang PP, et al. Temporal Trends in Hospitalization for Acute Decompensated Heart Failure in the United States, 1998-2011. Am J Epidemiol. 2016 Mar 1;183(5):462-70.

158. WHO | International Classification of Diseases [Internet]. WHO. [cited 2016 Oct 2]. Available from: http://www.who.int/classifications/icd/en/

159. Venkat-Raman G, Tomson CRV, Gao Y, Cornet R, Stengel B, Gronhagen-Riska $C$, et al. New primary renal diagnosis codes for the ERA-EDTA. Nephrol Dial Transplant. 2012 Dec 1;27(12):4414-9.

160. Levey AS, Stevens LA, Schmid CH, Zhang Y (Lucy), Castro AF, Feldman HI, et al. A New Equation to Estimate Glomerular Filtration Rate. Ann Intern Med. 2009 May 5;150(9):604-12.

161. Diamantidis CJ, Becker S. Health information technology (IT) to improve the care of patients with chronic kidney disease (CKD). BMC Nephrology. 2014;15:7.

162. Drawz PE, Archdeacon P, McDonald CJ, Powe NR, Smith KA, Norton J, et al. CKD as a Model for Improving Chronic Disease Care through Electronic Health Records. CJASN. 2015 Aug 7;10(8):1488-99.

163. Lunyera J, Mohottige D, Isenburg MV, Jeuland M, Patel UD, Stanifer JW. CKD of Uncertain Etiology: A Systematic Review. CJASN. 2016 Mar 7;11(3):379-85.

164. García-Trabanino R, Jarquín E, Wesseling C, Johnson RJ, González-Quiroz M, Weiss I, et al. Heat stress, dehydration, and kidney function in sugarcane cutters in El Salvador--A cross-shift study of workers at risk of Mesoamerican nephropathy. Environ Res. 2015 Oct;142:746-55.

165. Richardson K, Ananou A, Lafortune L, Brayne C, Matthews FE. Variation over time in the association between polypharmacy and mortality in the older population. Drugs Aging. 2011 Jul 1;28(7):547-60.

166. Tinetti ME, Bogardus ST, Agostini JV. Potential pitfalls of disease-specific guidelines for patients with multiple conditions. N Engl J Med. 2004 Dec 30;351(27):2870-4.

167. Gnjidic D, Le Couteur DG, Pearson S-A, McLachlan AJ, Viney R, Hilmer SN, et al. High risk prescribing in older adults: prevalence, clinical and economic implications and potential for intervention at the population level. BMC Public Health. 2013 Feb 7;13:115.

168. Frazier SC. Health outcomes and polypharmacy in elderly individuals: an integrated literature review. J Gerontol Nurs. 2005 Sep;31(9):4-11.

169. Mehta RL, Cerdá J, Burdmann EA, Tonelli M, García-García G, Jha V, et al. International Society of Nephrology's Oby25 initiative for acute kidney injury (zero preventable deaths by 2025): a human rights case for nephrology. Lancet. 2015 Jun;385(9987):2616-43. 
170. Perazella MA, Coca SG. Traditional Urinary Biomarkers in the Assessment of Hospital-Acquired AKI. CJASN. 2012 Jan 1;7(1):167-74.

171. Chawla LS, Dommu A, Berger A, Shih S, Patel SS. Urinary Sediment Cast Scoring Index for Acute Kidney Injury: A Pilot Study. Nephron Clin Pract. 2008 Nov;110(3):C145-50.

172. Silver SA, Goldstein SL, Harel Z, Harvey A, Rompies EJ, Adhikari NK, et al. Ambulatory care after acute kidney injury: an opportunity to improve patient outcomes. Canadian Journal of Kidney Health and Disease. 2015;2:36.

173. Green RC, Goddard KAB, Jarvik GP, Amendola LM, Appelbaum PS, Berg JS, et al. Clinical Sequencing Exploratory Research Consortium: Accelerating Evidence-Based Practice of Genomic Medicine. Am J Hum Genet. 2016 Jun 2;98(6):1051-66.

174. Jarvik GP, Amendola LM, Berg JS, Brothers K, Clayton EW, Chung W, et al. Return of Genomic Results to Research Participants: The Floor, the Ceiling, and the Choices In Between. Am J Hum Genet. 2014 Jun 5;94(6):818-26.

175. Tekola-Ayele F, Rotimi CN. Translational Genomics in Low and Middle Income Countries: Opportunities and Challenges. Public Health Genomics. 2015;18(4):242-7.

176. Lek M, Karczewski KJ, Minikel EV, Samocha KE, Banks E, Fennell T, et al. Analysis of protein-coding genetic variation in 60,706 humans. Nature. 2016 Aug 18;536(7616):285-91.

177. Rehm HL, Berg JS, Brooks LD, Bustamante CD, Evans JP, Landrum MJ, et al. ClinGen - The Clinical Genome Resource. N Engl J Med. 2015 Jun 4;372(23):2235-42.

178. Green RC, Goddard KAB, Jarvik GP, Amendola LM, Appelbaum PS, Berg JS, et al. Clinical Sequencing Exploratory Research Consortium: Accelerating Evidence-Based Practice of Genomic Medicine. Am J Hum Genet. 2016 Jul 7;99(1):246.

179. Chen R, Shi L, Hakenberg J, Naughton B, Sklar P, Zhang J, et al. Analysis of 589,306 genomes identifies individuals resilient to severe Mendelian childhood diseases. Nat Biotechnol. 2016 May;34(5):531-8.

180. A global reference for human genetic variation. Nature. 2015 Oct 1;526(7571):68-74.

181. Tzur S, Rosset S, Shemer R, Yudkovsky G, Selig S, Tarekegn A, et al. Missense mutations in the APOL1 gene are highly associated with end stage kidney disease risk previously attributed to the MYH9 gene. Hum Genet. 2010 Sep;128(3):345-50.

182. Köttgen A, Pattaro C, Böger CA, Fuchsberger C, Olden M, Glazer NL, et al. Multiple New Loci Associated with Kidney Function and Chronic Kidney Disease: The CKDGen consortium. Nat Genet. 2010 May;42(5):376-84.

183. Böger CA, Chen $\mathrm{M}-\mathrm{H}$, Tin A, Olden $\mathrm{M}$, Köttgen A, de Boer IH, et al. CUBN Is a Gene Locus for Albuminuria. J Am Soc Nephrol. 2011 Mar;22(3):555-70.

184. Böger CA, Gorski M, Li M, Hoffmann MM, Huang C, Yang Q, et al. Association of eGFR-Related Loci Identified by GWAS with Incident CKD and ESRD. PLoS Genet. 2011 Sep;7(9):e1002292. 
185. Pattaro C, Teumer A, Gorski M, Chu AY, Li M, Mijatovic V, et al. Genetic associations at 53 loci highlight cell types and biological pathways relevant for kidney function. Nat Commun. 2016;7:10023.

186. Wilkinson MD, Dumontier M, Aalbersberg IJJ, Appleton G, Axton M, Baak A, et al. The FAIR Guiding Principles for scientific data management and stewardship. Sci Data. 2016;3:160018.

187. Welter D, MacArthur J, Morales J, Burdett T, Hall P, Junkins H, et al. The NHGRI GWAS Catalog, a curated resource of SNP-trait associations. Nucleic Acids Res. 2014 Jan 1;42(Database issue):D1001-6.

188. Margolis R, Derr L, Dunn M, Huerta M, Larkin J, Sheehan J, et al. The National Institutes of Health's Big Data to Knowledge (BD2K) initiative: capitalizing on biomedical big data. J Am Med Inform Assoc. 2014 Nov;21(6):957-8.

189. Flannick J, Florez JC. Type 2 diabetes: genetic data sharing to advance complex disease research. Nat Rev Genet. 2016 Sep;17(9):535-49.

190. MacArthur DG, Manolio TA, Dimmock DP, Rehm HL, Shendure J, Abecasis GR, et al. Guidelines for investigating causality of sequence variants in human disease. Nature. 2014 Apr 24;508(7497):469-76.

191. Amendola LM, Dorschner MO, Robertson PD, Salama JS, Hart R, Shirts BH, et al. Actionable exomic incidental findings in 6503 participants: challenges of variant classification. Genome Res. 2015 Mar;25(3):305-15.

192. Linda Kao W, Klag MJ, Meoni LA, Reich D, Berthier-Schaad Y, Li M, et al. A genome-wide admixture scan identifies MYH9 as a candidate locus associated with non-diabetic end stage renal disease in African Americans. Nat Genet. 2008 Oct;40(10):1185-92.

193. Kundaje A, Meuleman W, Ernst J, Bilenky M, Yen A, Kheradpour P, et al. Integrative analysis of 111 reference human epigenomes. Nature. 2015 Feb 19;518(7539):317-30.

194. Suhre K, Shin S-Y, Petersen A-K, Mohney RP, Meredith D, Wägele B, et al. Human metabolic individuality in biomedical and pharmaceutical research. Nature. 2011 Sep 1;477(7362):54-60.

195. Rhee EP, Ho JE, Chen M-H, Shen D, Cheng S, Larson MG, et al. A GenomeWide Association Study of the Human Metabolome in a Community-Based Cohort. Cell Metab. 2013 Jul 2;18(1):130-43.

196. GTEx Portal [Internet]. [cited 2016 Oct 10]. Available from: http://www.gtexportal.org/home/

197. Nelson MR, Tipney H, Painter JL, Shen J, Nicoletti P, Shen Y, et al. The support of human genetic evidence for approved drug indications. Nat Genet. 2015 Aug;47(8):856-60.

198. Kiryluk K, Li Y, Scolari F, Sanna-Cherchi S, Choi M, Verbitsky M, et al. Discovery of new risk loci for IgA nephropathy implicates genes involved in immunity against intestinal pathogens. Nat Genet. 2014 Nov;46(11):1187-96.

199. Thomson R, Genovese G, Canon C, Kovacsics D, Higgins MK, Carrington M, et al. Evolution of the primate trypanolytic factor APOL1. Proc Natl Acad Sci USA. 2014 May 20;111(20):E2130-9.

200. McKnight AJ, McKay GJ, Maxwell AP. Genetic and epigenetic risk factors for diabetic kidney disease. Adv Chronic Kidney Dis. 2014 May;21(3):287-96. 
201. Harjutsalo V, Groop P-H. Epidemiology and risk factors for diabetic kidney disease. Adv Chronic Kidney Dis. 2014 May;21(3):260-6.

202. Nanayakkara S, Senevirathna STMLD, Abeysekera T, Chandrajith R, Ratnatunga N, Gunarathne EDL, et al. An integrative study of the genetic, social and environmental determinants of chronic kidney disease characterized by tubulointerstitial damages in the North Central Region of Sri Lanka. J Occup Health. 2014;56(1):28-38.

203. Batuman V. Fifty years of Balkan endemic nephropathy: daunting questions, elusive answers. Kidney Int. 2006 Feb;69(4):644-6.

204. Sekula P, Li Y, Stanescu HC, Wuttke M, Ekici AB, Bockenhauer D, et al. Genetic risk variants for membranous nephropathy: extension of and association with other chronic kidney disease aetiologies. Nephrol Dial Transplant. 2016 Feb 4;

205. Fogo A. WCN 2015 Renal Biopsy Histology Procedure Manual (in EN, ES, FR \& RU) [Internet]. [cited 2016 Oct 1]. Available from:

http://www.theisn.org/education/education-topics/pathology-topics/item/1720wcn-2015-histology-procedure-manual

206. Haas M. A reevaluation of routine electron microscopy in the examination of native renal biopsies. J Am Soc Nephrol. 1997 Jan;8(1):70-6.

207. Chang A, Gibson IW, Cohen AH, Weening JJ, Jennette JC, Fogo AB, et al. A position paper on standardizing the nonneoplastic kidney biopsy report. Clin $\mathrm{J}$ Am Soc Nephrol. 2012 Aug;7(8):1365-8.

208. Fassett RG, Venuthurupalli SK, Gobe GC, Coombes JS, Cooper MA, Hoy WE. Biomarkers in chronic kidney disease: a review. Kidney Int. 2011 Oct;80(8):80621.

209. Kitiyakara C, Yamwong S, Vathesatogkit P, Chittamma A, Cheepudomwit S, Vanavanan $S$, et al. The impact of different GFR estimating equations on the prevalence of CKD and risk groups in a Southeast Asian cohort using the new KDIGO guidelines. BMC Nephrology. 2012;13:1.

210. Gansevoort RT, Correa-Rotter R, Hemmelgarn BR, Jafar TH, Heerspink HJL, Mann JF, et al. Chronic kidney disease and cardiovascular risk: epidemiology, mechanisms, and prevention. Lancet. 2013 Jul 27;382(9889):339-52.

211. Schiffer E, Liabeuf S, Lacroix C, Temmar M, Renard C, Monsarrat B, et al. Markers of vascular disease in plasma from patients with chronic kidney disease identified by proteomic analysis. J Hypertens. 2011 Apr;29(4):783-90.

212. Kadatz MJ, Lee ES, Levin A. Predicting Progression in CKD: Perspectives and Precautions. Am J Kidney Dis. 2016 May;67(5):779-86.

213. Sun J, Axelsson J, Machowska A, Heimbürger $O$, Bárány $P$, Lindholm B, et al. Biomarkers of Cardiovascular Disease and Mortality Risk in Patients with Advanced CKD. Clin J Am Soc Nephrol. 2016 Jul 7;11(7):1163-72.

214. Cisek K, Krochmal M, Klein J, Mischak H. The application of multi-omics and systems biology to identify therapeutic targets in chronic kidney disease. Nephrol Dial Transplant. 2015 Oct 20;

215. Ju W, Nair V, Smith S, Zhu L, Shedden K, Song PXK, et al. Tissue transcriptome-driven identification of epidermal growth factor as a chronic kidney disease biomarker. Sci Transl Med. 2015 Dec 2;7(316):316ra193. 
216. WHO | WHO Model Lists of Essential Medicines [Internet]. WHO. [cited 2016 Oct 10]. Available from:

http://www.who.int/medicines/publications/essentialmedicines/en/

217. Kidney Disease: Improving Global Outcomes (KDIGO) CKD-MBD Work Group. KDIGO clinical practice guideline for the diagnosis, evaluation, prevention, and treatment of Chronic Kidney Disease-Mineral and Bone Disorder (CKD-MBD). Kidney Int Suppl. 2009 Aug;(113):S1-130.

218. Roberts MA, Pilmore HL, lerino FL, Badve SV, Cass A, Garg AX, et al. The rationale and design of the Beta-blocker to LOwer CArdiovascular Dialysis Events (BLOCADE) Feasibility Study. Nephrology (Carlton). 2015 Mar;20(3):140-7.

219. Ravindran S, Kuruvilla V, Wilbur K, Munusamy S. Nephroprotective Effects of Metformin in Diabetic Nephropathy. J Cell Physiol. 2016 Sep 14;

220. Johnson RJ, Nakagawa T, Jalal D, Sanchez-Lozada LG, Kang D-H, Ritz E. Uric acid and chronic kidney disease: which is chasing which? Nephrol Dial Transplant. 2013 Sep 1;28(9):2221-8.

221. Qualification of Biomarker-Total Kidney Volume in Studies for Treatments of Autosomal Dominant Polycystic Kidney Disease Guidance for Industry UCM458483.pdf [Internet]. [cited 2016 Sep 28]. Available from: http://www.fda.gov/downloads/Drugs/GuidanceComplianceRegulatorylnformation /Guidances/UCM458483.pdf

222. Parving H-H, Brenner BM, McMurray JJV, de Zeeuw D, Haffner SM, Solomon SD, et al. Cardiorenal End Points in a Trial of Aliskiren for Type 2 Diabetes. N Engl J Med. 2012 Dec 6;367(23):2204-13.

223. de Zeeuw D, Akizawa T, Audhya P, Bakris GL, Chin M, Christ-Schmidt H, et al. Bardoxolone Methyl in Type 2 Diabetes and Stage 4 Chronic Kidney Disease. N Engl J Med. 2013 Dec 26;369(26):2492-503.

224. Mann JFE, Green D, Jamerson K, Ruilope LM, Kuranoff SJ, Littke T, et al. Avosentan for Overt Diabetic Nephropathy. J Am Soc Nephrol. 2010 Mar;21(3):527-35.

225. Fried LF, Emanuele N, Zhang JH, Brophy M, Conner TA, Duckworth W, et al. Combined Angiotensin Inhibition for the Treatment of Diabetic Nephropathy. N Engl J Med. 2013 Nov 14;369(20):1892-903.

226. Pfeffer MA, Burdmann EA, Chen C-Y, Cooper ME, de Zeeuw D, Eckardt K-U, et al. A Trial of Darbepoetin Alfa in Type 2 Diabetes and Chronic Kidney Disease. N Engl J Med. 2009 Nov 19;361(21):2019-32. 